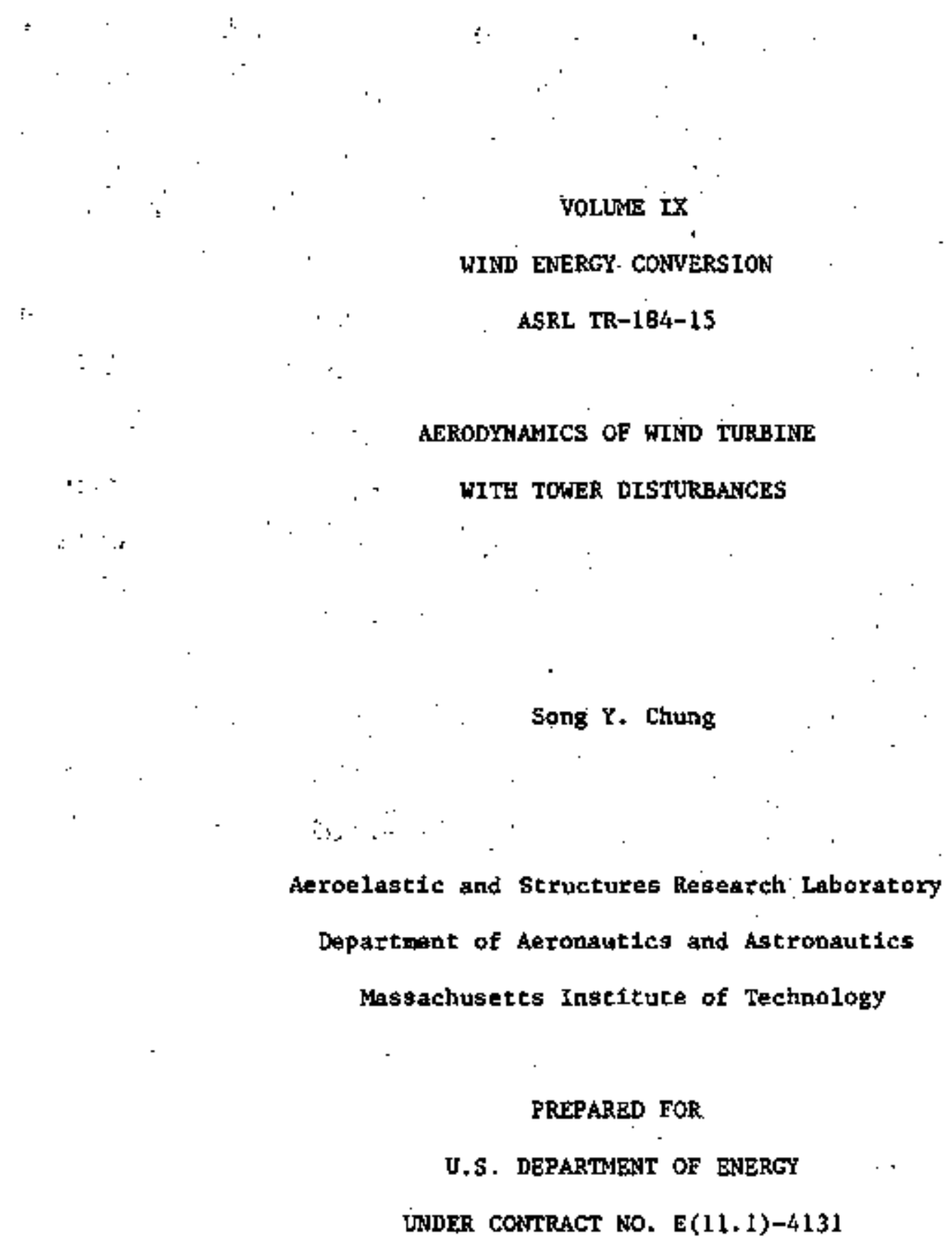




\section{DISCLAIMER}

This report was prepared as an account of work sponsored by an agency of the United States Government. Neither the United States Government nor any agency Thereot, nor any of their employees, makes any warranty, express or implied, or assumes any legal liability or responsibility for the accuracy, completeness, or usefulness of any information, apparatus, product, or process disclosed, or represents that its use would not infringe privately owned rights. Reference herein to any specific commercial product, process, or service by trade name, trademark, manufacturer, or otherwise does not necessarily constitute or imply its endorsement, recommendation, or favoring by the United States Government or any agency thereof. The views and opinions of authors expressed herein do not necessarlly state or reflect those of the United States Government or any agency thereof. 


\section{DISCLAIMER}

Portions of this document may be illegible in electronic image products. Images are produced from the best available original document. 


\section{AERODYNAIICS OF NIND TUREINE NITH}

TOHER DISTURBINES

\section{ABSTRACT}

Wfing line theory which is the counterpart of Frandti's lifting line theory for rotating wing is employed for the overall performance analysis of a horizontal axis wind turbtne rotor operIn a uniform flow. The wake system is modeled by non-rigid wate which includes, the radial expangion and the axial retardation of trailing vortices.

For the non-uniform flow which are caused by the ground, the tower reflection, or the tower shadow, the unsteady airloads aeting on the turbine blade are. computed, using lifting line theory and a non-rigid wake model. An equation which gives the wind profile in the tower shadow region is developed. Also, the equations to determine pitch angle control are aerived to minimize the flapplng monent variations or the thrust variations due to the non-uniform flow over a ratation.

It is concluded that the models developed can predict the overall performance coefficients for uniform flow and the unsteady airloads for non-uniform flow which are in good agreetent with experimental data. The unsteady airloads are found to have the sane forn variations as the wind profile on the rotor disk plane. 


\title{
NO:IENCLA IURE
}

\author{
a lift curve slope \\ $A_{j}$ coefficients of bound circulation series \\ $\left("=\overline{\Sigma A}_{\mathbf{j}} \sin \cdot \mathrm{j} \theta\right)$ \\ b number of blacies \\ c blade chost \\ $c_{d}$ drag coefflcient as blade \\ $c_{d t}$ drag coefficient of the tower \\ $c_{p}$ power coefficient, $c_{p}=8 / p+R^{2} W^{3}$ \\ $C_{T}$ thrust coefficient, $C_{T}=T / P=R^{2} u_{0}^{2}$ \\ dL lift per unit length of blade \\ - flapping ninge offset \\ "G $\left(w_{\text {pend }} / n\right)^{2}$ where $w_{\text {pend }}=\sqrt{3 \mathrm{~g} / 20 \bar{n}}$ is pendulum \\ trequency of blade \\ i index to denote control point \\ $I_{b}$ blade moment of lnertia \\ $\mathrm{K}_{1}$, characteristic constants of wind profile equation
$\mathrm{K}_{2}$ for a given tower \\ $\mathrm{k}_{\beta} \quad$ root cons iraint \\ l distance from hinge offat to blade tip nondimensioned by $R$ \\ LN lock number, IN $=a c p R^{4} / I_{b}$ \\ IT thrist coefficient, $L_{T}=T / \mu \pi n^{2} R^{4}$ \\ $I_{\text {Tn }}$ coefficients of thrust coefficient series \\ in mass per unit length of blade \\ $M_{A}$ aerodynami a noment about an offset flappling hirge \\ itg meinent due to gravity about an flapping hirge \\ M Enertia motosit about an flapping hinge \\ $H_{B}=\frac{L N}{\partial} \ell^{4}\left(1+\frac{4 e}{3 \ell}\right)$
}




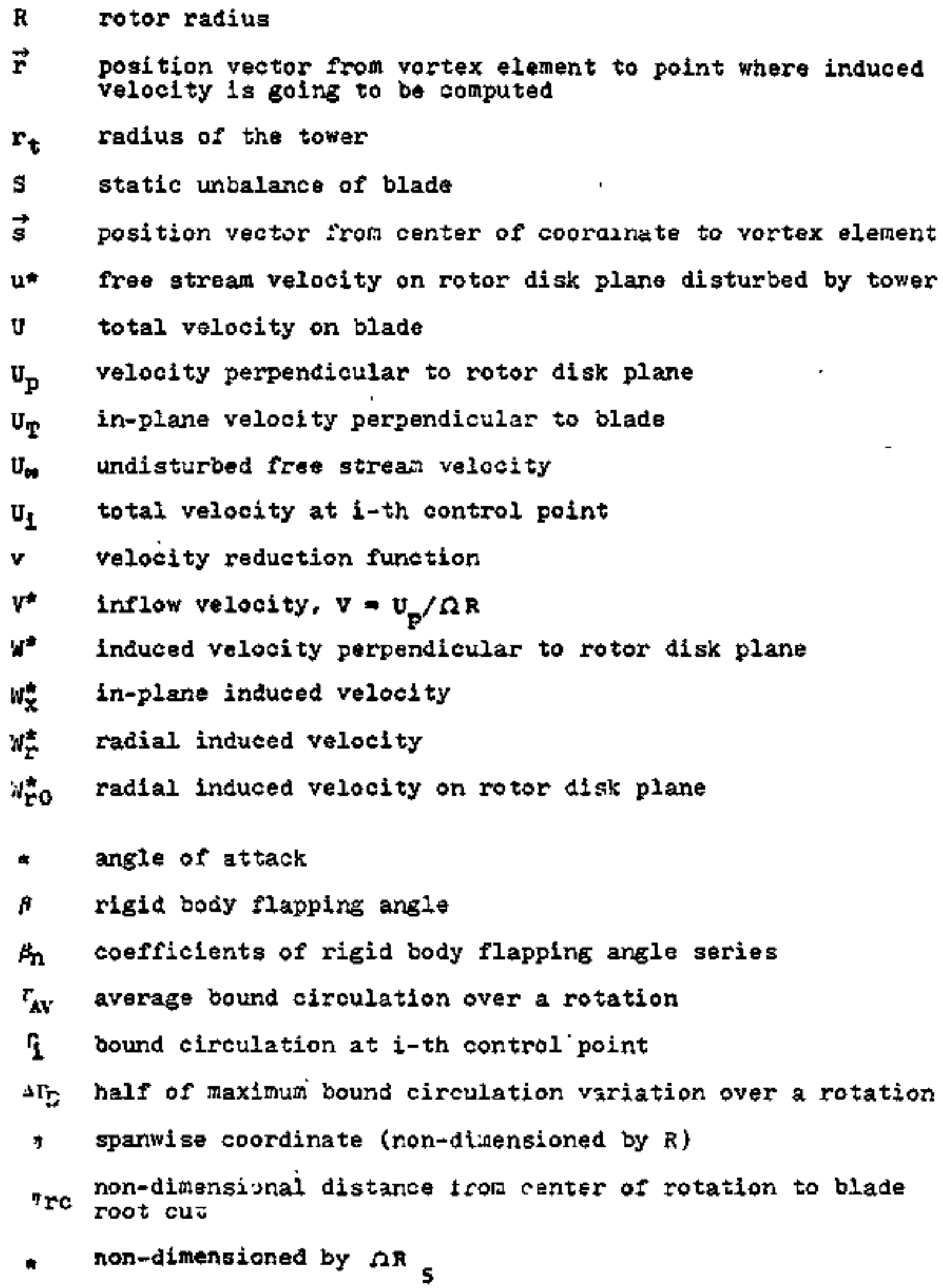


- angular coordinate to denote spanuise position

o coefficients of blade pitch angle series

Ap blade pitch angle

$\lambda$ Inflow angle

$\lambda_{i}$ indueed inflow angle (욤/ $n$ )

$\lambda_{a}$ absolute inflow angle (하. 40 )

p density of alr

H advance ratio, $\mu \neq U_{\infty} / \Omega R$

$r$ kinematic viscosity of air

- solidity. $\sigma=\mathrm{bc} / \pi \mathrm{R}$

\$ azimuthal angular coordinate of vortex element from blade †n phase angle between tlapplng angle series and inflow angle

$\phi_{i}$ phass angle bstwen pitch angle series and tnflow field series

* azimuthal angular coordinate

a rotational speed of wind turbine rotor 


\section{TABLE OF CONTENTS}

Section

Pages

1. INTRODUCTION $\ldots \ldots \ldots \ldots \ldots \ldots \ldots \ldots \ldots \ldots \ldots \ldots \ldots \ldots$,

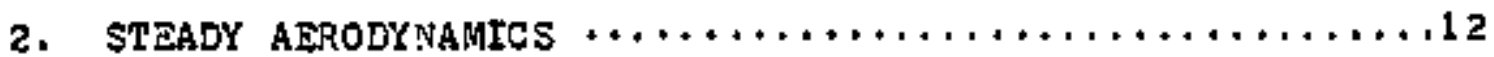

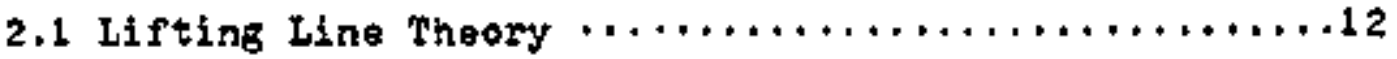

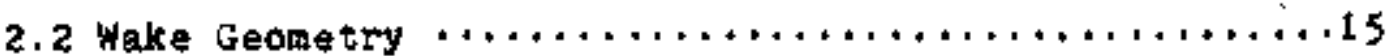

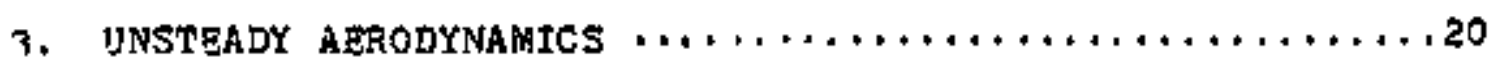

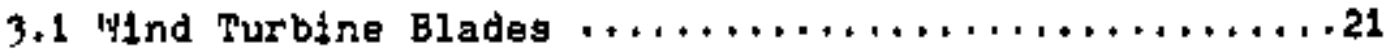

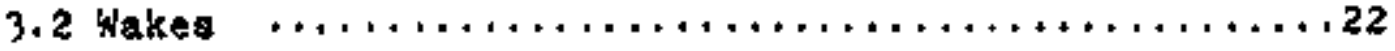

3.3 Non-rigid Wake Geometry $\ldots \ldots \ldots \ldots \ldots \ldots \ldots \ldots \ldots .22$

3.4 Caleulation of non-linear Movement of the Vortex...25

3.5 Calculation of Wake Expansion $\ldots \ldots \ldots \ldots \ldots \ldots 28$.

3.6 Effect of the up-wind Tower Presence on the wind Approaching the Rotor Disk Plane $\ldots \ldots \ldots \ldots \ldots \ldots$

4. SIMPLE BLADE DYNAMICS $\ldots \ldots \ldots \ldots \ldots \ldots \ldots \ldots \ldots \ldots \ldots \ldots$

4.1 Harmonic Analysis of Blade Plapping Motion $\ldots \ldots \ldots 33$

4.2 Pitch Angle Control to Minize Flapping Moment

Yariations over a Rotation $\ldots \ldots \ldots \ldots \ldots \ldots \ldots \ldots$ ?

4.3 Pitch Angle Control to Minize Thrugt varlations over a Rotation .......................38

5. RESULTS AND COMPARISON WITK EXPERIMENT $\ldots \ldots \ldots \ldots \ldots, 42$

5.1 Steady Results $\ldots \ldots \ldots \ldots \ldots \ldots \ldots \ldots \ldots \ldots \ldots \ldots, 42$

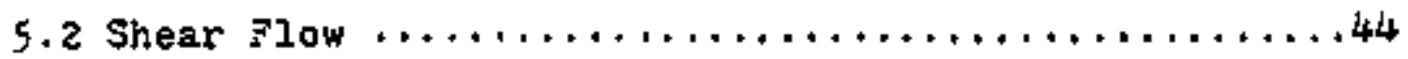




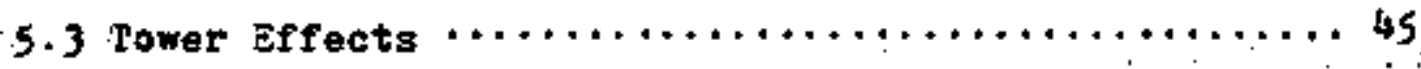

5.4 Effect of Blade Motion on Airloads $\ldots \ldots \ldots \ldots \ldots \ldots 46$

6. DISCUSSION AND CONCLUSIONS $\ldots \ldots \ldots \ldots \ldots \ldots \ldots \ldots \ldots \ldots, 48$

6.1 Discussion $\ldots \ldots \ldots \ldots \ldots \ldots \ldots \ldots \ldots \ldots \ldots \ldots \ldots, 48$

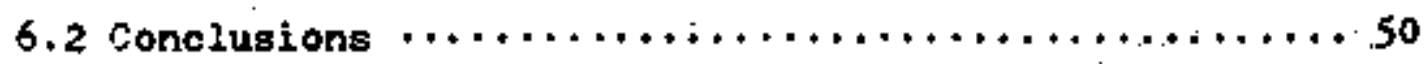

Referenges $\ldots \ldots \ldots \ldots \ldots \ldots \ldots \ldots \ldots \ldots \ldots \ldots \ldots \ldots \ldots \ldots \ldots 52$

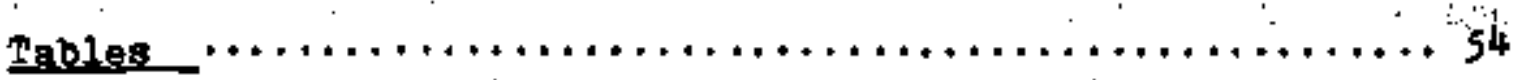

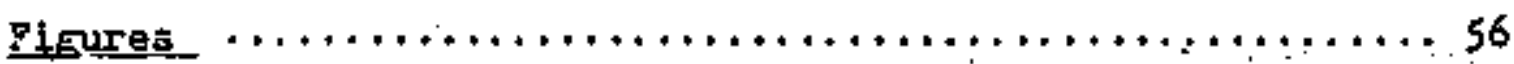

Appendices $\ldots \ldots \ldots \ldots \ldots \ldots \ldots \ldots \ldots \ldots \ldots \ldots \ldots \ldots \ldots \ldots \ldots, 87$

A. Caleulation of Influence coefficienta $c_{i j} \ldots \ldots \ldots \ldots .8$ ?

B. All Coofficienta used in Cilculating $c_{1 j} \ldots \ldots \ldots \ldots .94$

c. Yelocity Induced by A Trailing or Shed Yortex Elenent... 96

D. Hind Profile Equation Jp-wind of the Tower ..........101 
SECTION 1

\section{INTRODUCTION}

For uniform steady flow about a wind turbine, lifting line theory which is the counterpart of the Prandt's lifting line theory for rotating wing is employed in the analysis for a rotor blade In an effort to inglove the theoretical piatiction of power and thrust. The wake region is divided into three regions, namely, the near. Intermediate, and far wakes. At the junction between the near and intermedsate wakes, the nelghboring two vortices are merged together. Again, at the junction between the interuediate and the far wakes, all trailing vortices are assumed to be rolled-up into the root and tip vortices. The wake geometry is prescribed at equal angle spacings and the blade is divided into a number of segments according to cosine law. Each segment is represented by a constant strength bound vortex whose strength is determined at a control point which is located at equal angle center of that segment. The wake geonetry used in the analysis includes the linearly varying volocities induced on the tip or root vortex in the first spiral and the radial movement of thes. The results obtained with this waice geometry are compared with those obtained with the semi-rigid wake assumption. The computer program for the steady flow analysis permits the evaluation of several wake gepmetries ranging from the classieal helicoids, the semi-rigid wake to the radially expanded, variable-axial-velocity geonetry. The inboard trailing vortices mity be unrolled or fully rolled in tha last two wake geometries.

The importance of the correct axial and radial positioning 
of the tip. yortux was noticed in ref. (4). The digagreement of the theoretical predictions using the clasgleal. wake geometry with experimental results is malnly due to the neglect of the rapid contraction of the slipstream under a hovering rotor which places the vortex systam close to the rotor blades ${ }^{4}$. The free wake analyeis was introduced in [14] to account for the signiflcance, of blade. wake interference and the influence of blade number. The cross. section viep of the calculated wake geometry (ref.14) shows that the outer end of the vortex system; that is, the vortex emanated at blade tip becomes the center of the rolled-up concentrated tip vortex:

For the unisteady nonunlform flow which is inevitable due to wind shear, and tower reflection or tower shadow, the non-linear rariable-axial-velocity induced on the tip or root vortices are computed for each azimuthal. increment within the first spiral: The calculations show that the velocity induced on the tip vortex Increases sharply and is almost doubled within the first spiral. After that inducid velooity remains reiativoly unchanged. This Deans that the retardation of the tip vortex occurs immediately behind the rotor. This radial expansion 18 computed from the condition of constant mass flow inside the cylinder bounded by the tip vortex. Tower offect is included in the analysis through the nonuniform flow field on the rotor disk plane caused by the tower reflection or its shadow. The distortions of the trailing vortex system due to this nonuniform flow is, also, included. But In the tower reflection case, the vortex-tower intaraction is 
neglected because it occurs after several spirals of the tip vortex. The shed vortex lines in the far wake are positioned by the connecting lines of the points determined by the velocities induced on the two control points near the tip or the root. In the rigid or aemi-rigid wake the shed vortex was located by the tip and root vortices. The trallind vortices are permitted to have varying directions and strengths.

The equations are derived to determine the blade pitch angle required to minimize the elapping moment variations, or the thrust varlations over a rotation. All blade are assumed to be rigid. For the tower shadow case the rigid boty flapping angle is calculated and its effects are ovaluated.

Willer, R,H, in [2] has pioneered the unsteady harmonic atrload computation for the forward flight of the hellcopter with rigid wake geometry. Onsteady alrloads acting on rotor blades ware predicted satisfactorily and their orgins were discusaed $\operatorname{Ln}[1]$ and $\left[J^{-}\right.$ The concept of the semi-rigid wake geometry was introduced in those reportg, Scully, M.P. in [6] has done the free wake analysis for the hellcopter forward fliqht, where the induced veloeitsis on the firgt two spirals of the tip vortex were computed in order to locate the tip wortex and the inboard shed wakes were positioned by the rigtd wake geotmetry. 


\section{SECTION 2}

\section{STEADY AERODYNAIATCS}

The bound eirculation which describes the blade as a lifting line is represented by a Fourier sine series. The velocities induced by the prescribed wake are computed at control points on the blade ag a function of the coeffleients of the bound circulation series. These coefficients are calculated from the matrix equation which are formed according to the Kutta-joukowsky theorell. The aultiplication of these coefficients with the influence coefficlents yields the induced velocities on the blade. From these non-uniform induced volocities and the free stream velocity the wake is generated within the framework of the assumed geometry. Now influence coefficients, induced velocitiea and bound circulation are obtained from this new geometry. This procedure is usua11y iterated three times to get the converged bound circulation and Induced velocities. The usual strip analysis gives the porformance coefficients of the wind turbine.

\subsection{Lifing Iine Theory}

Bound circulation along tra blade is.represented as a sine series. The velocity induced at each control point on the blade by the wake system is computed as a function of the coefficients of the bound circulation harmonic series. Then, the induced angle of attack is obtained at each control point as a function of those coefficlents. The angie of attack calculation also includes antributions frot the pich angle, the rotational velocity 
of blade and the free streas velocity.

All of the above contributions are included in lifting line equation at each control point, which generates a syster of linear algebraic equations for the coefficients of bound clreulation series as follows. The sectional 12ft at a control point on the blace $2 \mathrm{~s}$ given by Kutta-Joukowsky theorem.

$$
d E=\rho U r=\frac{1}{2} \cdot P \cdot v^{2} \cdot a \cdot a \cdot c
$$

Here, $\alpha=\lambda_{p}+\lambda_{a}+\lambda_{1}$ as shown in fig.2.1.

$$
\begin{aligned}
w_{1} & =\sum_{j=1}^{N} A_{j} \cdot C_{i j} \\
r & =\frac{1}{2} \text { Ua } \in\left(A_{p}+\lambda_{a}+\lambda_{j}\right)
\end{aligned}
$$

The influence coefficients $q_{j}$ are computed from the equation derlved in the appendix. $A_{j}$ is the coefficients of bound ciroulation series, that.ls,

$$
r_{1}=\sum_{-i}^{N} A_{j} \sin \left(j \cdot A_{i}\right)
$$

$N$ is the number of control points on the blade.

The spanicse coordinate on the biade, $\eta_{i}$, is transformed into a polar coordinate, $\theta_{i}$. whlch varies from 0 to $\pi$ according to the following transformation equation

$$
\eta_{i}=\eta_{r c}+0.5\left(1-\cos \theta_{i}\right)
$$

(See fig. 2.2 for details.)

During tho intozmediate calculations erery value was non-dimensioned by the distance from the rootcut to the blade tip. In the 
final output the non-dimensional parameter was switched to the blade radius. Introduction of equations $(2.2)$ and $(2.4)$ into $(2.1)$ gives the desired linear algebraio equation for the coefficients of circulation.

$$
\begin{aligned}
& \sum_{j=1}^{N} A_{j} \sin \left(j \cdot \theta_{i}\right)=\frac{1}{2} U_{i} \cdot a_{i} \cdot c_{1}\left\{\theta_{p 1}+\lambda_{a j}+\left(\sum_{j=1}^{N} A_{j} c_{i j}\right) / \eta_{i}\right\} \\
& \sum_{j=1}^{N} A_{j}\left[\sin \left(j \cdot \theta_{i}\right)-\frac{1}{2} U_{i}+a_{1} \cdot c_{i} \cdot c_{i} y \pi_{i}\right]=\frac{1}{2} U_{i} \cdot a_{i} \cdot c_{j}\left(\theta_{p i}+\lambda_{a i}\right)
\end{aligned}
$$

$$
\sum_{j i j}^{N} a_{1 j}=D_{1}
$$

This equation $1 \mathrm{~s}$ valid at oach control point (1). Therefore, it Glves the following metrix oquation.

$$
\begin{aligned}
& {\left[a_{1 j}\right]\left\{A_{j}\right\}=\left\{D_{1}\right\}} \\
& \left.\left\{A_{j}\right\}=\left[a_{1 j}\right]^{-\frac{1}{b_{1}}}\right\}
\end{aligned}
$$

Here, in-plane fnduced velocities were neglected because the effect of these velocitieg on the results was shown to be negligible in [?].

In generating equation (2.5), $\mathrm{U}_{2}$ is a function of zaduced velocity and $C_{i j}$ is a runction of wake geometry which is determined from indued velocity distribution within the assuration for geometry. That means an itezative procedure, as described below, must be elployed to compute the actual $A_{j}$.

\section{Iteration Procedure}

1. Estimate induced relocitłes

2. Celculate $U_{i}$ 
3. Generate waks geometry

4. Caleulate 1nituence coefficients $G_{1 j}$

5. Solve equation (2.5)

6. Calculate induced velocities from equation (2.2)

7. Repeat step 2-6 until the solution converges

Knowing the proper Induced valocities a strip analysis is uged in calculating the thrust and power distribution. Experimental data for section lift slope and drag can be used. Nind turbine cotor in this analysis can have any number of blades which can have an arbitrary distribution of taper and twist. Ref.[9] applied the vortex lattice method to propeller blades with a single bound vortex located at the quarter-ohord point and the control point at the three-quarter chord point of each blade section. For non+rotating rectangular wing [8] shows that lifting line theory with trallins vortices arranged by equal angle distence and control point at the equal center between them converges faster and is more accurate than other vortex latifice methods.

2.2 inke Geometry

The prescribed wake geometry resulting from a series of investigations of model rotor wakeg was successfully applied to the caleulation of helicopter rotor hover performance with lifting line theory in $[4,5]$ and lifting suzface theory $i$ id [11]. At the present time, there is no wake geometry available for the wind rotor which has been developed from such experimental studies. 
Hence, two major features from the prescribed wake eeometries for helicopter rotor hover performance analysis are incorporatad in the calculation of wake geometries.

First, the tip vortex axial settling rate (or velocity) was doubled when the tip vortex passes basenth tho following blade. This doubling is predicted by momentum theory and in vortex theory can be explained by the effect from the trailing and bound vortex system of that blade generated during that portion of the cycle preceeding the following blade passage. For wind turbine rotor the-. Ie is the same effect on the tip vortex from the following blade's" trailing and bound vortex system. Also, the equation derived in [12] shows that the thrust predicted by simple vortex theory for the rotor with an infinite number of blades will be equal to that estimated by momentum theory when the axial induced velocity on the tip vortex in taken over the rotor disk.

The second foature is that the point of maximum wake contraction is reached at the end of four times the azimuthal angle between ajacent blades ${ }^{10,11}$ in the ane?ysis the polnt of maximum wake expasion for the wind turblne rotor is taken to be the maximum wake contraction point for the helicopter rotor.

The radial induced veloctty $\left(w_{r 0}\right)$ at the blade tip on rotor diak plane ie computed as followa. The tip vortex beging to move radlally with that velocity when it is tralled from the blade. It is assumed that the tip vortex radial velocity decreases linearly to zero when it reaches tine assumed maximum expansion point. Therefore, the radial velocity of tip vortax is 


$$
w_{r}=w_{r_{0}}-\frac{\phi}{(8 n / b)} \cdot w_{r_{0}}
$$

where lofis the radial lnduced velocity at the blade tip in the rotor disk plane, $b$ is the number of blade and $\phi$ is the azimuthal position of yortex. The maximum expansion distance d( $\phi)$ is given as follows for $b=2$.

$$
\begin{aligned}
& d(\phi)=\int w_{r} d \phi=w_{r o} \phi-\frac{\phi^{2}}{8 \pi} \cdot w_{r o} \\
& d_{\max }(\phi=4 \pi)=2 \pi w_{r o}
\end{aligned}
$$

The radial movement of tip vortex is dise to the radial velocity.: Induced by the spiral tip vortex below the rotor disk plane as show in fig. 2.3. In fig. 2.3 the radial velocity of tip vortex, C is decreased due to the radial velocity induced by the vortices trailed since tip vortex $C$ nad been trailed, that is, vortices $A$ and $B$. The tip vortex moves radially until the radial velocity induced by the almost helical vortex below that vortex is balanced by the radial velocity induced by the spiral vortex above it. After the tip vortex reaches its maximum expans:on point, it begins to contract much mor* slowly than when it expands just below the rotor disk plane. This is due to the fact that the radial velocity induced by the lower helleal vortex ceases to dominate over the velocity induced by the upper sprial vortex because of wake diffusion due to the viscous effects. Since this tip vortex begirs to contract relatively far below the rotor disk plane and very slcwly, its ofsect on performance and tincust cart be neglected. Experimental invostlestion in [11] shows for helicopter hovering rotor that the 
wake system contracts first and then expands very alowly. This radial movement of rolled-up tip vortex has a falrly large effect on power resultg because the axial velocity of tip vortex is infiuenced by the radial position of tip vortex and the induced velocity near blade t1p is affected very much by the axial andradial position of rolled-up tip vortex. The axtal induced,. velocity of rolled-up tip or root vortex is computed under the scheme that the vortex originating at the blade tip or root cutout becomes the center of the rolled-up tip or root vortex and that. the vortices trailed from the maximum-bound-cireulation point to the tip or rootcut are around those center vorticess.: Concentrated tip or root vortices are explained to be caused by a very high slope dropping toward zero of the bound circulation $(\mathrm{d} \Gamma / \mathrm{dy}=\infty)$ on those points. These concentrated vortices tend to induce strong velocities around them and to make the neighooring vortex sheet around thew. Therefore, the rolled-up vortex moves wi th the velocity which is the sum of the undisturbed free strean velocity and the induced velocity at the blade tip or rootcut. The velocity Induced on the tip or root vortex is agsumed to increase linearly untill it is doubled when it passes underneath the following blade as discussed above.

The wake system will be divided into three regions, near, intermediate, and far wakes as discussed in Table II. At the junction between the near and the intermediate wakes the number of trailing vortices is eut in half by merging two adjacent trailing vortices into one. All trailing vortices are assumed to be rolled-up 
Into the root or tip vortex at the junction point between the intermediate and far wakes. The velocity induced by the intermediate and the far wakes is computed at the blade tip or the rootcut point. But the velocity induced by the near wake is cosputed by averaging the velocities linduced at two points outside and inside the blade tip or rootcut. In semi-rigid wake the induced velocity at the tip or the rooteut is tidcen as the half of the velool ty induced at the nearest control polnt, which is equivalon to the aesumption that the velocity outatde $1 \mathrm{~s}$ zero. For a rotor with an infinite number of blader the lnduced velooity at the tip was shown to be the half of the velocity induced at inboard station of the tip in [12]. 


\section{SECTION 3}

UNSTEADY AERODYNAIIICS

Wind turbines always operate in the influence of their towerg and the ground. The unsteady girloads act on the wind turbine blades which rotate through the non-uniform flow field caused by these influences. The calculations of these unsteady airloads heve been performed by the vortex wake and lifting line theory. which means the lifting blade is modeled by a bound circulation and the chordwise circulation variation is neglected. The wake geowetry employed is the non-rigid wake which includes the effects of the retardation of trailing vortices and of the radial movement of the tip vortox. This geometry is calculated from the gemirigld wake geometry by suitable and systematic modiflcations. In this non-rigid wake the shed vortex lines in the far wake are placed on a plane other than the one defined by the rolled-up tip or root vortices because the induced velocities on those vortices are ontirely different from the induced velocities inboard of then.

The influence of the town on the vortex wake syater has been included. These vortex rakes are positioned by the the timewise integration of the velocitieg which are the sum of the digturbed velocities on the rotor disk plane due to the tower and the velocities induced on vortex itself. But in the tower reflection case when vortlces approach the tower the free stream velocitieg are decreasing and there are interactlons between ths vortex system, espesially the tip rortex ard the ,tower. It may happen after several spirals that the ilg vortex will 
touch the tower and end on the solid boundary because of the decrease of the fret atream velocity and the vortex-tower interactions. The effect of this phenomena on the induced velocitieg have been neglected because the contact of the tip vortex with the tower will uaually take place after aeveral epirals. The disturberce velocities due to the tower would be determined by satfafying the solid boundry condition on the tower surface with the frese strean veloclty under the influences of the vortex wakes and the bound clreulations of the blades.

The blades are assumed to be rigid. The rigid body flapping potion is determined for the tower shadow case and its effect on the unsteady afrloada are diacussed.

The equation which gives the wind profile downwind of the tower has been developed by using bounday layer approximations. That gquation is shown to be a good charactarlzation of the wind profile downind of the tower.

\subsection{Wind Turbine_Blades}

All blades are assumed to be identical, to rotate at a conatant anzular velocity, and to have arbitrary twist digtribution. The tower and blades are asgumed to be rigid. Each blade is represented by number of congtant-strength bound vortex segments which have the bound circulation that is determined by two dimension alrioll theory at their mid-points. The same method as used in [7] is used for the modeling of the blades. 


\subsection{Hakes}

.i The wake consiats of trailing vortices and shed vorticesnas shown in fig. 3.1 which are caused by the spanwise and azimuthal variations of bound circulation and is divided into near, intermodiate, and far wakes. The near wake region extends from the blade to 15 degrees aft and has three 5 degree seotions. It has been modeled by curved trailing vortex elements having varying strengths and varying directions within ono element and lattice vortex sheet elements each of which has constant strength and direction. The modeling of the intermediate and far wake rogions are discusged in Table II. The same procedure as the ore in [7] has been tollowed in dividing the wake reglons and determing the strengths of vortices.

\subsection{Non-rigid Waks Goometry}

The semi-rigid waxe ueually assumes that the vortles tratled from the blades are carried away from the rotor at a rate equal to the relative velocity of the flow pasoing through the rotor. These velocities are in general different at different points of this flow. Also, the vortex system is continuousiy being deformed due to these different velocities and the mutusl interactions of the tip vortices. As reandt, the velocity with which the tip or root vortex is carried away from the rotor plane is radically different frow the velocities on the sheet vortices between the tIp and root vortices. The vertical transport velocity of the outer portion of these gheets is much lower than that of the tip vortex

If we consider the vertical transport veloolty of one tip vortex element, the assumption made in the usual seml-rigid waike 
Is roughly equal to neglecting the internetion by the vortex seguents trailed after the tip vortex element was tralled. Lot the velocfty with which the element $A$ in fig.3.2A is carried away be $v_{A}$. When one tip vortex element $A$ is trailed, the verifical transport veloof ty $v_{A}$ becomes

$$
v_{A}=v+s_{b}=v+\sum_{b} \int_{l=0}^{\phi=\infty} \frac{d r}{d \eta} \frac{\overrightarrow{d s} \times \vec{r}}{4 \pi r^{3}} d \eta
$$

where $b$ is the number of blades, it the shed wake is neglected, If we considex that vortex element after the time interval, $2 t=$ $\phi_{6} / \mathrm{a}$ : it is positioned as shown in fig. 3.23. The vertical velocity of the element $A$ at position becomes

$$
\begin{aligned}
& v_{A}=r+w_{a}+w_{b}+w_{r} \\
& w_{a}^{*}=\sum_{b} \int_{\phi=\phi_{0}}^{\phi=\infty} \int_{0}^{1} \frac{d r(\eta, \phi)}{d \eta} \frac{\vec{d} \times \vec{r}}{4 \pi r^{3}} d \eta \\
& w_{b}=\sum_{b} \int_{\phi=0}^{\phi=\phi_{0}} \int_{0}^{1} \frac{d \Gamma(\eta, \phi)}{d \eta} \frac{\overrightarrow{d S} \times \vec{F}}{4 \pi r^{3}} d \eta \\
& w_{r}=\sum_{b} \int_{0}^{1} \Gamma(\eta, \phi) \frac{d \vec{\eta} \times \vec{r}}{4 \pi r^{3}}
\end{aligned}
$$

$W_{a}$ is the velocity induced at point $a$ by the rortex system trailed fron the blade before the vortex element $A$ was trailed. It can be reqsonably assumed that $N_{a}$ is equal to $N_{a}$. If one oonsiders the ind turbine to have more than one blade, average $u_{r}$ is almogt 
cancelled. Eut actually the instaneous velocity induced at point $Q$ by the bound circulation is not cancelled.

The most important factor which invalidates the assumptiotimade in usual semi-rigid wake is $w_{b} \cdot A t \phi_{*}=15^{*}$. $w_{b}$ is of the order of $40 \%$ of the velocity induced at polnt $p$ by $w_{a}:$. After one spiral $w_{b}$ is almost equal to $70 \%$ of $W_{a}$. Therefore the thal semi-rigid wake assumption causes us to underestimate 'the induced velocity at the blade'; especially near the blade tip because the spiral should be much close to the blade than indieated by rigid wake theory due to the wake inducedrvelocity. As a result, the performance of the wind turbine is overegtimated for a given pitch angle. In helicopter hovering case. the situation is roveresed.

The velocity induced at $Q$ by the vortex segant $\theta$ in fig.3.28 causes the retardation of vortex elenent A. The tip vortex trailed by the preceding blade therefore passes near the following blade, but not as in helicopter forward flight rotor case because this tip vortex goes a llttle outgide of the following blade tip. This tip vortex increages the induced velocity naer the blade tip, compared to the rigid wake assumption.

In the caleulation of velocitios induced at the blade by its wates sygtem, the seni-rigid wake assumption of velocity $v_{A}$ equal to initial veloctty 1a used in the noar wate region. In the intermediate and far wake regions, the velocity $Y_{A}$ of the vortex element A which was trailed when the blade was at $P$ is modified by the velocity induced by vort tex elements tratled by the biade since its orgin. The contribution of these regions is similarily divided into near, intermediate, and far wake regions for the potnt $A$. The near wake contribution is obtained from the near wake when the blade was at point $P$ and is thus not 
recomputed. Simflerly the intermediate and far wake contributions are obtained frow the corresponding reglons for the polnt F'. After the first spiral of the wake, $V_{A}$ is assumed to keep the velocity obtained according to the above procedure since the contributions of the remainint spirals will have a negligible effect on this geometry. The axial distance of element $A$ in fig. $3.2 B$ from the rotor disk plane is calculated by integrating the changing $V_{A}$ w.r.to the tide interval corresponding to the various induced velocities on element $A$. The radial location of the tip vortex is established by gatisfying the equation of continuity for the flow inside the vortex spiral.

This scheme does not need any more difficult steps to calculate the wake geometry than for the usual assumption made in semi-rigid wake. To reduce execution time and avoid some usoless calculations. the calculation of the velocity induced by the shed or trailing wake element was not performed, it the strength, $\left|\frac{d \Gamma_{\Delta}}{d \phi} \phi\right| 0 r\left|\frac{d}{d \eta} 3 v\right|$ was less than the corresponding reference values. In far wake after 6 spirals, the velucities induced by the half vortex system nearest the bliste are calculated and those Induced by the other half are neglected.

3.4 Calculation of Non-1 inear iovement of the Vortex

The tip vortex decelerates and expands quickly in the first - opiral after it was trailed. After the first spiral it maintains almost constant pitch and radial distance frot the rotor axis. When the blad; passes above the rolled-up tip vortex trailed from the preceding blade, that vortex plays a determinate role on the velocitj at the bladt tip, and consequently on the pertormance of the $+\frac{1}{1000}$ of mean value of $\Gamma 25$ 
wind turbine. Thus, the correct position of that vortex w1 th respect to the blede 1s required, All, these considerationg necessitate the Introduction of the caloulation of the non-11near morement of the tip vortex in the first apiral. Mnla celculation is done in a relatively simple way.

The non-1inear movement of the near wake is negleoted. gince the age of the near wake after it was trailed is noglfgible go that any doparture from a linear movement is lnsignirleant. In fig. 3.3 the axial velocity $v_{L}$ of tip vortex element I is

$$
v_{L}=v_{O L}+\sum_{K=1}^{L-1} w_{L, K}
$$

where $\omega_{I, K}$ is the veloct ty induced at the element $L$ by the element $K$ and $V_{O L}$ is the atarting velocity of element' $I$ at that instant when the blade is located at the eximuthal angle $t_{b}$. The axial distance $\mathrm{H}_{\mathrm{f}}$ of element $\mathrm{L}$ is

$$
H_{L}=v_{O L} \cdot \phi_{I}+\sum_{K=!}^{L-1} J_{L, K^{*}} \Delta \phi \cdot K
$$

,where $\phi_{L}$ is the azimuthal angle between element $A$ and the ourrent blade position and 14 is the angular interval between the vortex elements. The calculation of $N_{L}, 3$ for each vortex element I is very time consuming. Wl thout actually computing NL,K it is obtained from th velocity which is induced by each vortex element I at the blade tip.

$$
w_{L, K}=w_{N, L-K} \cdot \frac{\Gamma_{t}(K)}{\Gamma_{t}(I-K)} \quad \text { for } 1 \leqq K \leqq I-8
$$

yere, $\Gamma_{t}(K)$ is the strength of the vortex element $K$ and $d_{N, I-K}$ 
is the velocity Induced at the blade tip $\left(\eta_{N}\right)$ by the vortex element $L-K$. The factor $\Gamma_{t}(K) / \digamma_{t}(L-K)$ is necessary because the stren-" gths of trailing vortices are different at different arimuthal angles due to the non-uniform free streas velocity on rotor plane.

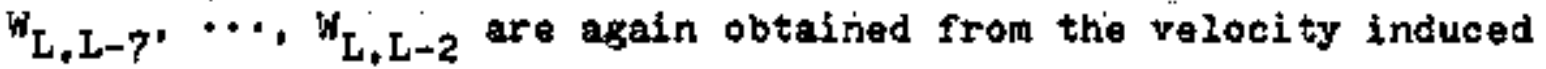
at the blade tip by the intermediate wake and $W_{L, L-1}$ from the veloc1ty induced by the near wake.

The position of the shed line vortex in the tar wake is defined by the line connecting two positions which are determined by the sum of the froe atriam velocity and the velocities induced at $\eta_{2}$ and $\eta_{\mathrm{N}-\mathrm{i}}$ in $\mathrm{fig} .3 .3$. Using the same method which was used to position the tip and root vortices, the relations (3.1) to (3.2) are, omployed while $W_{\mathrm{N}, \mathrm{L}-\mathrm{K}}$ is replaced by ${ }^{2, \mathrm{~L}-\mathrm{K}}$ in order to 2ocate the inboard and of the shed line vortex and by" $W_{N-1, L-K}$ in order to locate the outboard end of that line vortex. The radial position of the tip vortex is computed from the condition of constant mags flow Inside the vortex cylinder. This point is discussed in the next section.

The axial velocl ty at the rolied-up tip or root vortex is cowp: puted according to the scheme that the vortex originating at the blade tip or rootcut becomes the center of the rolled-up tip or root vortex and the vortices trailod from the maximun-bound-cireulation point to the tip or the rootcut are around that center vortex. Therefore, the rolled-up vortex woves with velocity whohite the sum of the undisturbed free stream veloclty and the induced velocity at the blade tip or rooteut and its axial velocity changes 
are computed in the mannez explained above. The velooity induced at the t1p or rooteut by the near wake is computed in the save way as discussed in gection 2.2 and is negligibly gmall, compared to the velocities indueed at inboard polnts between the tip and the raotcut by the near wake.Therefore, the initial velocity of the tip or root vortex becowea very different from those of the inboard trailing or shed vortices. The velocity induced by the intornediete and far wakeg is caleulated at the blade tip or rootcut polnt itgelf.

\subsection{Galculation of Wace Exponton.}

The radial position of the rolled-up tip vortex has a signifleant effect on the axiel velocity induced on the tip vortex which are trailed around the blade tip. Also. from the velocity induced on the blade tip, the axial pogition of the rolled-up vortex. is computed with free strean velocity es explained in section 3.4 . In the near and intermediate wakes, which have $90^{\circ}$ azimuthel interval together, the wake expengion ig neglected in the non-rigid wake ealculations of unsteady and steady problems. In the far wake the wake expangion is deterained from the condition of constant mags flow ingide the vortex cylinder with the total average velocity on the rotor plane and the one in the far wake postifion of Interest. The total average veloct ty on the rotor plane is the sum of the froe strean velocity and the average of the velocity induced on the blace. The total average velooity in the far wake, where the wake expansion is to be computed, is the sum of two velocities. One is 
the total average velocity on the blade. The other is the averase of the velocities Indueed at $\eta_{2}$ and $\eta_{N-1}$ in fig. 3.3 by the near and intermediate wakes, and the part of the far wake elements up to the nolghboring vortex element of the far wake point of Interest.

Fig. 5.23 shows the importance of the wake expansiton for the o degree constant pitch angle case. This figure ls obtained by the non-rigid wake steady program which 1a simplified from the nonrigid wake ungteady program due to the azimuthal symmetry of atoady flow. In the figure the maximum wake expanaion, $\max _{\text {for }}$ fhe pitch 4 of 8 degreeg cage does not exceed $1 \cdot 30 \cdot R$. But for the 0 degree pitch case, this value is alwayg exceeded, Also, this case is In vortex ring condition as shown in [12]. Hence, the simple condltion of constant aass flow can not predict the correct wake expansion due to a partial reverse and recirculating flow inslde the vortex cylinder. The powor coefficients with the maximum waxe expansion confined to $R_{\max }=1.15 \cdot R$ ar sienificantly higher than those with $R_{\max }=1,30 \cdot R$. The former resulta are in good agreement with the experiments from [13]. 
3.6 Fffect of the Up-wind Tower Pregence on the wind Approaching the Rotox Disk Plane

The airrect effect of the presence of tha tower is the continual spreading of the wake. The velocity distribution in the wake is likely to be complicated in the nelqhborhood of the tower. even when the flow is steady. Farther downstream in a steady wake the vorticity shed from the tower is convected in the atrear dire- . otion and diffused by viscosity. In this region the boundary layer approximations are applicable asymptotically. Thus, assuning that the flow downstream of the tower is a steady two dimensional wake, the governing equation of motion is

$$
\text { प. }\left(\frac{\partial u}{\partial x}\right)=\nu\left(\frac{\partial^{2} u}{\partial y}\right)
$$

and the boundary condition at the edge of the wake is $u \rightarrow u_{\infty}$ as $y \rightarrow \infty$. Ref. [15] giver the asymptotic solution for equation (3.4).

$$
v_{-}-v \rightarrow 0 \sqrt{\frac{\bar{v}_{x}}{4 \pi x}} e^{-\frac{\pi_{0} y^{2}}{\nu x}} \quad \text { as } x \rightarrow \infty
$$

Here, $x$ is the downstream distance from the tower center to the rotor disk plane and $y$ is the lateral distance from the tewer center to the position of fiterest in the rotor Alsk plane. O is 
a conatant dater alined by $Q=D_{t} / \rho$ to where $D_{t}$ is the drag of the tower.

Lat the velocity reduction function, $v$, be defined as follows.

$$
\begin{aligned}
& v=\frac{\Sigma_{0}-u}{U_{0}}=0 \frac{1}{\sqrt{4 \pi \nu \times u_{\infty}}} e^{-\frac{v_{0}}{4 \nu x} y^{2}} \\
& o_{t}=\rho 4_{6} Q=\frac{1}{2} c_{d t} \rho 4_{6}^{2} \mathrm{~A} \\
& 0-\frac{1}{2} \cdot c_{d t} \cdot U_{d} 2 \cdot r_{t}=c_{d t}+\psi_{d} \cdot F_{t}
\end{aligned}
$$

, where $r_{t}$ is the radiug of the tower. The introduction of equation (3.6) into $(3,5)$ yielda

$$
\begin{aligned}
& v=c_{d t} \frac{1}{\sqrt{4 \pi \nu k}-r_{t}} \sqrt{1_{\infty}} e^{-\frac{1}{\nu x} 4_{\infty} y^{2}} \\
& -k_{1} x_{t}: a_{0}^{-k_{2} \cdot \psi^{2}}
\end{aligned}
$$

$$
x_{1}=f\left(c_{d t}, \nu, x\right), x_{2}=f(\nu, x)
$$

$\mathrm{r}_{1}$ and $\mathrm{x}_{2}$ can be considered as chacteristic constants for a aiven tower which dcpends on the tower and ting dowstream distance from tewer to the rotor atsk plane. In the present anaigsis $x_{1}$ and $x_{2}$ are obtained by somparing the typical experimental wins protile with equation $(3.7)$. 


\section{SECTION 4}

\section{SIHPLE BTADE DYNAWICS}

The harmonic analysis of the blade flapping notion was done in order to get an idea of the effect of the blade motion on the airloads. This slapping motion is caused by a change in the clrculation of the lifting blade due to disturbance of the flow fleld by the tower. Cylic changes in the aerodynamic flapping moment of the blade and in the force acting on the tower are caused by the ehanges in the blade 1fft. These cylic changes are undesirable in view. of the fact that the plapping wotion can give rise to severe vibrational problems, vibrations coupled th the other motions of the blade and with the tower vibrations. The periodfcally varying blade thrust acts on the tower as a cyclic external force and a varying torque.

The equation for moment equllibrium about an offset flappins hinge is derived to determine the coefficients of the flapping motion series, given the known disturbed flow field due to the presence of the towr and the induced flow fleld. Based on the series representation of the inflow field( $V)$ on the rotor disk plane, equations are derived to determine the pitch angle control which can minimize the flapping moment variation or the thrust variation over a rotation. The minimization of the rigid body flapping motion is equivalent to winimizing the flapping moment variations over a rotation because $k_{\beta} \cdot \beta$ is equal to the flapping soment acting on the offset hinge. 
4.1 Harmonie Anazysis of Blade Flapping Motion

Considering the ribia flapping motion about an offiset hinge the blade flapping moment equilibrium gives the flapping equation of motion.

$$
\mathrm{H}_{\mathrm{A}}+\mathrm{H}_{\mathrm{I}}+\mathrm{H}_{\mathrm{S}}=\mathrm{K}_{\beta} \cdot \dot{\beta}
$$

where $M_{A}=$ flapping moment due to aerodynamic force -

$M_{I}=$ flapping moment due to inertia force

$u_{\mathrm{g}}=$ Mlapping moment due to gravity

$K_{\beta}=$ root constriint

$M_{A}, H_{I}$, and $H_{B}$ are derived as follows. (Ses $11 \mathrm{~g}, 4.1$ for details)

$$
\begin{aligned}
& d u_{I}=-r \ddot{\beta} \cdot r R^{3} d r-n^{2} R^{3}(r+e) r \beta \text { 向 } d r \\
& M_{I}=\int_{0}^{d R_{I}}=-\left[I_{b} \ddot{\beta}+\left(I_{b}+I_{b} \frac{\partial}{2} \frac{e}{\ell}\right) \Omega^{2} \beta\right] \\
& d \mathrm{~d}_{\mathrm{A}}=\mathrm{L}(\mathrm{x},+) \cdot \mathrm{R}^{2} \mathrm{x} d x
\end{aligned}
$$

with $I(r, t)=\frac{1}{2}$ pac $U^{2}(r, \downarrow) \alpha(x, \phi)$

where $\alpha(r, \psi)=\theta_{p}(r, \psi)+\tan ^{-1}\left(U_{p} / U_{p}\right)$

$$
\begin{aligned}
& \mathrm{U}_{\mathrm{T}} / \mathrm{RR} \cong(\mathrm{r}+\mathrm{e}) \\
& \mathrm{U}_{\mathrm{p}} / \mathrm{QR}=u(\mathrm{r}, \psi)-r \dot{\beta}+\mathrm{u}(\mathrm{r}, \psi) \\
& \mathrm{v}^{2}=\mathrm{v}_{\mathrm{T}}^{2}\left(1+\mathrm{U}_{\mathrm{p}}^{2} / \mathrm{v}_{\mathrm{T}}^{2}\right) \equiv \mathrm{U}_{\mathrm{T}}^{2} \\
& \tan ^{-2}\left(\mathrm{U}_{\mathrm{p}} / \mathrm{v}_{\mathrm{f}}\right) \equiv \mathrm{U}_{\mathrm{p}} / \mathrm{v}_{\mathrm{p}}
\end{aligned}
$$

These approximations are valid for the usual operating coifiltions of high tip speed ratio. 
Then, $H_{A}=\frac{I_{b} \Omega^{2} L N}{2} \int_{0}^{L} r\left[\theta_{p}(x, v)(x+e)^{2}+v(x, \psi)(x+0)\right] d r$

$-\frac{L N}{8} I_{i} \cap \ell^{4} \cdot\left(1+\frac{4 e}{3 \ell}\right) \dot{\beta}$

$(4.3)$

$$
\begin{aligned}
& d \pi_{\mathrm{g}}=\mathrm{R}^{2} \cdot \mathrm{A} \cdot \mathrm{g} \cos \psi \cdot r \cdot \beta \cdot d r \\
& \mathrm{H}_{\mathrm{g}}=\mathrm{g} \theta \cos \psi \cdot \mathrm{S}
\end{aligned}
$$

In these expressions,

$$
\begin{aligned}
& I_{D}=\frac{1}{3} m(\ell R)^{3} \\
& L=a c+R^{4} / I_{b} \\
& i_{B}=\frac{L N}{8} \ell^{4}\left(1+\frac{4 e}{3 \ell}\right) \\
& S=\frac{1}{2} \dot{m}(\ell)^{2}
\end{aligned}
$$

Substitution of the equations $(4.2),(4.3)$ and (4.4) into squatIon (4.1) yields the flapping equation of motion.

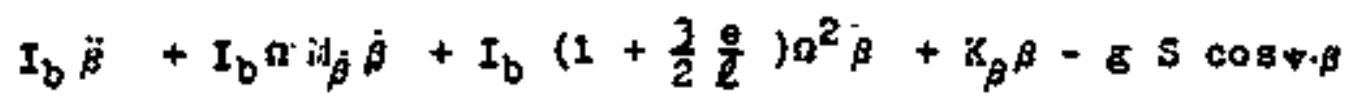

$$
\begin{aligned}
& =\frac{I_{b} a^{2} L N}{2} \int_{0}^{\ell} r\left[A_{p}(r, t)(r+e)^{2}+V(r, t)(r+e)\right] d r \quad(4,6)
\end{aligned}
$$

Switching the independent variable from time to azimuthal angle $(+)$ renders the final flapping equation.

$$
\vec{\beta}+\mu_{\dot{\beta}} \dot{\beta}+\mu_{\beta}^{2} \beta-G \cdot \cos \psi \cdot \beta=\frac{L N}{2} \int_{0}^{e}\left(\beta(r, \phi) \cdot r \cdot(r+\theta)^{2}\right.
$$

34 
$+v(r, y) r(r+e)] d r$

where $(\dot{)}$ denotes differentiation w.r.to $*$.

Here, $\nu_{\beta}^{2}=L+w_{\beta *}^{2} / \Omega^{2}$

$$
\begin{aligned}
& L=1+\frac{1}{2} \frac{e}{g} \\
& W_{\rho_{0}}^{2}=K_{a} / I_{b} \\
& \dot{G}=g S / I_{b} \Omega^{2} \\
& V(r, \Psi)=[u(x, \Psi)+w(x, \Psi)]
\end{aligned}
$$

In order to get the steady atate solutions for the blade flapping motion one enploys harmonic serieg representations for the disturbed inflow field and the blade pitch angle.

Lot

$$
\begin{aligned}
& v(r, \Psi)=v_{0}(r)+\sum_{n=1}^{\infty} v_{n}(r) \cos n \Psi \\
& \beta(\Psi)=\beta_{0}+\sum \beta_{n} \cos n\left(\Psi+\phi_{n}\right) \\
& \theta_{p}(r, \Psi)=\theta_{0}(r)+\sum \theta_{n} \cos n\left(\Psi+\phi_{n}^{\prime}\right)
\end{aligned}
$$

One introduces equation (4.6) into equation (4.7) and takes the harmonic balance, while neclecting the coupling between the firat harmonic excitation due to gravity and the higher harmonics of the flapping sotion because this gravity offect is not appreciable for the thodel used in the experiment. The experimental wind 
turbine model whose radius is relatively sal rotates fast to keep the same tip speed ratio as the real wind turbine. Hence, the centrifugal force is so large that the gravity force is negligibile, compared to this force. For real wind turbines, however, this .. does not generally hold true.

$$
\begin{aligned}
& \beta_{0}=\frac{L N}{2 L_{p}^{2}}\left\{\int_{0}^{Q} \theta_{0}(r) r(r+e)^{2} d r\right. \\
& \left.+\int_{0}^{2} v_{0}(r) r(r+0) d r\right\} \\
& \beta_{1}\left(\nu^{2}-1\right) \cos \phi_{1}-G \beta_{0}-i \beta_{1} \sin \phi_{1} \\
& =\frac{L N}{2} \int_{0}^{e} r\left[(r+e)^{2} \theta_{1} \cos \phi_{i}+(r+e) V_{1}(r)\right] d r(4.10) \\
& \beta_{1}\left(\nu_{\beta}^{*}-1\right) \sin \phi_{1}+i \phi_{\beta} \beta_{1} \cos \phi_{1}=\frac{L N}{2} \int_{0}^{k} r(x+\theta)^{2} \theta_{1} \sin \phi_{1}^{\prime} d r \\
& \left\{\left(\nu_{k}^{2}-n^{2}\right) \cos n \phi_{n}=n \mu \sin n \phi_{n}\right\} \beta_{n} \\
& =\frac{n N}{2}\left\{\int_{0}^{2} r(r+e)^{2} d r \theta_{n} \cos n \phi_{n}+\int_{0}^{l} v_{n}(r)(r+e) r d r\right\} \\
& \left\{\left(\mu_{p}^{2}-n^{2}\right) \sin n \phi_{n}+n \omega_{j} \cos n \phi_{n}\right\} \beta_{*}=\frac{L N}{2}\left\{\int_{*}^{\ell} r(r+e)^{2} d r \theta_{n} \cdot \sin n \phi_{n}^{\prime}\right\}
\end{aligned}
$$

When the blade pitch anglo is kept constant, the coefficients of the flapping motion are obtained as follows.

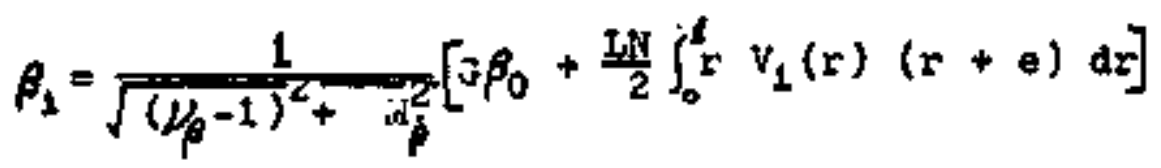

$$
\begin{aligned}
& \beta_{n}=\frac{L N \int v_{n}(r) r(r+e) d r}{2 \sqrt{\left(\nu_{p}^{2}-n^{2}\right)^{2}+n^{2}+w_{p}^{2}}} \quad n=2,3, \ldots(4.13)
\end{aligned}
$$

36 
$\operatorname{Tan} n \phi_{n}=\frac{-n}{\left(\phi^{2}-n^{2}\right)}$

$\mathrm{n}=1,2,3, \cdots \cdots(4,14)$

Once the computed wake geometry is determined, the induced flow field in the rotor disk plane is conputed. Then the coefficlents of the inflow field series $\left(v_{t}\right)$ are obtained by Fourier decomposition. From equations (4.9), (4.16) and (4.13) the coefficlents of the rigid body slapping angle are caleulated for the blade of constant chord and constant mass along the span. The Plapping velocity is obtained from the time difforentiation of the flapping angle ( $\beta$ ). The effects of the blade flapping motion on the afrloads are determined by simple superposition of the velocities due to the slapping motion and the inflow field. The equations for the blade flapping coefficients determine each harmonic of the flapping wotion from the corresponding harmonic of the inflow field.

4.2 Pitch Angle Control to Winimize Plapping ifoment Vaclations over a Rotation

The flow fisld on the wind turbine cotor disk plane is affected by the tower whether it is operating upwind or domwind of ite tower. Thus the tower causes variations in the blade circulation and its elapping motion. However, the tower interference effects and hence the blade flapping motion, or the flapping moment variation can be reduced by controlling the blade pitch angle, onkancing the performance of the vind turbine at the same time. The coefficlents of the fiton angle control $\left(t_{1}\right)$ are determines from equattons $(4,10)$ and $(4,1:)$ by setting $\beta_{x}$ equal 2 oro. 


$$
\begin{aligned}
& \theta_{1}=\frac{-G \beta_{0}-\frac{L N}{2} \int_{r}^{\ell}(r+e) v_{1}(r) d r}{\frac{L N}{2}\left[\frac{\ell^{4}}{4}+\frac{2}{3} \ell^{3} e+\frac{1}{2} \ell^{2} e^{2}\right]}, \phi_{1}^{\prime}=0 \\
& \theta_{n}=\frac{-\int_{0}^{2} r(r+e) v_{n}(r) d r}{\left(\frac{\ell^{4}}{4}+\frac{2}{3} \ell^{3} e+\frac{1}{2} \ell^{2} e^{2}\right)}, \phi_{n}^{\prime}=0 \text { for } n \geq 2 \text { (4.16) }
\end{aligned}
$$

11so, from equation (4.11), the amount of the llapping sotion. control, or the control of the flapping moment variation by the unit pi teh control $1 \mathrm{~s}$ determined.

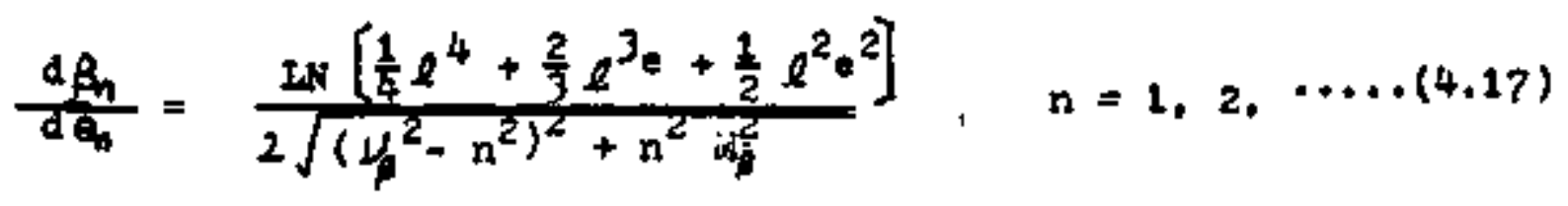

Since the coefficients of the inflow field $\left(\mathrm{v}_{\mathrm{n}}\right)$ as well as the Induced velocities are dependent on the pitch control. equations (4.15) and (4.16) should solved iteratively untill converged valueg of $h_{n}$ and $\theta_{n}$ are reached. For different $\theta_{n}$, the strength of the bound clrculation varies and, also, the induced velocities on the zotor disk plane changes. These new induced ralocities glve the new en, according to equationg (4.15) and (4.16). These equations show that the pitching variations should follow the inflow field variations, that is, there is no phase shift between the two.

. 4.3 Pitch Angle Controf to innimize Thmust Varlations over a Rotation,

The unsteady blade lift acts on the tower as an unstuady exolting force while the wind turbine rotor 1s rotationg. 
Obvlougly this kind of exclting force can cause sote serlous vibrational problems for the tower wh1ch undergoes strong alde vibration. By controlling the blade pitch angle the variation of thrust generated by a blade can be minimized for a rotation of the blade. It would be better to minigize the thrust. - variation while keeping the blade flapping motion to a ninimum than to accompliah only one of these two purposes. Referring to fig. 4.2, the elemental blade thrust is

$$
\begin{aligned}
& \mathrm{dT}=\mathrm{dL} \cos \lambda+\mathrm{dD} \sin \lambda . \\
& \mathrm{dL}=\frac{1}{2} \rho \mathrm{U}^{2} \mathrm{a} \alpha c d r \\
& \mathrm{dD}=\frac{1}{2} \rho \mathrm{J}^{2} \mathrm{C}_{\mathrm{d}} c \mathrm{dr}
\end{aligned}
$$

Hence, the thrust acting on one blade is

$$
T=\frac{1}{2} P c\left[a\left(U(\lambda+\theta) A R^{2} \eta d \eta+c_{d} \int U R^{2} \Omega V d \eta\right]\right.
$$

Here $\lambda \equiv \operatorname{sin\lambda }, \quad \mathrm{v} \cong \hat{\Omega}_{R} \eta$

$$
\frac{T}{\rho \pi^{2} R^{4}}=L_{T}=\frac{\sigma}{2 b}\left[a \int\left(v \eta+\theta_{p} \eta^{2}\right) d \eta+c_{d}(v \eta d \eta]\right.
$$

The coefficients of the required piteh angle control are obtained by employing serieg representations for the thrust and for the inflow field and by taking the harmonic balance of the resulting equation. 
Let

$$
\begin{aligned}
& I_{T}=L_{T 0}+\sum L_{T n} \cos n\left(\Psi+\phi_{n}\right) \\
& \nu(\eta, \Psi)=v_{0}(\eta)+\sum \eta_{n}(\eta) \cos n \Psi \\
& \theta_{p}(\Psi)=\theta_{0}(\eta)+\sum \theta_{n} \cos n\left(\Psi+\phi_{n}^{\prime}\right)
\end{aligned}
$$

Then, equation (4.18) is decomposed as follows.

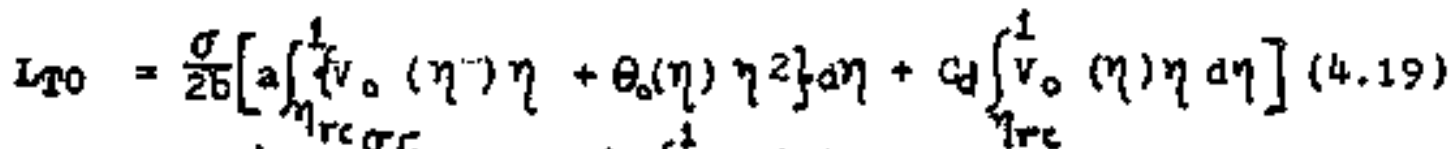

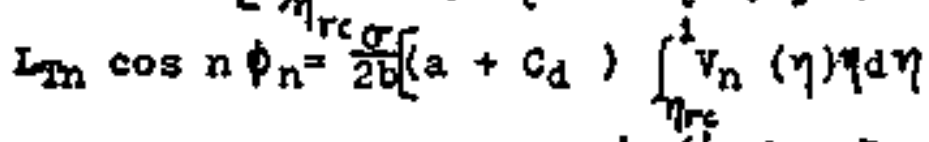

$$
\begin{aligned}
& \left.+a \theta_{n} \cos n \phi_{n}^{\prime} \int_{\eta_{r e}}^{i} \eta^{2} d \eta\right] \\
& \left.-I_{m} \sin n \phi_{n}=\frac{\sigma}{2 b}\left[-\operatorname{\theta en} \sin n \phi_{n}^{\prime} \int_{\eta_{\text {rec }}}^{t} \eta^{2} d \eta\right] .\right\}
\end{aligned}
$$

Again, the coefeicients of the pitch angle control $\left(\theta_{n}\right)$ are obtained by setting $L_{\text {In }}$ to be zero.

$$
\theta_{n}=-\frac{3\left(1+\frac{c_{d} / a}{a}\right)}{\left(1-\eta_{r c}^{j}\right)} \int_{\eta_{r e}}^{1} \eta v_{n}(\eta) d \eta, \quad \phi_{n}^{\prime}=0
$$

Furtheremore, the sensivity of the blade thrust to pitch shange, or the amount of the thrust control by the unit pitch control is obtained froa equation $(4,20)$.

$$
\frac{d L_{m}}{d \theta_{n}}=\frac{\sigma a}{2 b} \int_{\eta_{r c}}^{1} \eta^{2} d \eta=\frac{\sigma a}{6 b}\left(1-\eta_{r c}^{3}\right)
$$

As mentioned in setion 4.2 , the coefficients ( $v_{n}$ ) are dipendeut on the blade pitch angle $\theta_{n}$. Iherefore, the required pitch control 
argle should be determined iteratively srom equation (4.,21) in the same manner which was used to determine the on which minimize the blade flapping motion. The equation (4.21) shows that there is no phase shift between the pitching variations required to minimize the thrust variations and the inflow fleld variations. 
. SECTION 5

RESTLTS AND COMPARISON-WITH EXPERIMENT.

5.1. Stesgdy Rasults ...

The calculated power coarficlents in a uniform tlow for pitch angles of $4^{\circ}$ and $8^{\circ}$ are prasented in $1 . \mathrm{g} .5 .2$ with measured results from [13]. The thrust coefflelents are shom in fig. 5.3. The drag representation, $c_{d}=0.01+1.5 . \alpha^{2}$, is employed. The results shown are in good agreement with experiment for tip speed ratios where stall effects are not important. The same stall model as used in [7] is enployed with stall angle, 0.2 ; radians. Fig. 5.2 suggests that this stall model does not describe the atall nistory adequately. It should be noted that the drag polar used in Vol.II for comparison between theory and test wag different than the one assumed here. Hence there is a question as to which drag cosfficiont beat represents the model. The comparisone presented are of interest primarily in showing. the relative effects of the different analytical models.

In $51 \mathrm{~g} .5 .4$ to $\mathrm{fig} .5 .7$ the calculeted power and thrust coofficionts are compared with experiments and some results frot [7]. The same semi-rigld wake model as the one used in [7] is employed in these calculations. Here the Induced velocity on the rootcut or the blade tip ig taken to be half of the Induced velocity at the inboard control point of the blade. For an $8^{\circ}$ pitch - angle the three resulta give almost ldentical velues of thruat and power coefflcients. The departure of the theoretical predict- 
ions from the experimental results aeems to show that for an : $8^{\circ}$ plteh angle the wake behaves like the eqml-rield wake nodel, but for $4^{\circ}$, plteh angle where thrusts and hence Induced veloctties are much highor it behaves like the new wake aodel uosd in calculating the regults in $\mathrm{fl}$. .5 .2 and $\mathrm{ftg} .5 .3$ which linoludes the retardation and radial movement of the rortlces In the . . .... firat opiral.

The effect of the etall modela on the power coeffielents is ghown in $1 \mathrm{~g} .5 .24$. The gteady non-rigld-wake program, which.te discused in.gection 3.5. Is uged in this calculation. It. is show that the otall decreases the power cooffleients fairly when the

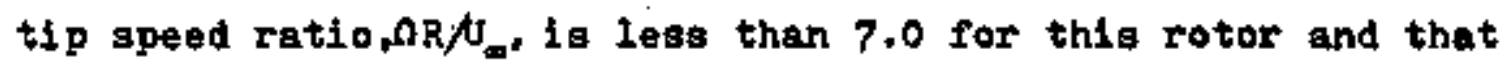
the atall model, $C_{Q}=$ congtant for $Q>Q_{g}$, is not proper.

In the analysis enploying the sine series representation of. the bound circulation 15 coefficients of the geries are computed. As the nuber of harmonics is increased, the magnitude of the corresponding harmonic coefficient decreages rapidly as ghow in fig. 5.8. For every calculation the coeffictents for the 7 th and higher harmonies are negligible. The flrgt and gecond coeff. lcients are especially dominant. Ten control points and harmonics are thought to be adequate to obtain pratical reaults. All the calculations In the present analysis converge within three iter-: ations.

The bound circulation diatributions along the blade are shown for two pitch angleg in $\mathrm{Pig} .5 .9$. It ghows that the bound elrcul- 
ation 1ncreases near the root and decreases near the tip as the blade pitch angle increases. At the $t i p d \Gamma / d \eta$ is infinite in. both casas because $d \Gamma / d \theta$ ta finite at the thp and nence $d \Gamma / d r=$ $2 \frac{d \Gamma}{d \theta} \cdot \frac{1}{\sin \theta}=\infty$ for $\theta=0$ or $\pi$. Induced velocittes along the span : are presented in 1 .5.5.10 with the induced velocities on the root cut or the blade tip. It is intereating to notice in the cage of $4^{\circ}$ pitch that the induced velocitles are almost constant and about $1 / 3$ of the free stream velocity which the momentum theory predicts to be the ideal condltion for maximum power. The induced velocity on the blade tip is shown to be lasg than half of the veloctities induced inside of that point.

The dependence of the induced velocity at the blade tip on the radial distance, $A$, is presented in $\mathrm{fig}$. 5.11. As a aproaches zero, the induced velocity approaches infinity. The converged value occuring for $d>0.03$ was used in calculations. 5,2 Shear Flow

Calculated disturbance pressure ratios are presented in $\mathrm{flg}$. 5.12 with test results from [13] and the calculated results with the sem1-rigld wake from [7]. They are in excellent agreement with experiment, and the effect of the shed wake has increased when wake was allowed to become non-rigid. This is due to the fact that the seperation of the shed vortex lines frow the rolled -up vortices position them nearer the rotor disk.plane than. in the previous seni-rigid wake model. Pig. 5.10 shows this phenomena cleariy and the improved prediction is shown by fig. 5.12 . 
For powered rotors the shed vortex 11 nes will be located below the rolled-up vortices and hence their effects on unsteady alrloads will be decrased. It is demonstrated fron fle. 5.12 and fig. 5.25 that the seperation of the gned wake ourface from the plane determined by the rolled-up vortices Is dastrable, especia11y for the predietion of unateady alrioade and the approach used in the present calculationg works.

Tower reflection effect in inherently included in the experinental reoults of fig. 5.12. The caloulated disturbance pressure ratios are obtained by using the equlvalent shear flow without the tower reflection effect. In fig. 5.13 the regult for ghear flow with tower reflectlon is compared with the one for the equivalent onear flow without the tower reflection. As far as the disturbance pregsure ratio. is concerned. the two results gito the ane ratio of disturbance pressure to average blade pressure. But shear flow with equivalent slope as tower reflection 1g a little optimistic in the prediction of the performance coefficients as indicated by the respective values of $\mathrm{c}_{\mathrm{p}}$ in $1 \mathrm{fg} 5.13$.

In fig. 5.25 the lift deficlency valueg are computed by three defferent methods, "Two of then are the $\operatorname{sen}$-rigld and non-rigld wake methode. The other ont is obtalned by the equation $c(k)=k=\frac{1}{1+\frac{F r}{4 \lambda_{0}}}$ which is derived in [3]. Here. $k$ is the ratio of the unstedy iff variation ( $\Delta L$ ) obtained with the velocitles induced by the trailing and shed wakes and the quasi-steady $21 f t$ variation $\left(\Delta \mathrm{L}_{\mathrm{q}}\right)$ obtalned without them, that is, $\mathrm{K}=\Delta \mathrm{L} / \Delta \mathrm{L}_{\mathrm{q}}$. 


\section{$5+3$ Toupr_Effectg}

The calculated afrloads at the $75 \%$ apanwiae position of the blade are prosented.in $\mathrm{PIg} .5 .14$ for the rotor model operating upwind of the tower in oteady and undform flow. Por the froe gtream veloetty reduction (VR) 0.116518 used and the value 0.375 non-dinenstoned by the rotor radlug 16 uged for the width (Y) of the flow flold Interfarence due to the tower. in the calculations. These two values were obtalned from the experimental wind profile as ghown in 118 . 5.15. The computed ungteady alrloads, which are normalized by the average, are shown in flg. 5.16 with test values for the tower reflection case with Xmag tres shown in fig. 5.1. From the free stream velocitieg meagured at $75 \%$ spanmige position of the blade, the equation giving the wind profile on the . rotor disk plane is derived. The velocities computed from this equation are shown in fig.5.15 with the measured velocties. The calculated instaneoug thrust and performance coefficients are pro-

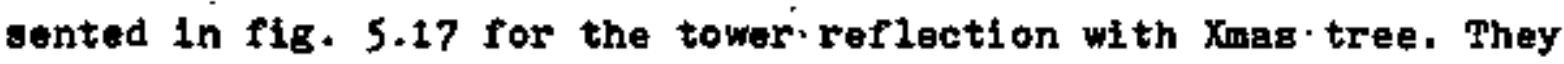
are periodic by $180^{\circ}$ because the rotor has two blades. $C_{p}$ varies more than $50 \%$ of 1 ts maximum along the azimuthal angle. This means that the torque acting on the wind turbine shaft varies periodically by that much. $C_{T}$ varlations are within $30 \%$ of its maximus. and hence a vibratory force of this order acts on the tower. The prodicted ungteady disturbance airload ratiog are in close agreement with experimental values for the tower reflection (Fig. 5.16), even for the flow disturbed due to the Xmas tree. The vartations 
in airloads on the blade show the same form variations as the freo stream velocities on the rotor disis plane. Pig. 5.26 showe the lift defictency values for the tower shadow and reflection cases. These values are calculated by the non-rigid wake method and by the ilft deficiency function, $c(k)=\frac{1}{1+\frac{\sigma \pi}{L u}}=K$, from [3]. This figure and $t \mathrm{ig} .5 .25$ show that $K$ decrefsts as the azimuthal interval $\Delta \Psi$, where the free stream velocity ia decreased due to the tower interferences, is reduced.

Wind profile equation (3.7) gives results in good agreement with experimental values behind the tower as shom in fig. 5.18 , That equation is, thus, believed to be the proper characterization of the wind profile behind the tower. The calculated peak disturbance pressure ratio is shown to be slightly larger than the measured value in fig. 5.19. Also. fig. 5.19 shows that the shed wake reduces the peak afload defiett drastically.

It ig show in fig. 5.20 that the uge of the non-rigid wake model has increased the Induced velocitios on the blade and hence has reduced the airloads on the blade, compared to the semi-rigid wake model. Reductions are $10 \%$ in airloads, $13 \%$ in $C_{p}$ and $7 \%$ in $C_{T}$. The seperation of the shed vortex sheet from the plane defined by the rolled-up tip or root vortices has increased the effect of the shed wake, that is, hag reduced the peat airload variation by $4 \%$.

5.4 Effect of Blade Motion on Alrloads

The rigid body flapping velocity show in $\mathrm{flg} .5 .21$ is less than $2 \%$ of the free otream velocity. The blade angle of attack or 
the airloads will be changed by this percentage. Therefore, the effect of the flapping velocity on airloads is negligible for this model wind turbine rotor used in the experiments. This conclusion dons not imply that it is true for any wind turbine rotor because the structural design of the blade can be varied greatly from this experimental model. Generally, it is belfeved that the one per revolution excitation due to the tower is not enough to $\%$ cause fast blade flapping motion, except for the resonance case. It is shown in fig. 5.21 the maxisum flapping angle is about $0.4^{\circ}$ for this model. The deflection of the blade tip due to this flapping angle is $4 \%$ of the blade chord. The nearest distance between. the following blade and the tip vortex from the preceding blade is farther than one chord length at least. Also, the tip vortex is located outside the blade tip because the tip rortex expands fast in the first spiral. Therefore, this flapping angle will not have appreciable effoct on airloads. When the deflection of the tip exceeda half chord length. it is believsd that the deflection of the blade tue to flapping motion should be included in determining the relative distance between the blade and the tip.vortex.

The actual inflow velocity, which is obtained frot the free i strea. velocity and induced velocities on the blade, is compared with the one calculated from the 10 harmonics of the corresponding. Fourier series in fig. 5.22. That figire shows that theil 10 terms $: i$, of the Pourier series atill do not degcribe the peak velocity variation. It seems that some caution should be paid for using the Fourtir series for the representation of the inflow field. 
SECTION 6

DISCUSSION AND CONCLUSIONS

\section{6.t Dfscussion.}

For the transport velocity of the tip vortex, instead of using one constant velocity for the tip vortex in the first blade spacing and a different constant velocity outside the : first blade apacing as in $[4]$ and [5], varying velocities are used for the firat apiral of tip vortax. This was done becauge the velocities induced by the first spiral tip vortex are of almost the same order as those induced by the near wake. The assumption that the induced velocity on the tip or root vortex varies linearly until it is doubled at the first blade oncounter is open to question. But it is not likely that the induced velocity on the tip vortex is suddenly doubled. Experimental investigation. on the wake geometry or the free wake analysis can give information as to how the Induced velocity on the tip vortex varies. The non-rigid wake model used for the non-uniform flow shows that the induced velocity varies continuousiy rather than being suddenly. doubled. The accurate calculation of the induced velocity on the tip vortex in the first spiral ia required in view of the fact that the coprect axial and radial positioning of that vortex is. important for the good prediction of airloads and performance. All these facts necessitate a theory which can handle the trang-. ient rolling-up process of trailing vortices and the offect of the tip shape or Its modification on this process. Obviously the flow fleld near the blade tip is very complex and three dimensional. 
The rate of convergence becomes much alower with the nonrigid wake model than with the usual semi-rigid wake model becauge the wake undergoes considerable deformation and the geometry varies congiderably more per iteration in the forwer than in the latter cage. The velocities incuced by the far wake are approximately doubled near the blade tip when the non-rigid wake model Is used, as compared to the rosults obtained when the usual semirigid wake model is used in [7].

The retardation of the tip vortex places the tip vortex so close to the rotor blade that it causes a significant increage in the induced velocitios near the blade tip, which results in a reduetion of the wind turbine performance. This retardation has an effect on the wind turblne performance which has the reverse tendency to that of the rapid contraction of the rotor slip strean in the hovering flight of a helicopter noticed in [4], This contraction makes the tip vortex pass inglde the blade tip and this vortex passage increases the angle of attack near the tip for the powered rotor.

\subsection{Conelugions}

Lifting line theory using a sine series representation of bound eirculation with now wake geometry gives pratical reaults and is very cost effective. With a more realistic wake gemetry lifting line theory will accurately predict the experimental values. It is suggested that a proper gtall model be employed to compute the best tip speed ratio for the rotor of a solidity 
higher than approximately 0.07 . It is belleved that the gicheme developed to compute the initial Induced velocity on the tip or the root vortex is uaseful and rellable, and that the vortices trailed from tive tip or root becones the center of the rolized-up

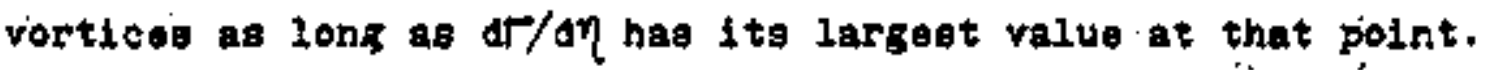

It 1s recommended that the shed line vortices in the far waxe be located on a plane other than the one deflned by the rolled-up. tip and root line vortices,

The ualn effect of the tower has been found to be a ceductIon in aifloads on the blades with almost the eame form as that of the tower effect on velocity. It is concluded that the vertical transport velocities change rapidiy fin the flrot spiral in the wake, which Invalidates the assumption that vortices retain the relative velocities of the flow passing through the rotor..

It is concluded that the disturbance pregsure ratio can bo accurately calculated by using the equipalent shear flow for the cage of shear flow which includea tower reflection effect and that the shed wake can not be neglected. Further conclugion is that tho non-rigid wake model, which 18 developed by oyatematic modifications of semi-Figid wake. Is accurately and falrly simple, compared to free wake model. 


\section{References}

1. Miller, R.K. "Unsteedy Airloads on Helfcopter Rotor Blades". Royal Aeronautioal Society Journal, Vol.68,No.640, April 1964.

2. Miller, R.H. "On the Computation of Alrloads Acting on Rotor Blades in Forward Flight". American Helicopter Society Journal - Vol. 7. No.2, April 1962.

3. Millor, R.H. "Rotor Blade Hamonic Alrloeding". AIAA Journal , vol. 2, No.7, July 1964.

4. Jenny, D.S., Olson, J.R., and landgrebe, A.J. "A Reasseasment of Rotor Hovering Parformence Prodlction Methods". AmerIcan Helfcopter Socitty Journal, Vol, 13, No.2, April 1968,

5. Landgrebe. A.J. and Egolf, T.A. "Rotoreraft Wake Analysis for the Prediction of Induced Velocities". United Technologies Research Center, USAAMRL Tech. Rpt.75-45, Eustic Directorat*. U.S. Army Mobility R\&D Lab, Fort Eustic, Yirgina, January 1976.

6. Scully, M.P. "Computation of Helicopter Wake Geometry and Its Influence on Rotor Harmonic Airloads". Messachusetts Institute Technology. Fh. D. Thesie, February 2975.

7. Vol. II, Section 3.

8. DeJarnette, F.R., "Arrangement of Vortex Lattices on Subsonic Wings". Yortex zattice Utilization, NASA SP 405, May 17-18. 1976 
9. Sullivan, J.P. "The Effect of Blade Sweep on Propeller Performance". AIAA Paper No. 77-716, AIAA 10th Fluld \& Plasma Dynamics Conference, Albuquer, N.mex./June 27-29, 1977.

10. Landgrebe, A.J., Moffltt, R.C, and Clark, D.R. "Asrodynamic Technology for Advanced Rotorcraft- Part I". J. Anerican Helleopter Soclety, Yo1.22, No,2, April 1977, pp, 21-27.

11. Kocurek, J.D. and Tanglor, J.L. "A Pregerdbod Weke Iffting Surface Hover Porformance Analygts". 32nd Annual National Porum, Amerlcan Hellcopter Soclety, Washington. D.C.. May 1976

12. Vol. II, Section 2 .

13. Dugundji, J, and Larrabes, E.E. "Experlmental Investigation". Chapter VII, Wind Enerey Conversion, Final Report, Oct.1976.

14, Clark, David R, and Reiper, Albert C. "The Fres Wake AnalysisA Method for the Predfction of Hellcopter Rotor Hoverlng Perforwance". American Hellcopter Society Journal, Vol,15, No.1. January 1970.

15. Batchelor, G.K., An Introduction to Fluid Dynanice, Cambridge at the University Press, 1967. 
TABIE I

ROTOR WODEL USED IN THE ANALYSIS

.$=0.1061$

$c_{d}=0.01+1.5 \cdot a^{2}$

2 Blades

No Twist

No Taper

$\eta_{\text {re }}=0.2$

\section{TABTE II}

MODETING OR THE BROALEAL

No. of lake Splrals

Uaed in Calculations

No. of Control Points

Near lake Region

Intermediate dake Region

Far wak Region

Wake Azimuthal Increment

Tip or Root Yortex Elements
Steady Program Unsteady Program

$$
\begin{aligned}
& 10.5 \quad 10 \\
& \forall=0-10^{\circ} \quad \forall=0-15^{\circ} \\
& 10^{\circ}-90^{\circ} \quad 15^{\circ}-90^{\circ} \\
& 90^{\circ}-10.5 \quad 90^{\circ}-10 \\
& \text { ، syirals spirals } \\
& x \quad 15
\end{aligned}
$$

Azimuthal Integration

Interval of Line Vortex

(1) Wement in Near Wake

$10^{\circ}$

(2) - in Intermedlate Nake $10^{\circ}$

(3) " in Far vake $20^{\circ}$

i)

$15^{\circ}$

$15^{\circ}$ 


\section{TABLE TII}

PROFILE DRAO RIPRESENTATION ERFECT

Advance rat10 $\mu=0.1197$, Fitch angle $\theta_{p}=4^{\circ}$

Profile Drag Representation Shed Hake Neglected Shed Vake Included
$0.01+\frac{c_{d}}{0.5 .2^{2}}$
$\frac{c p}{0.123}$
$\frac{C_{T}}{0.333}$
$\mathrm{C}_{\mathrm{p}}$
$\frac{c_{T}}{0.331}$
$0.01+1.5 \cdot 0^{2}$
0.109
0.333
0.121
0.331

* Rotor is operating upwind of the tower in uniform flow.

\section{THALE IV}

\section{SHED WAKE ERFECTS}

\begin{tabular}{|c|c|c|c|c|}
\hline$\mu$ & Shed Wake & $\mathbf{c}_{\mathbf{p}}$ & $c_{T}$ & $\Delta V_{\mathrm{D}}^{*} / \mathrm{r}_{\mathrm{AV}}$ \\
\hline \multirow{2}{*}{0.18} & In(Included) & 0.178 & 0.363 & 0.169 \\
\hline & NE(neglected) & 0.178 & 0.362 & 0.201 \\
\hline \multirow{2}{*}{0.1197} & IN & 0.136 & 0.368 & $0.20 ?$ \\
\hline & NE & 0.136 & 0.367 & $0.31 \mathrm{k}$ \\
\hline \multirow{2}{*}{0.0972} & IN & 0.055 & 0.331 & 0.318 \\
\hline & $\mathrm{NE}$ & 0.055 & 0.330 & 0.462 \\
\hline 0.1087 & IN & 0.107 & 0.359 & 0.230 \\
\hline
\end{tabular}



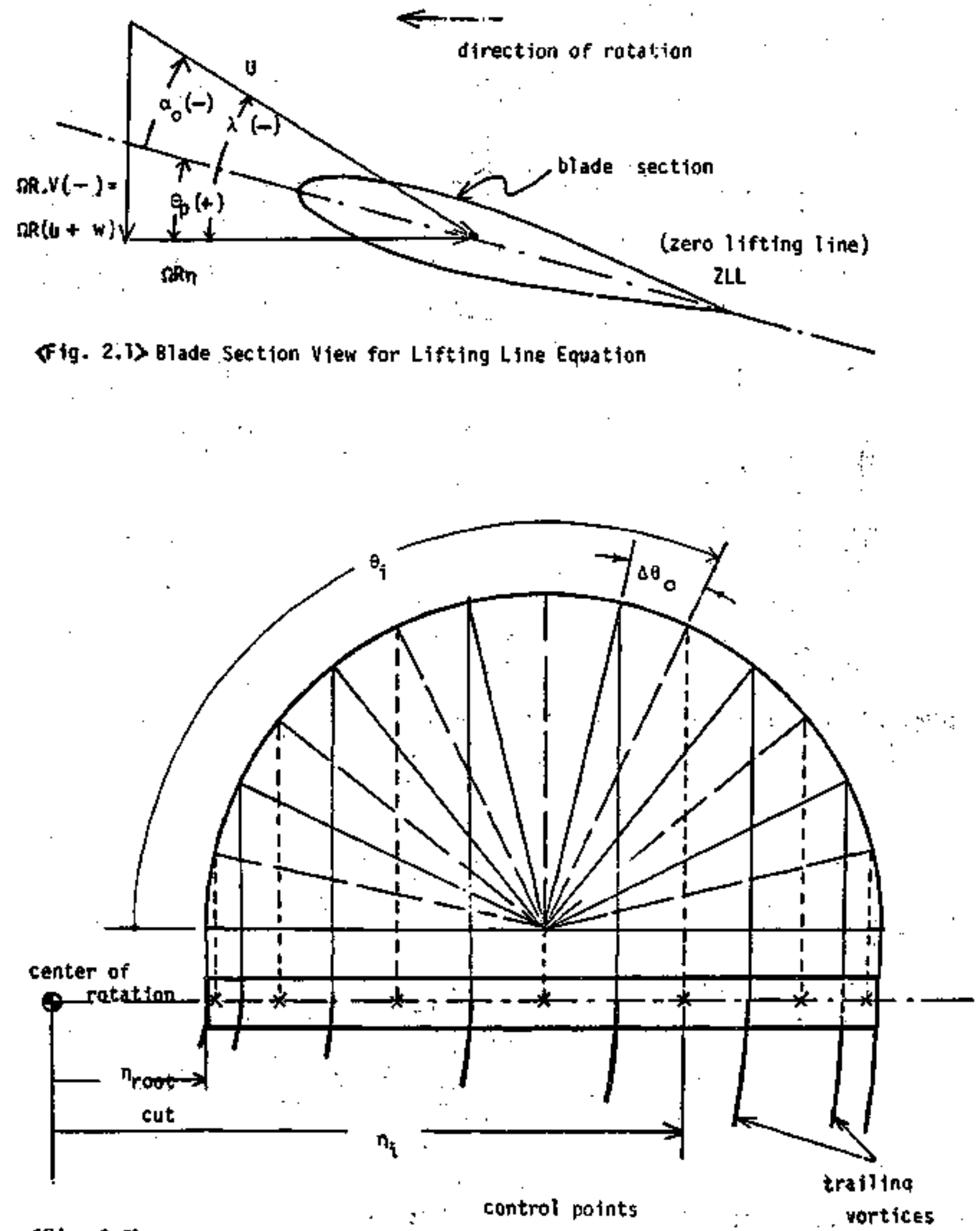

〈Fig. 2.3〉 arrangement of Trailing Vortices 


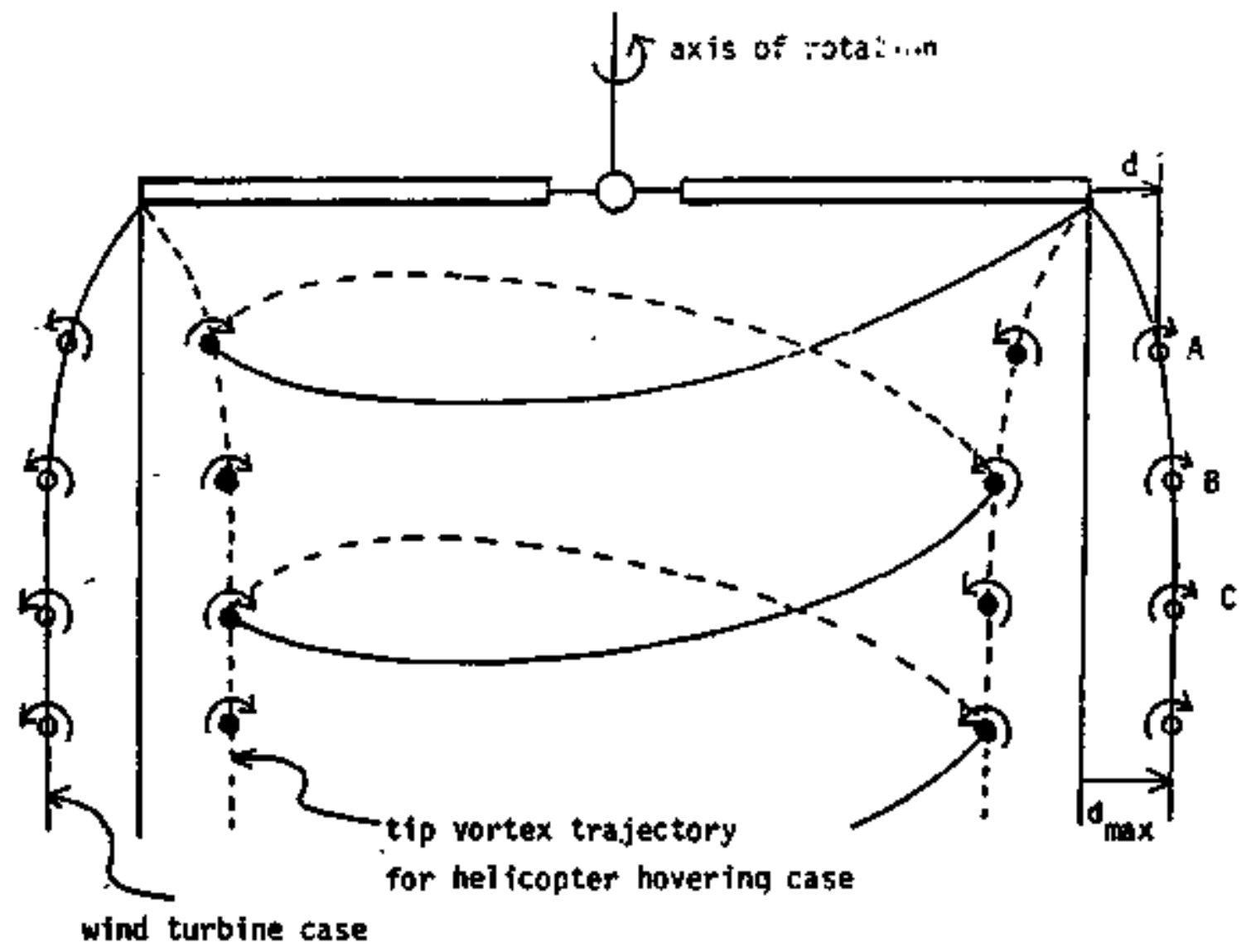

<Ffg. 2.3 Tip Vortex Radial Movenent Trajectory

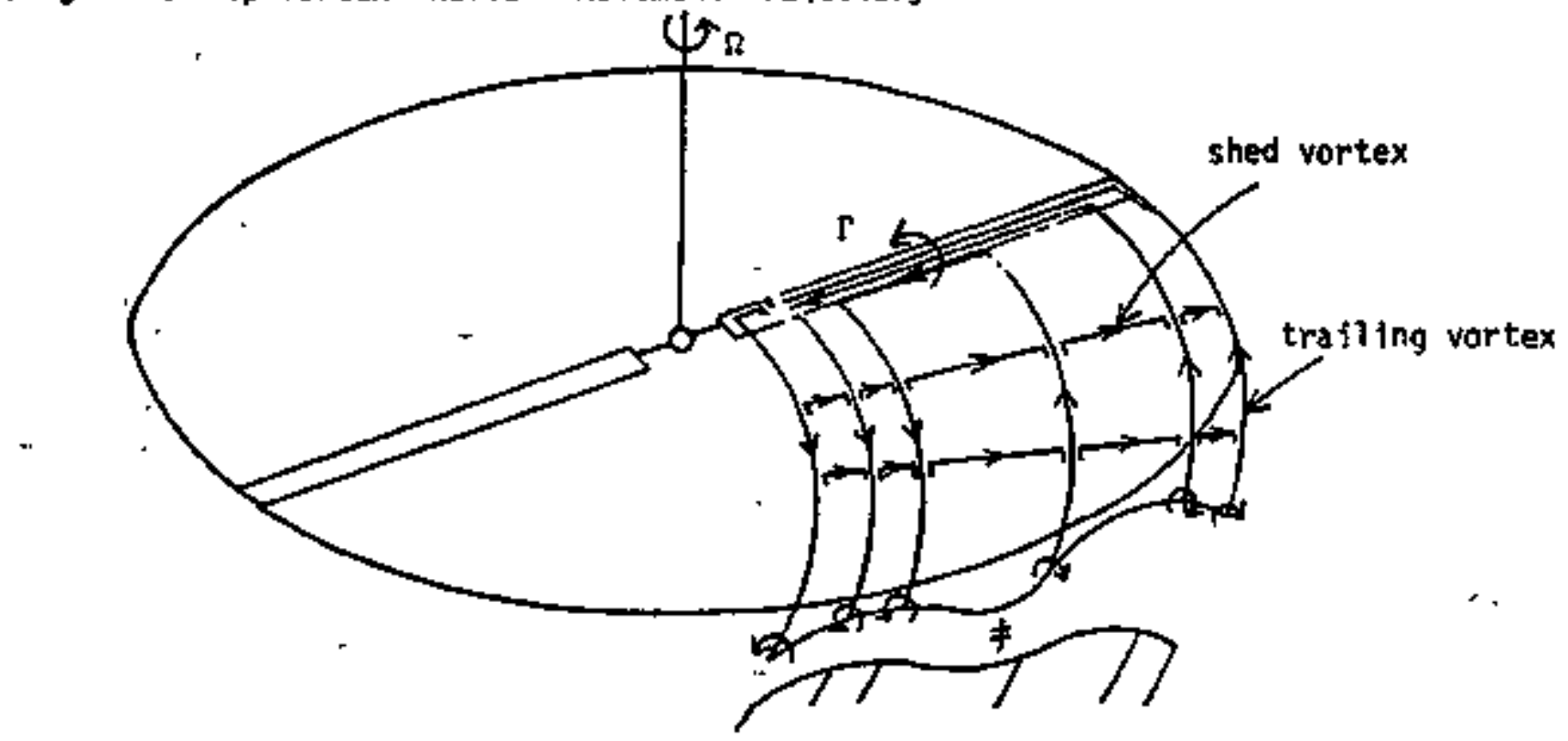

Fig. 3.B Trafling and Shed irortex System 


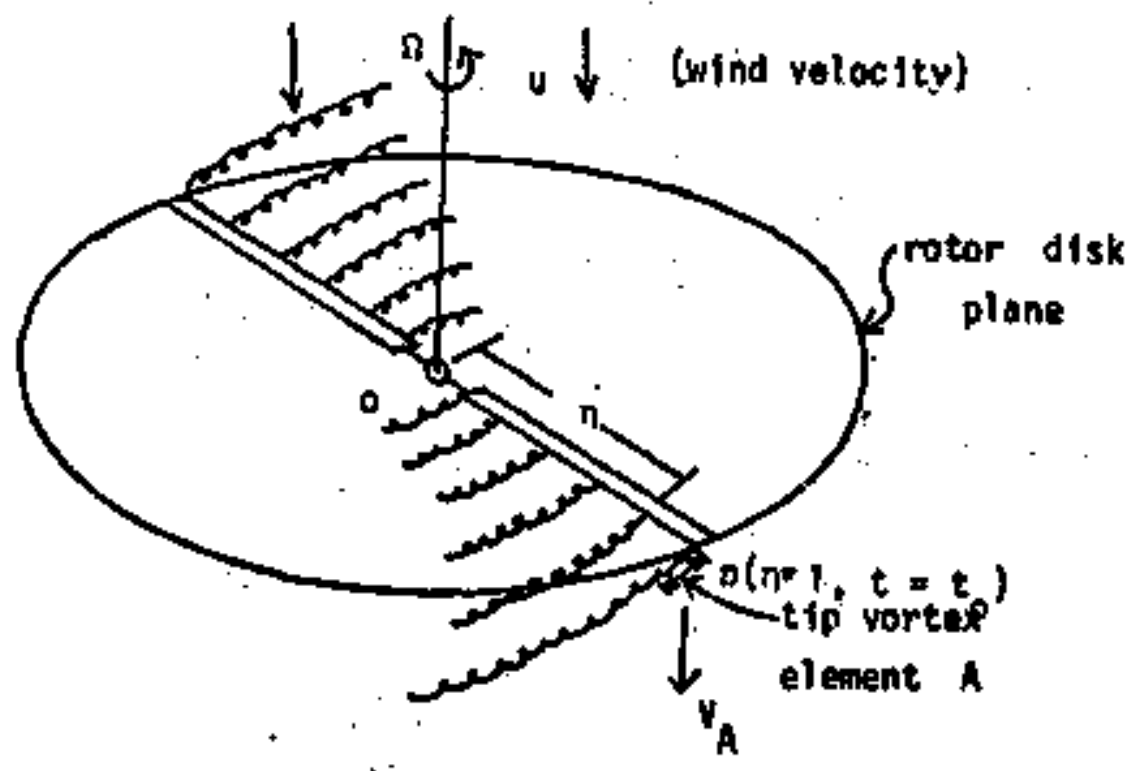

Sfig. 3.2A Representation of Transport Velocity of Tio Vortex at toto

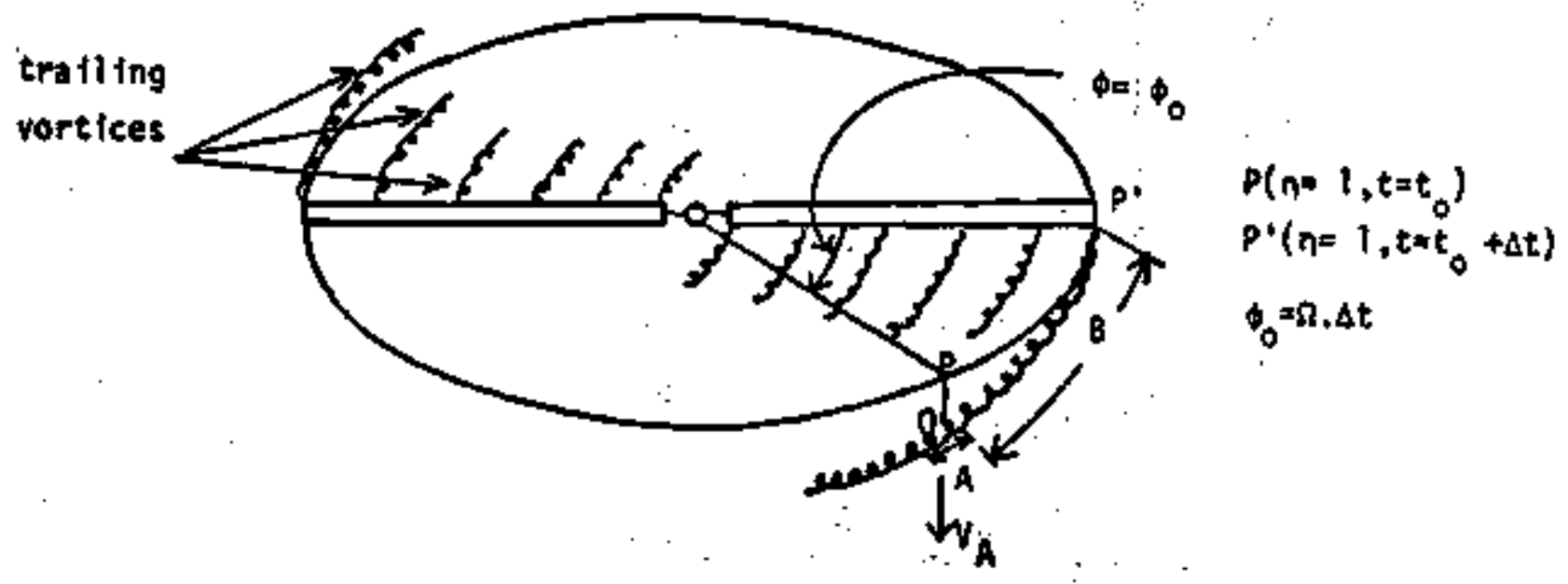

(Fig. 3.2B) Transport Velocity of Tip. Vortex at $t=t_{0}+\Delta t$ 


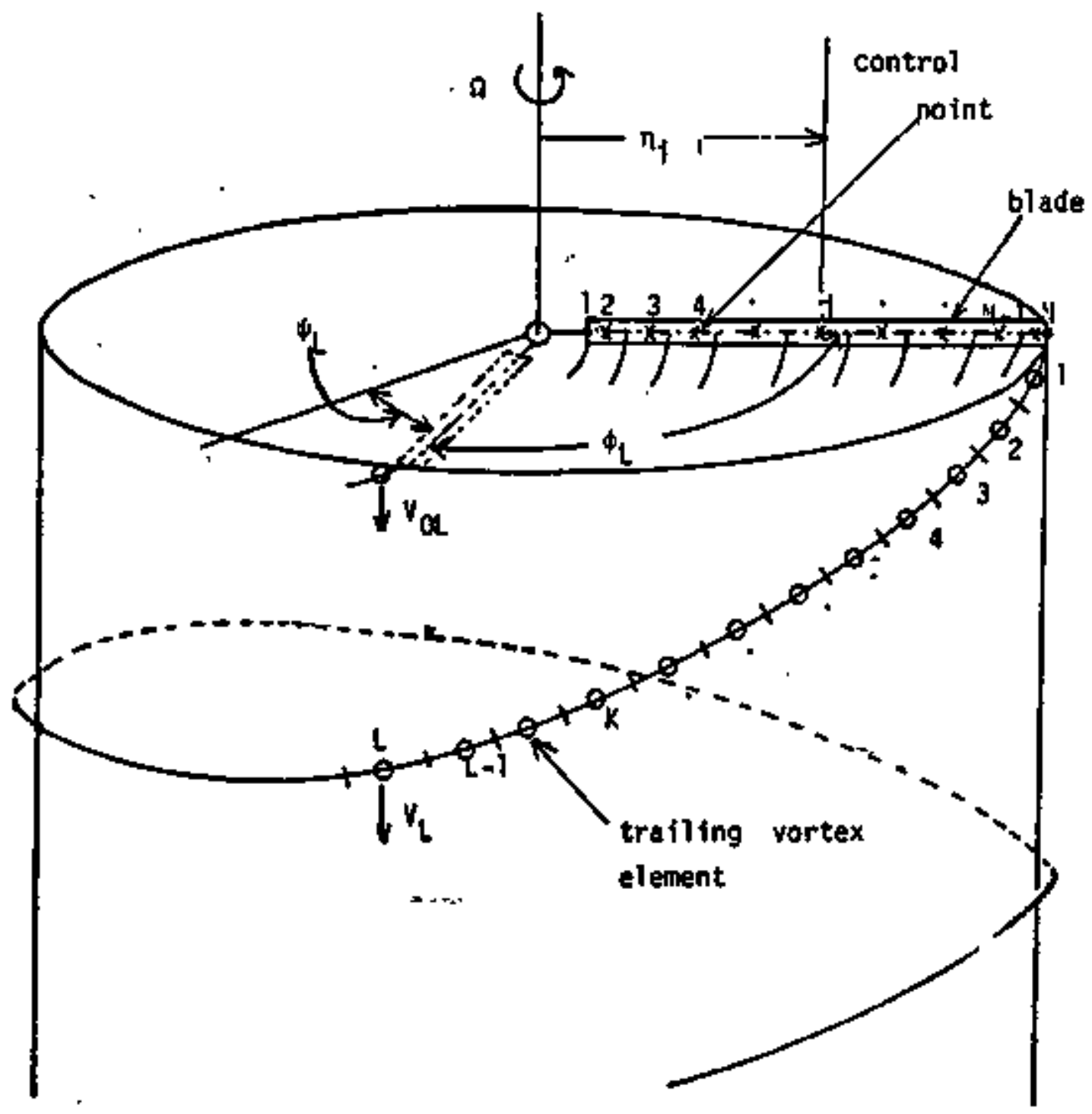

<fig. 3.3>Illustration for the Cateulation of Monlinear Hovement. of tip Yortex 


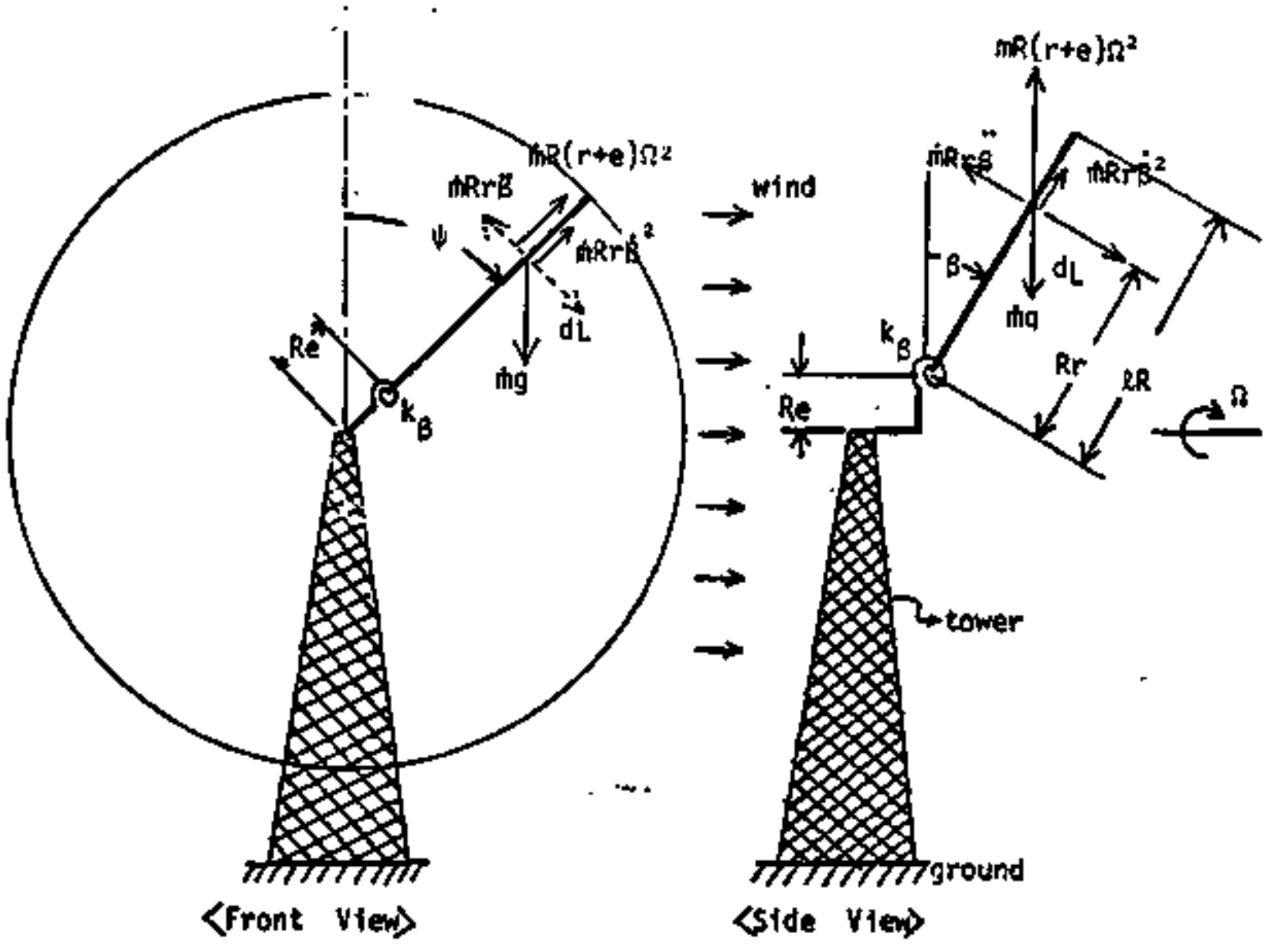

<FIg. 4.V forces Acting on the Blade Inciuding Inertia forces

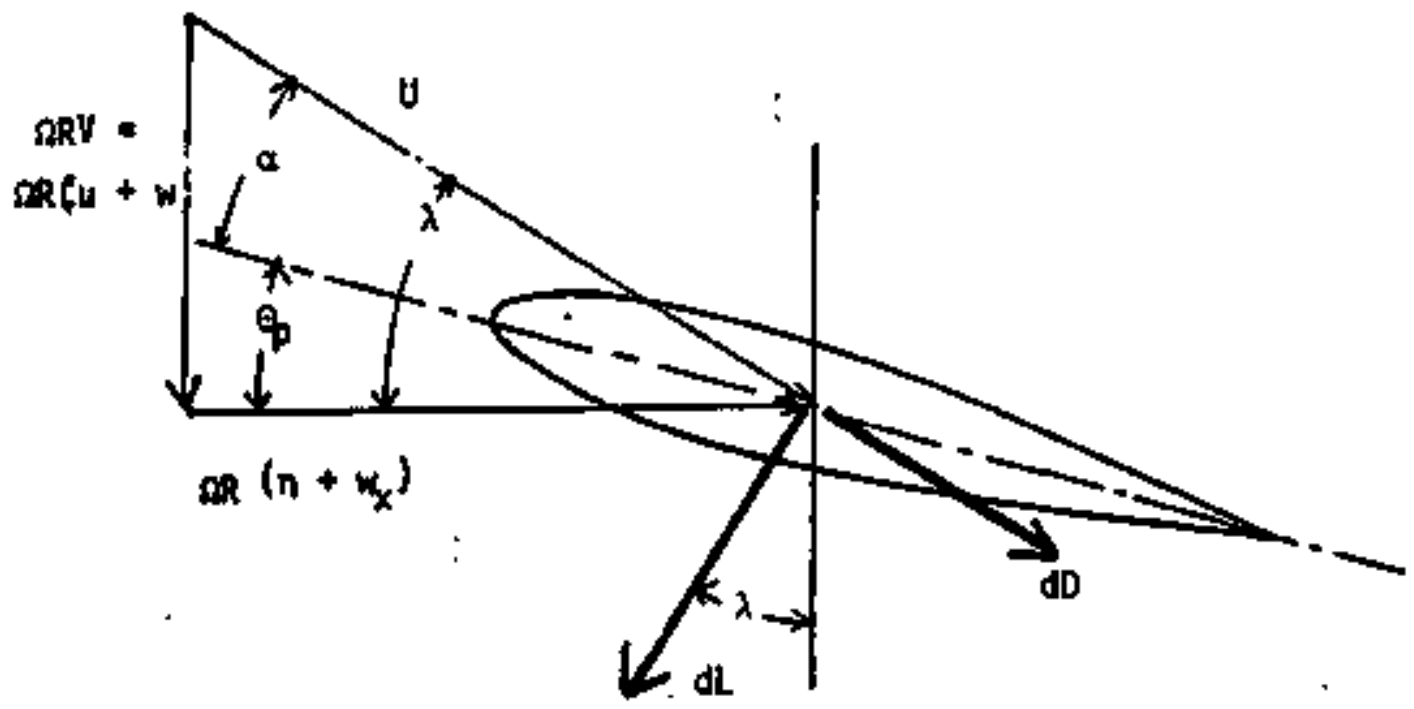

$\langle$ Fig:-4.2〉 Flow around B1ade Element 


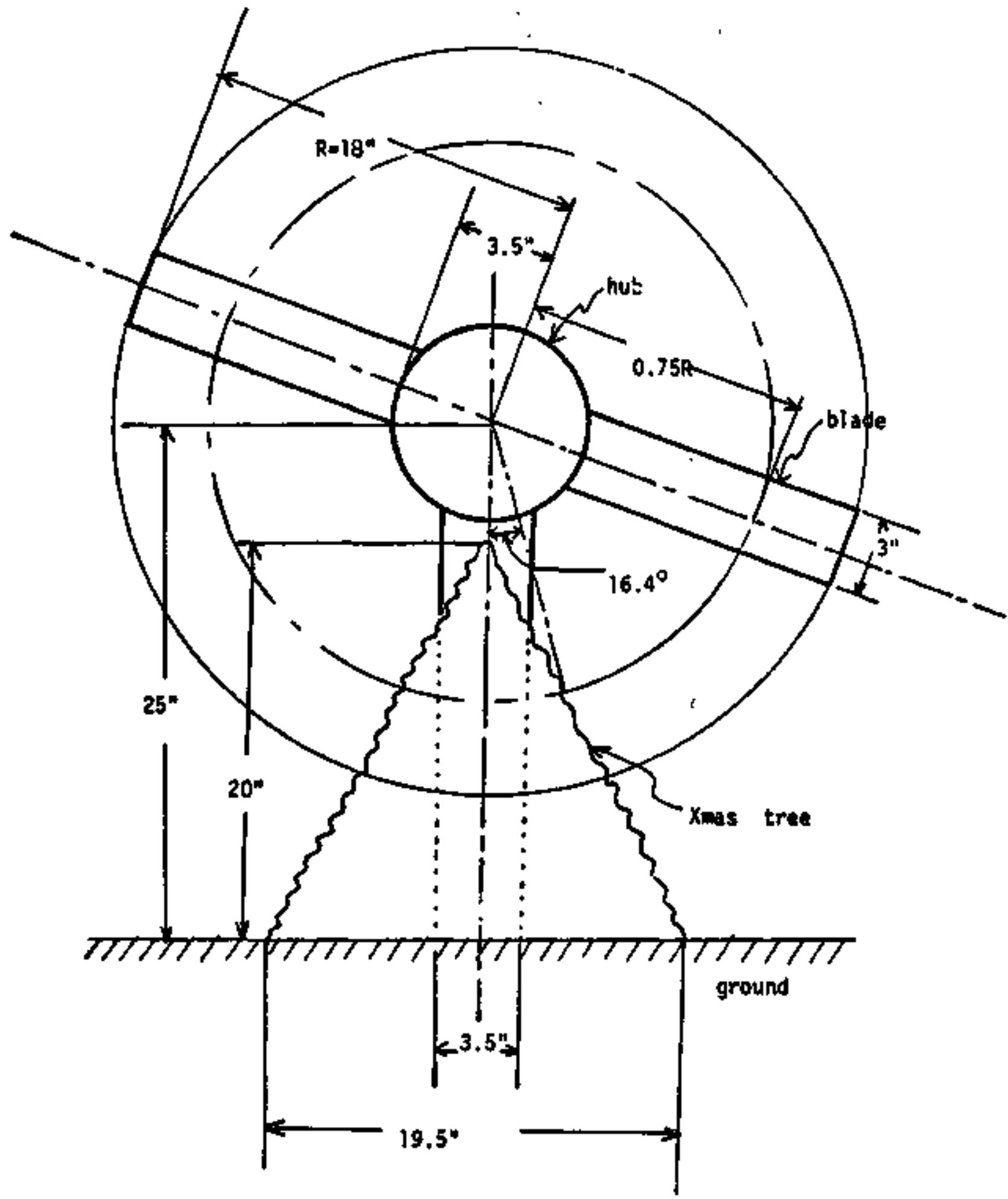

$\langle F 19,5$;) Front Vlew of the Tower and the Wind Turbine Rotor with Xmas Tree (usad in Experiment) 


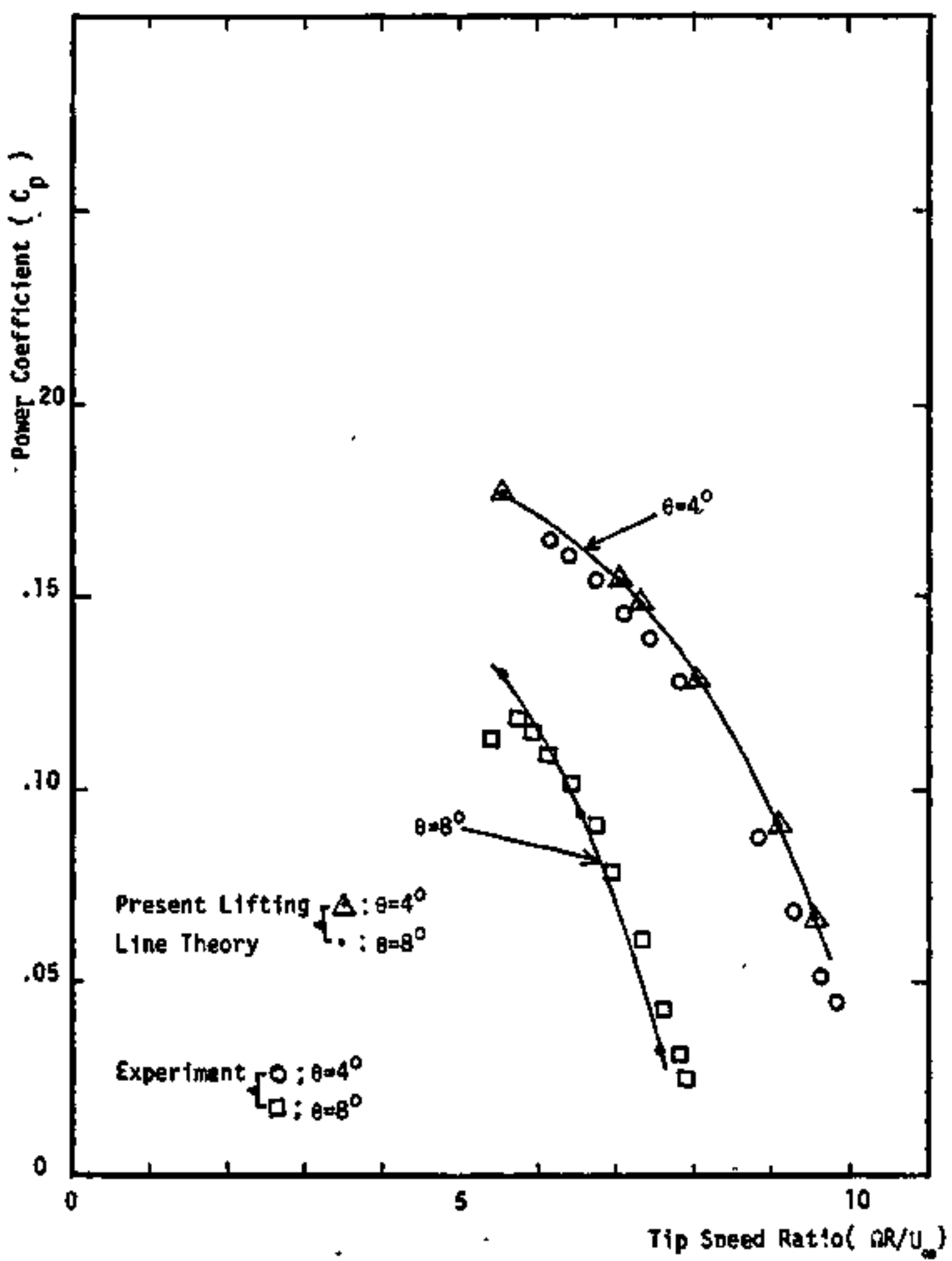

(fig.5.DComparison of Present Lifting Line Theory and Experiment

62 


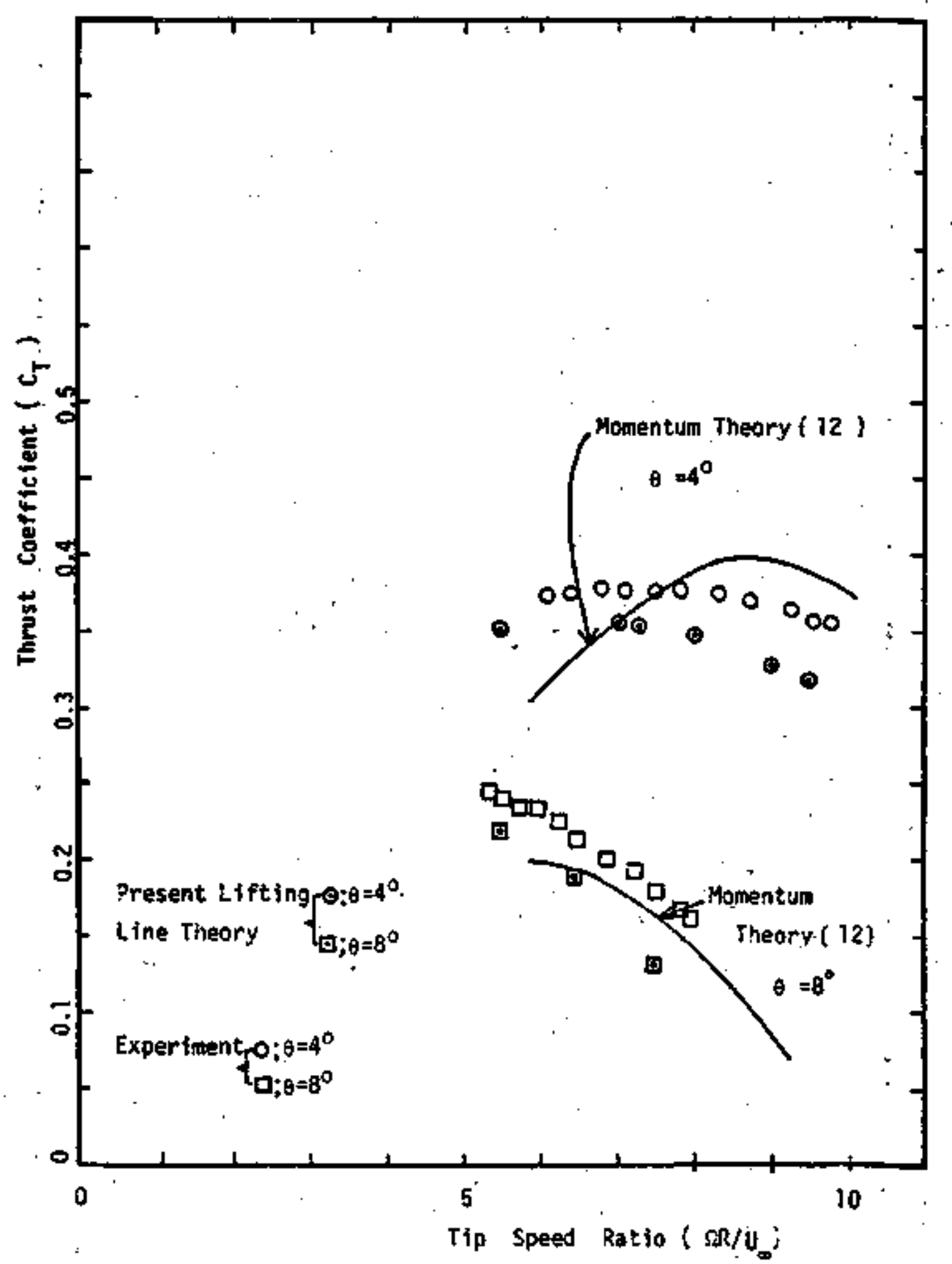

SFig. 5. \$Compariscr of Lifting Line Theory, Momentum Theory, and zxneriment 


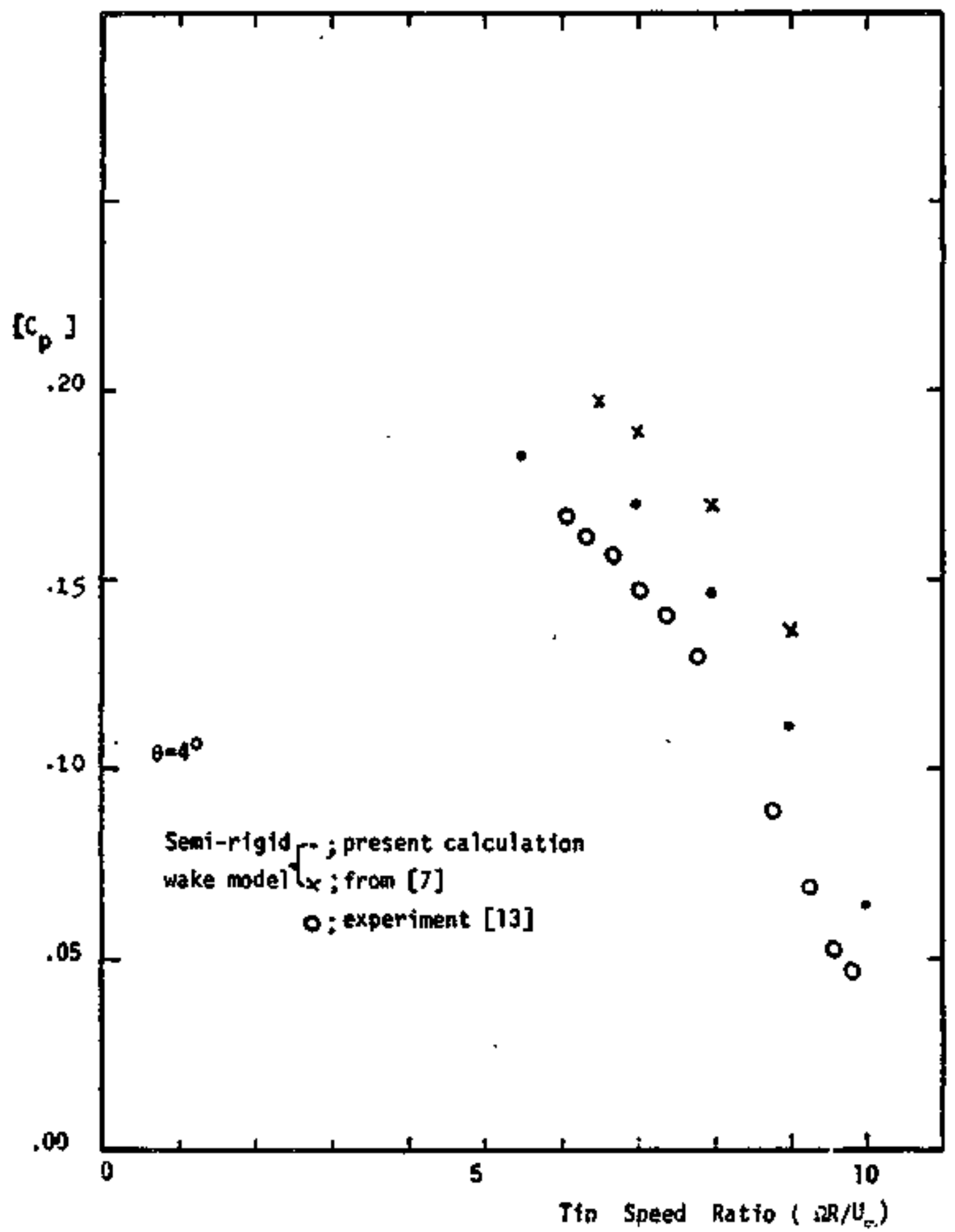

Sig.5.9Comparison of Present Lifting Theory and the Presious one [7] 


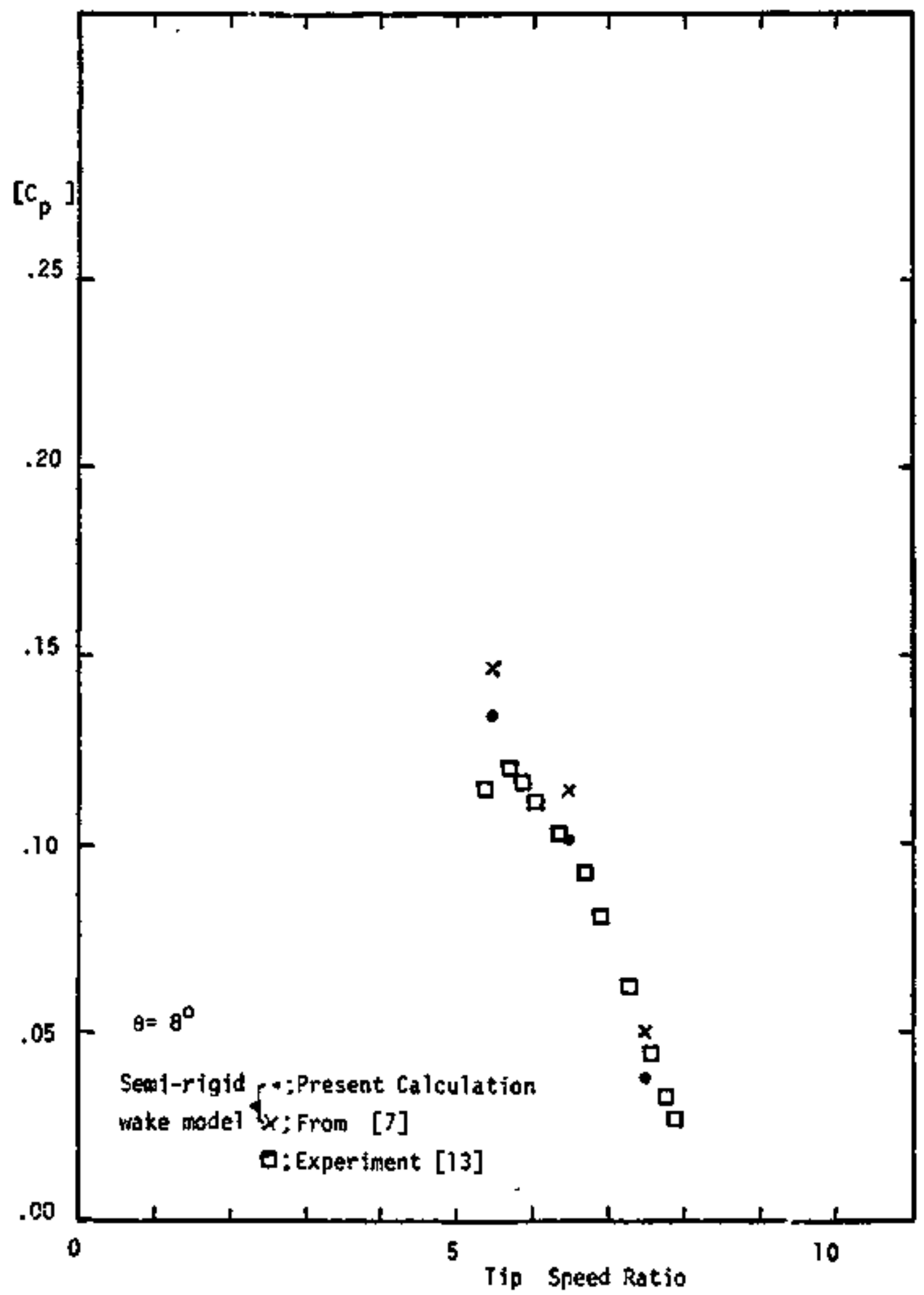

Fig. 5.FComar ison of Present Lifting Line Theory and Previous One 


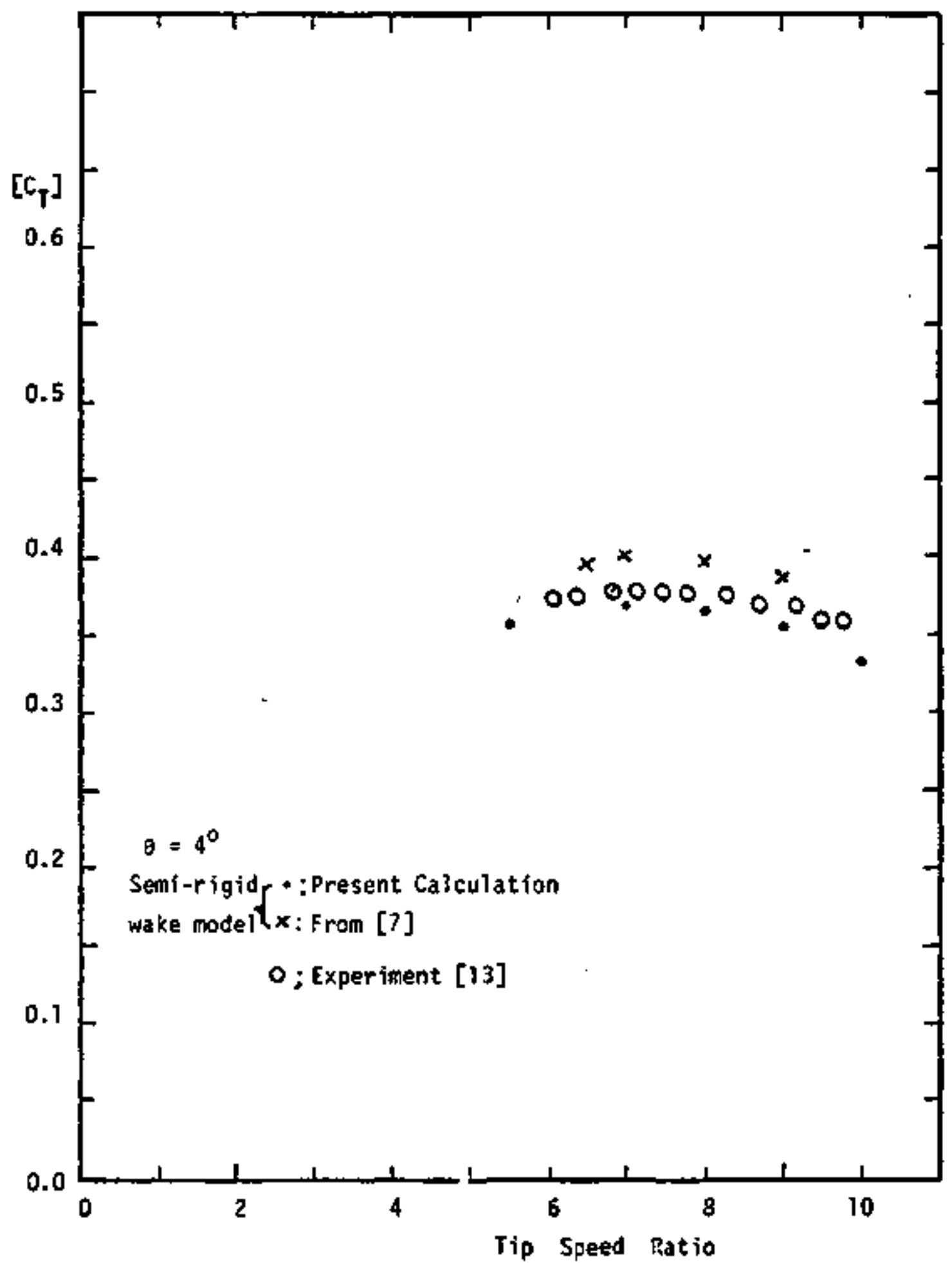

SFig.5.6Comparison of Present Lifting Line Theory and Previous One 


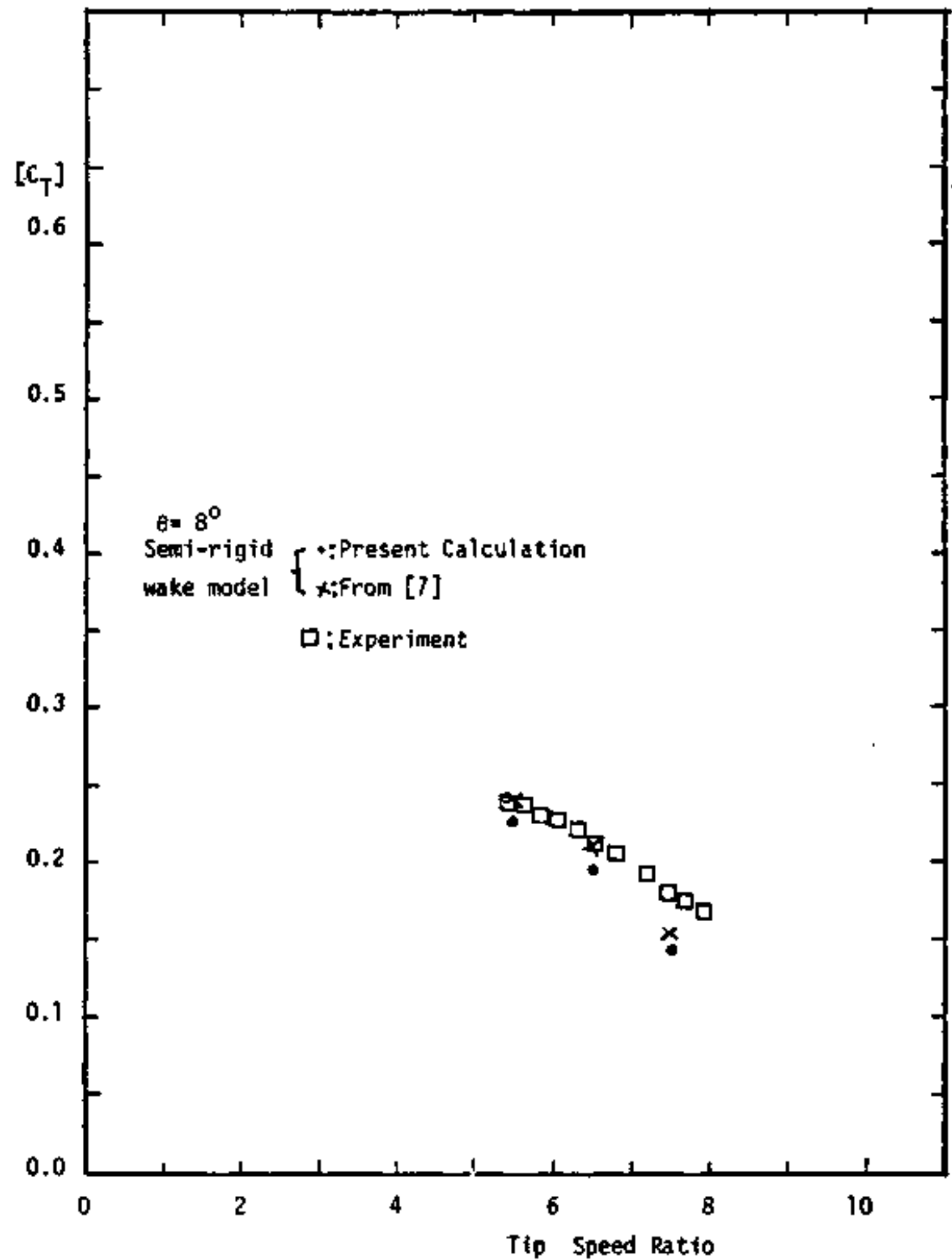

$\langle$ Fig.5. $\Rightarrow$ Comparison of Present Lifting Line Theory and the Previous One 


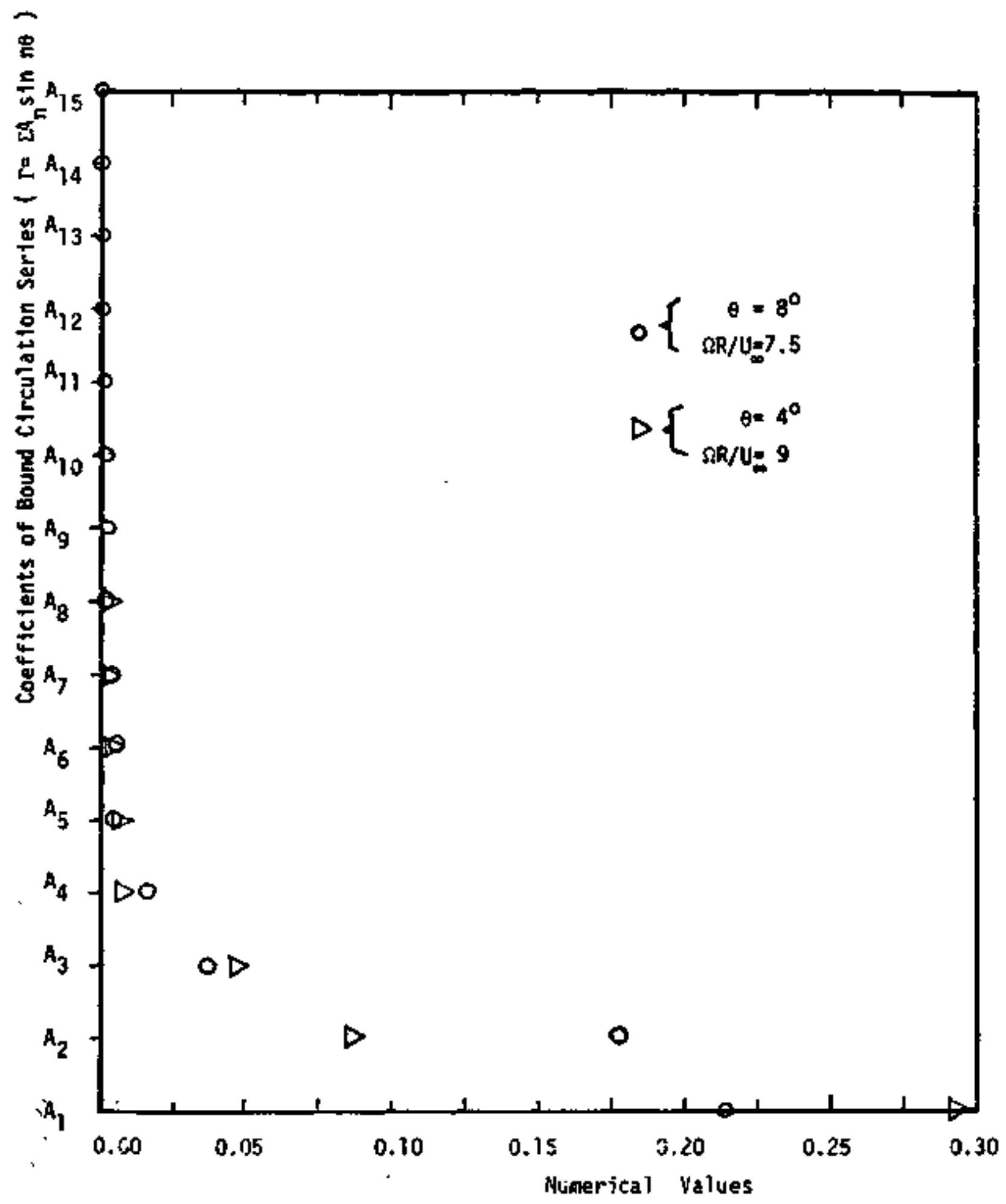

$\langle F$ ig:5.\$Numerical Values of the Coeffitients of the dound Circulation Series for Typical Cases 


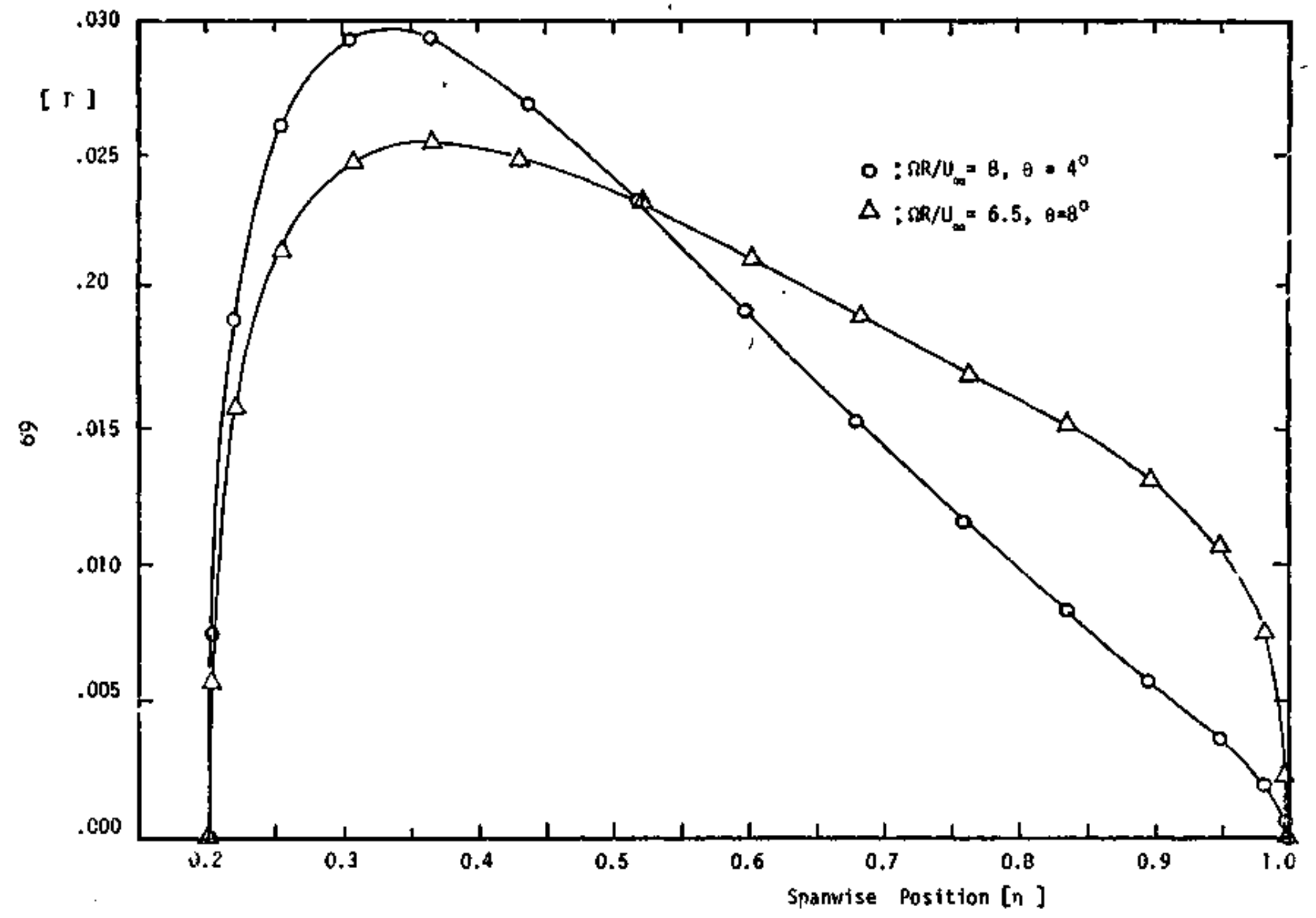

<. 1 . 5.9>Bound Circulation Distribution along the 81ade 


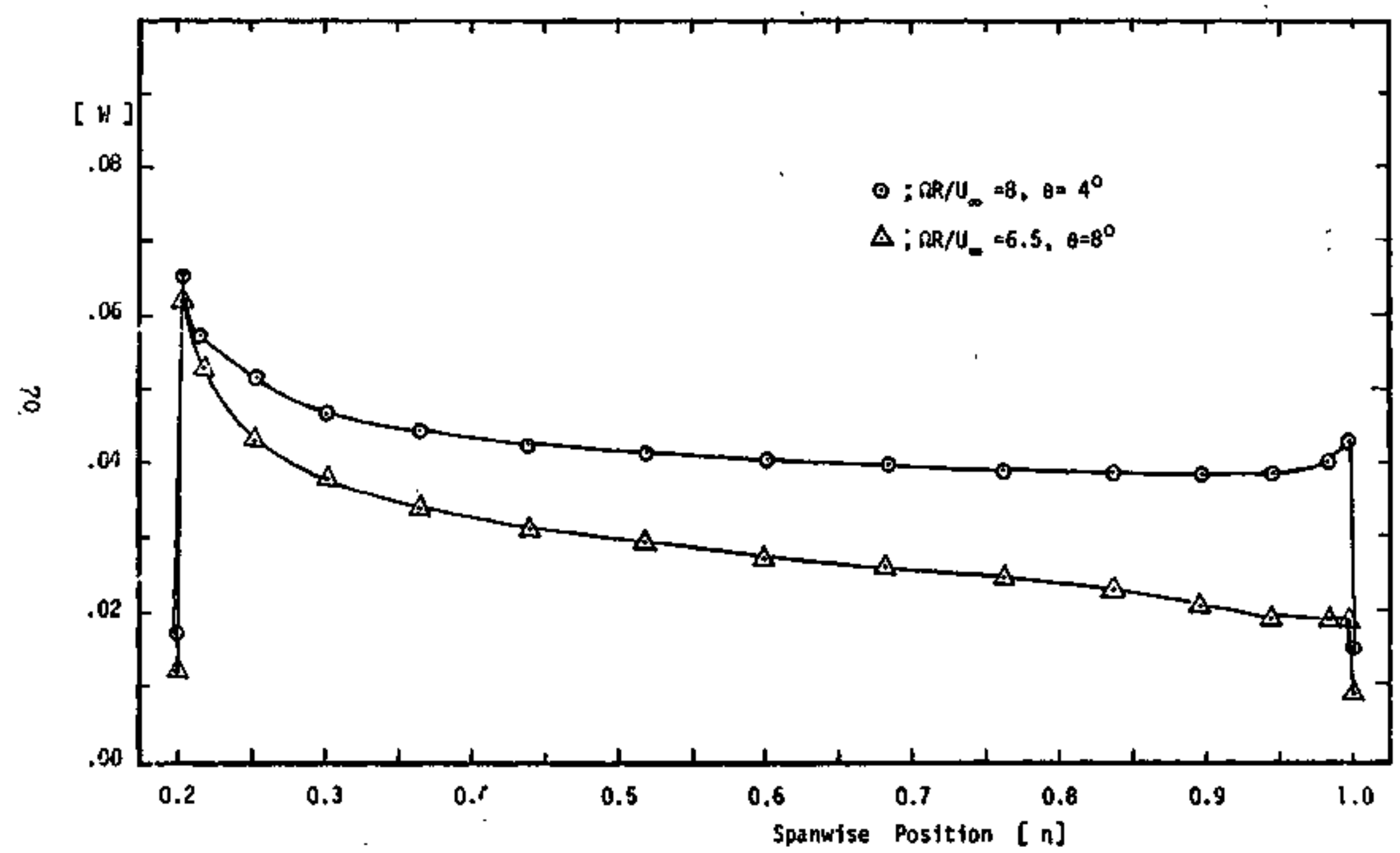

$\langle$ Fig.5.10 Induced Velocity Distribution along the Blade 


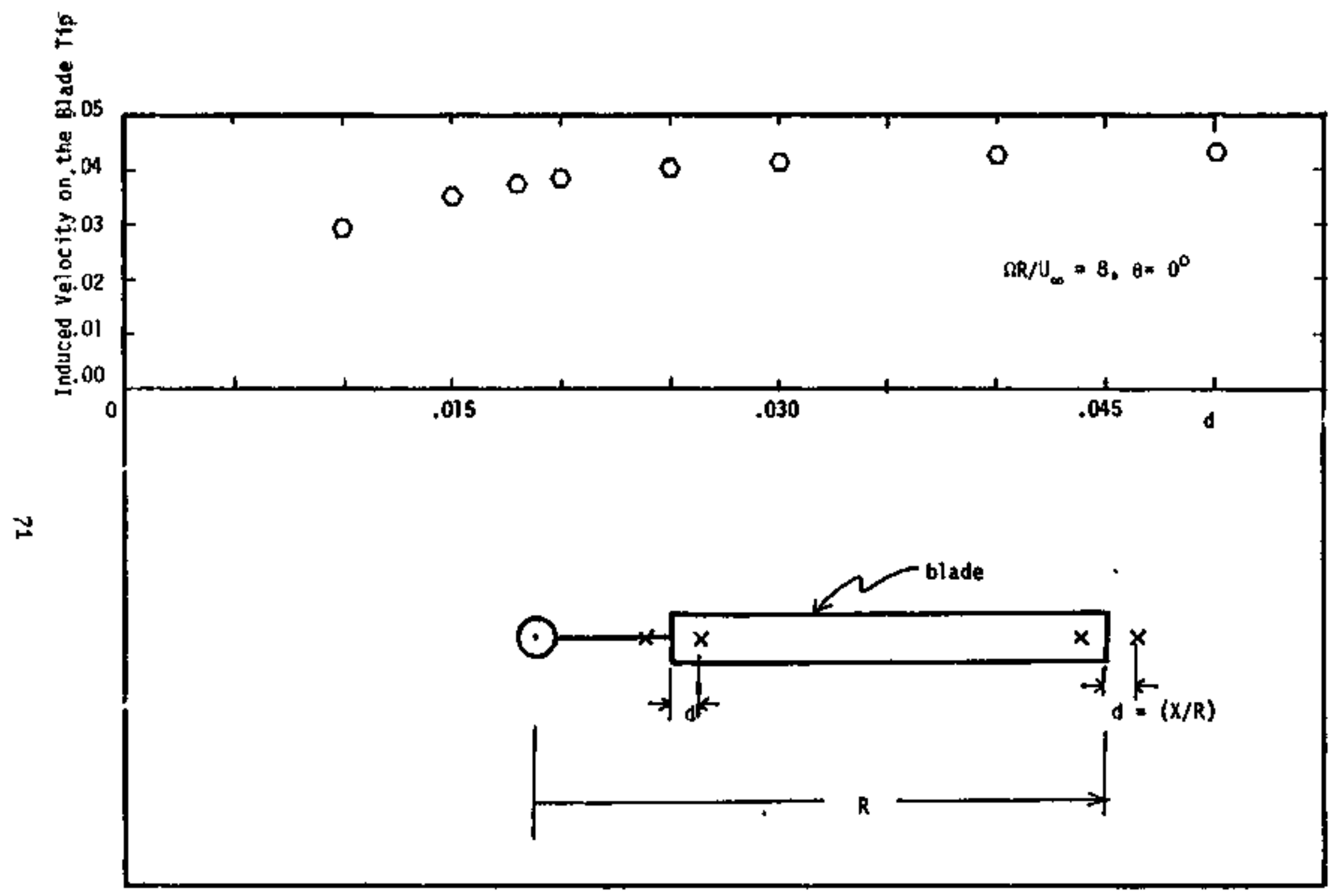

〈FIg.5.1DInduced Velocity on the Blade Tho as a Function of Radial Distance d. 


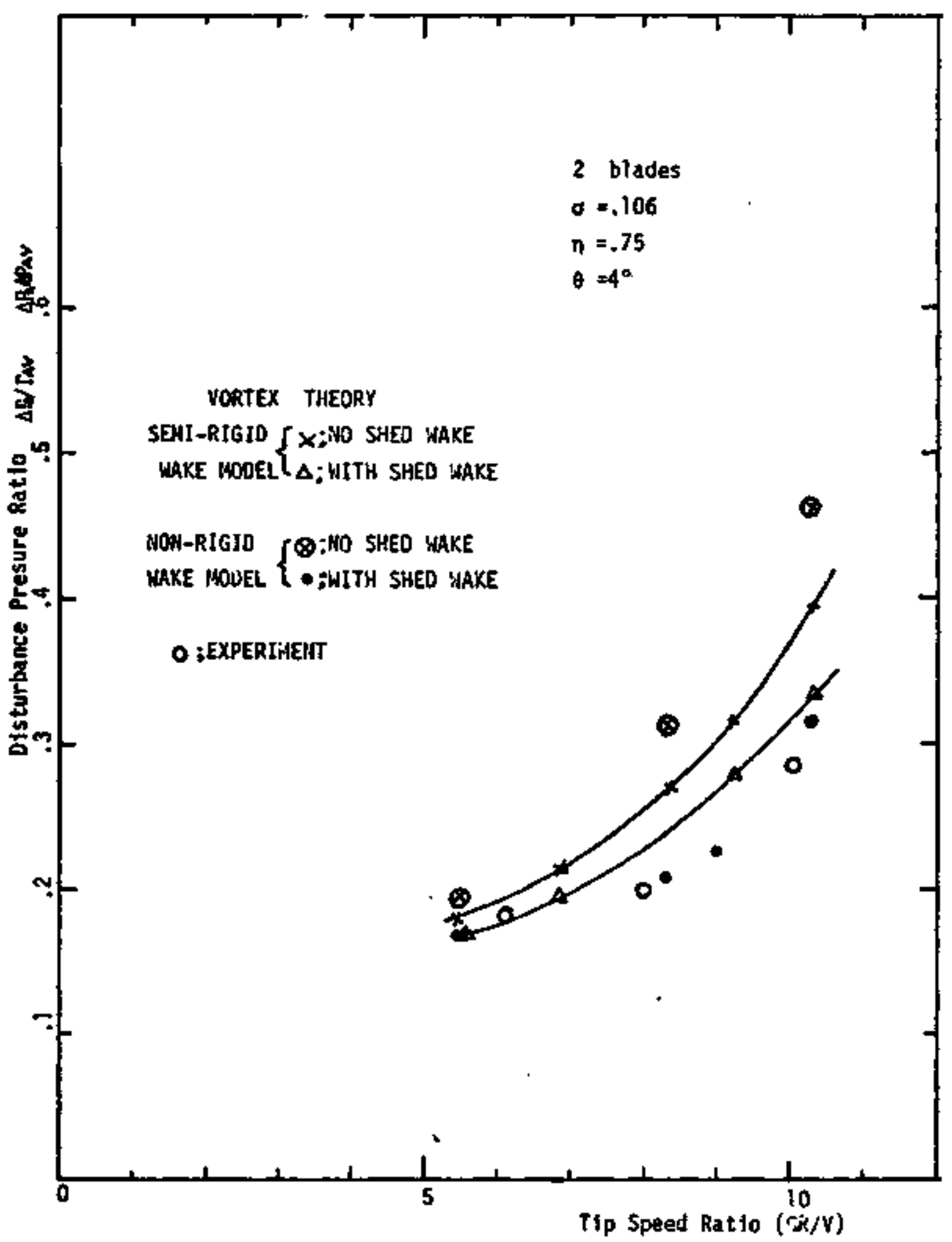

<Fig.5.1DComparison of Theory and Experiment (Otsuturhance fresure Ratio) 


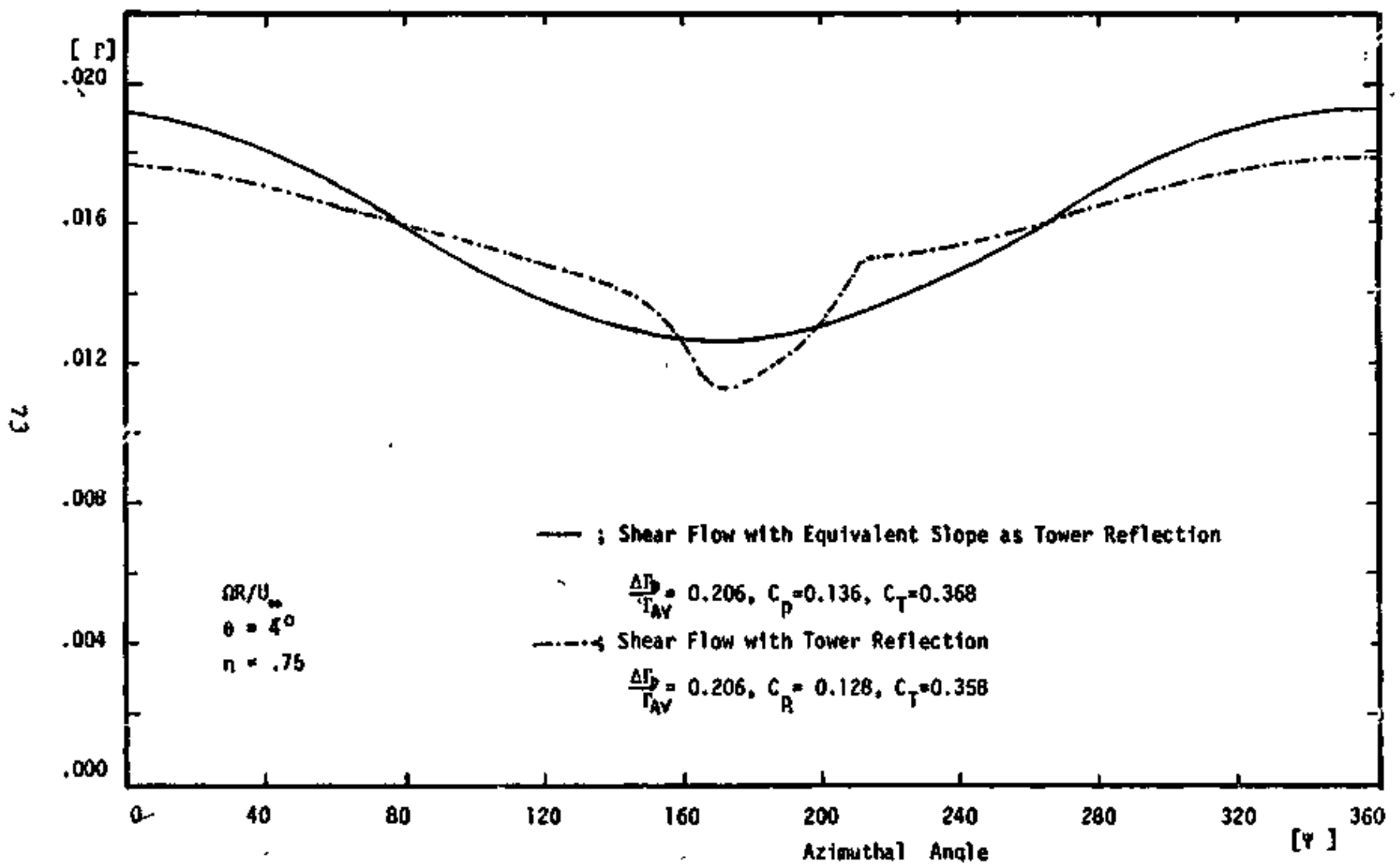

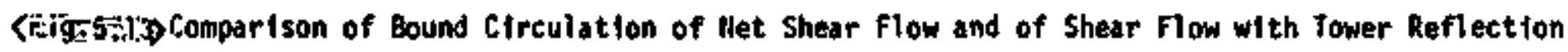




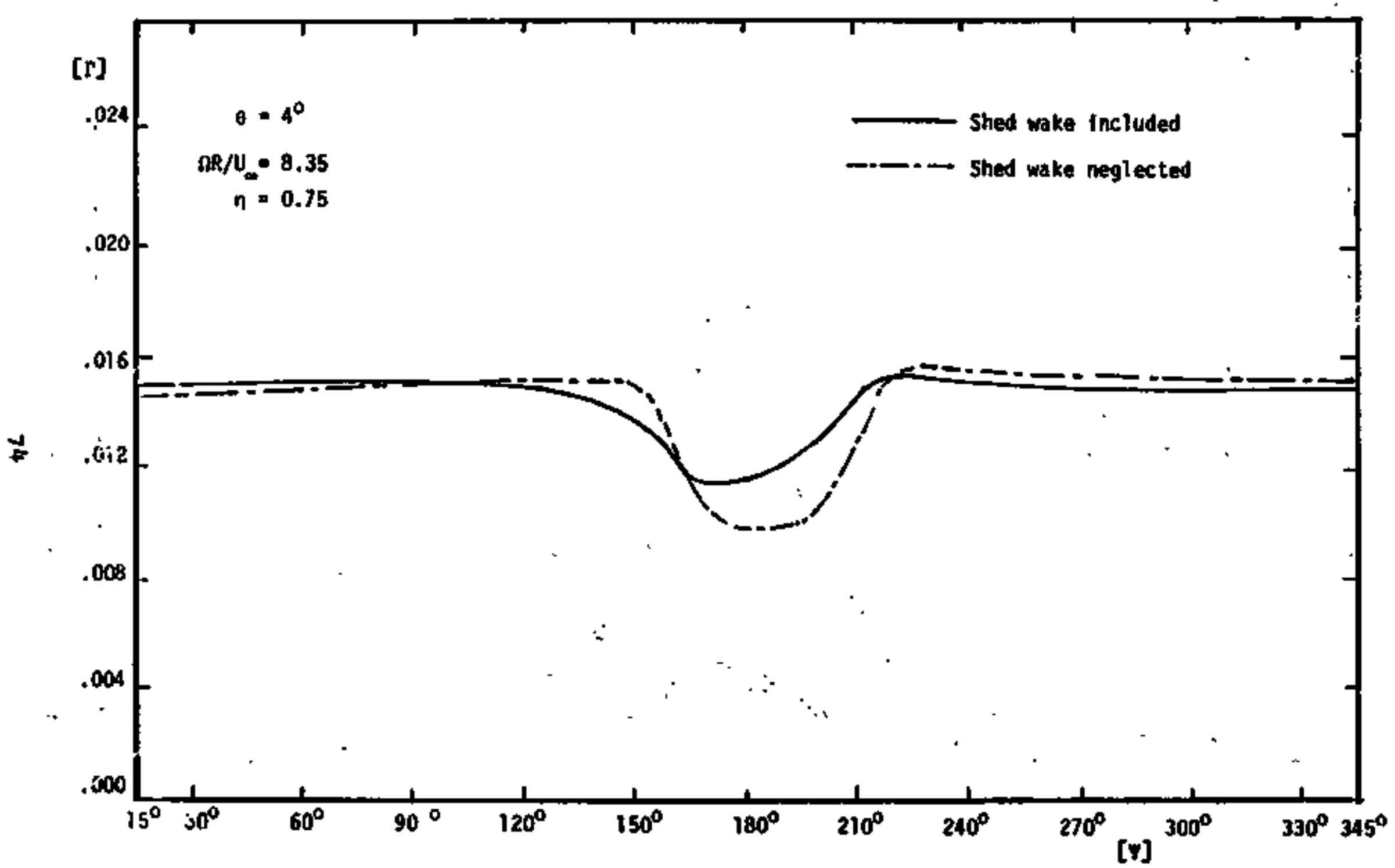

〈Fig.5.i.)Bound Circulation along Azinuthal Angle for the Tower Reflection with Unifore Free Stream 


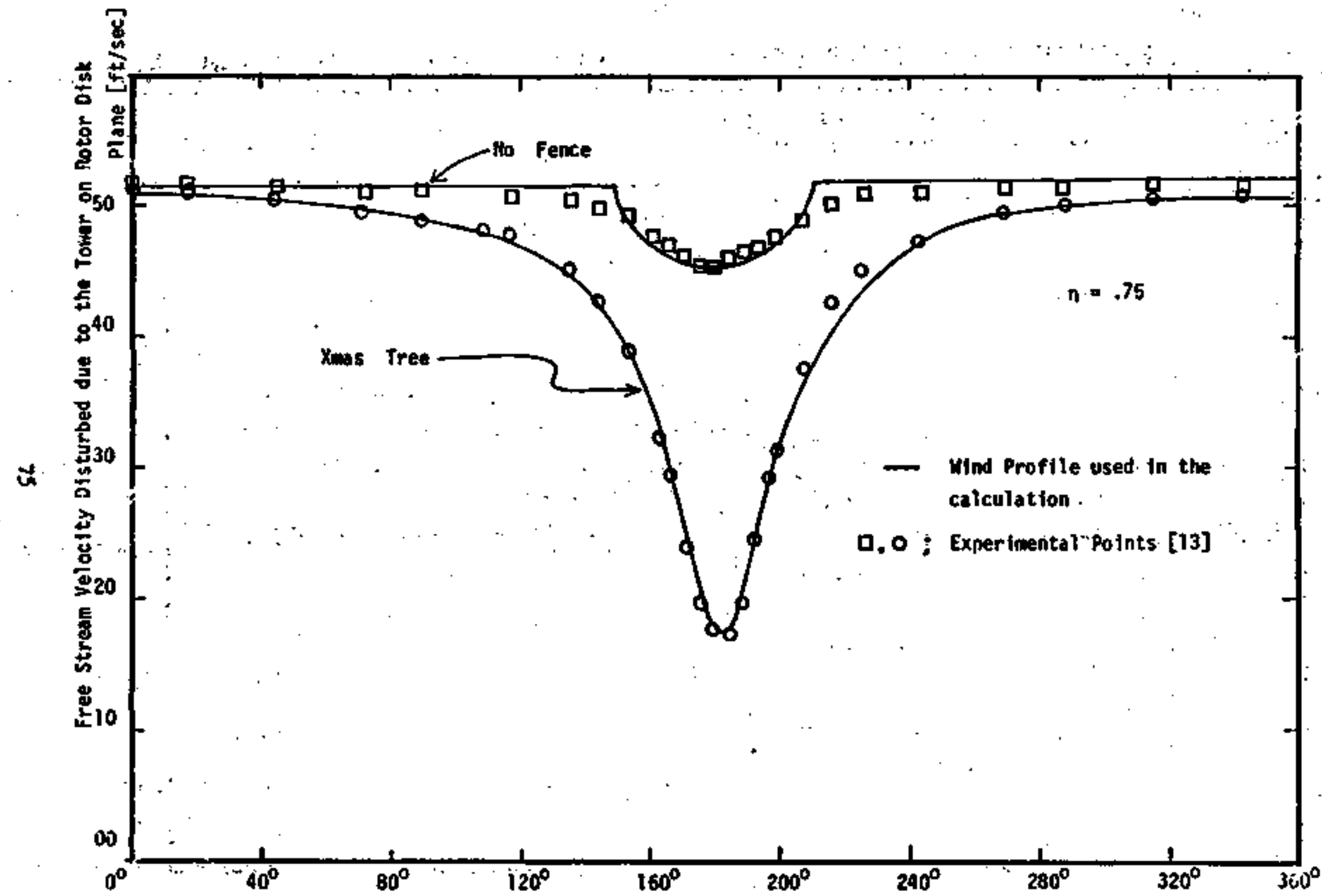

(FAg.5.15) Wind Profile Used in the Analysts and Experiwental Points 


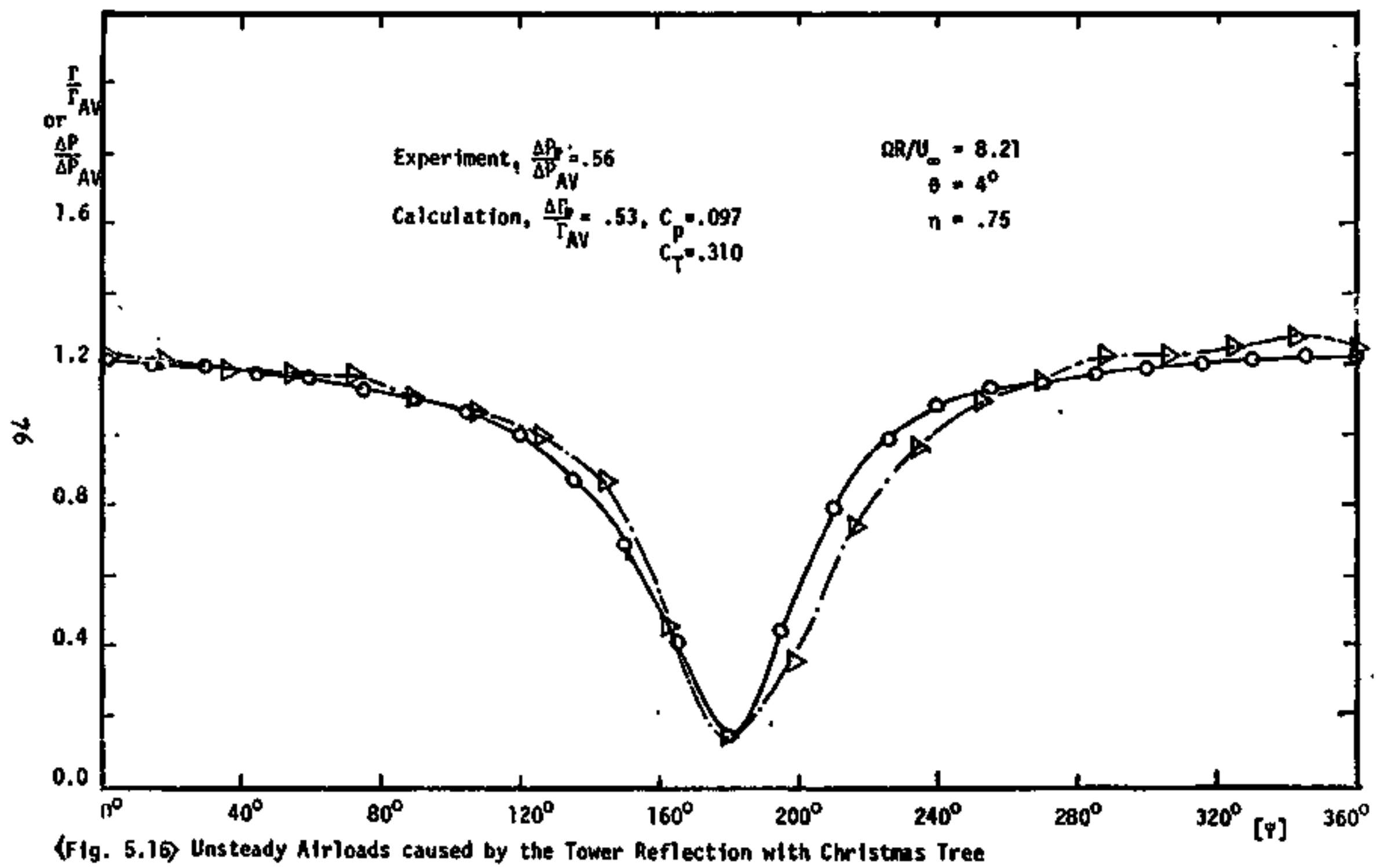



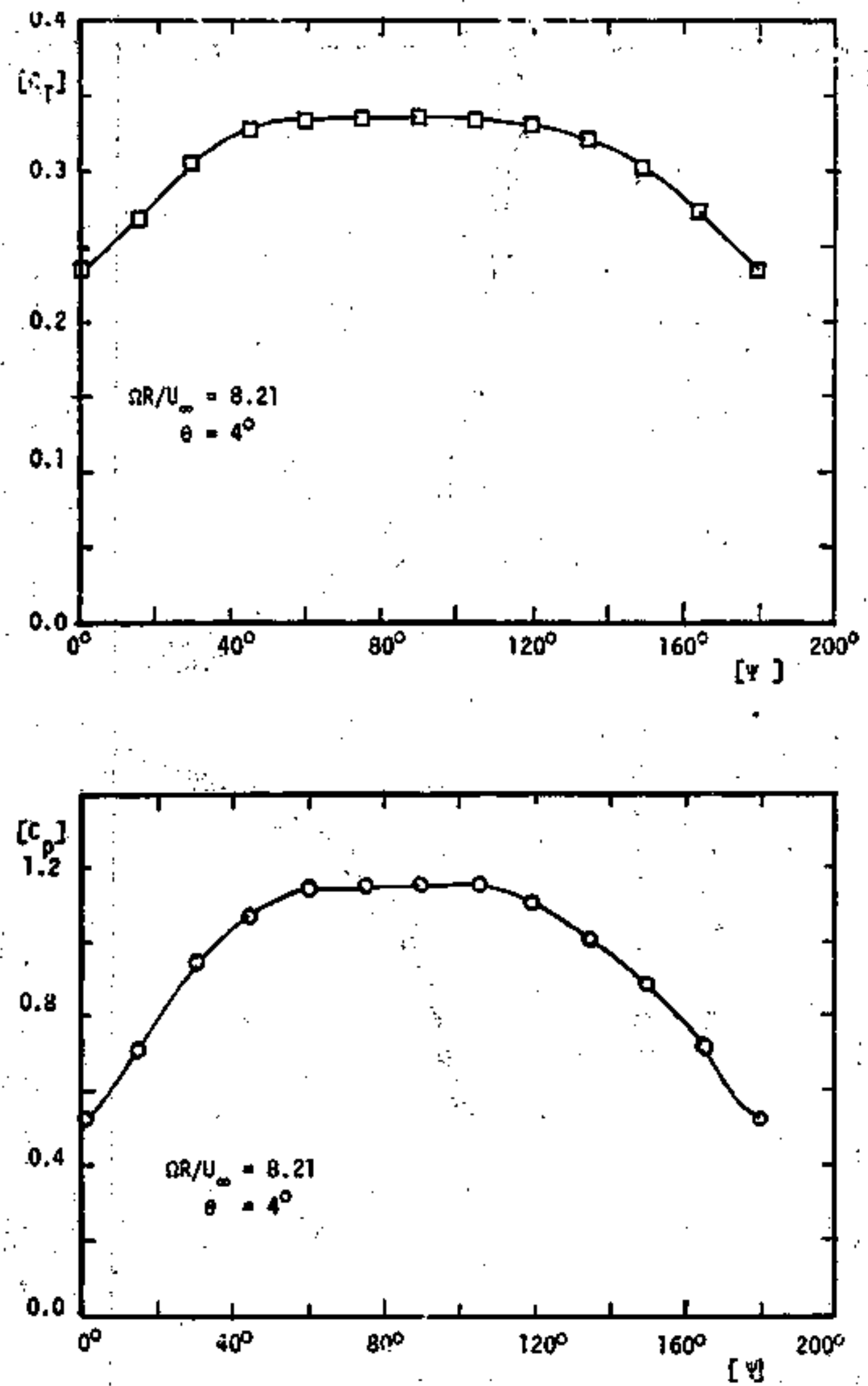

<Fig.5.it Instantaneous Power and Thrust Coefficients of the Rotor Operating in the Tower Reflection with Christmas Tree 


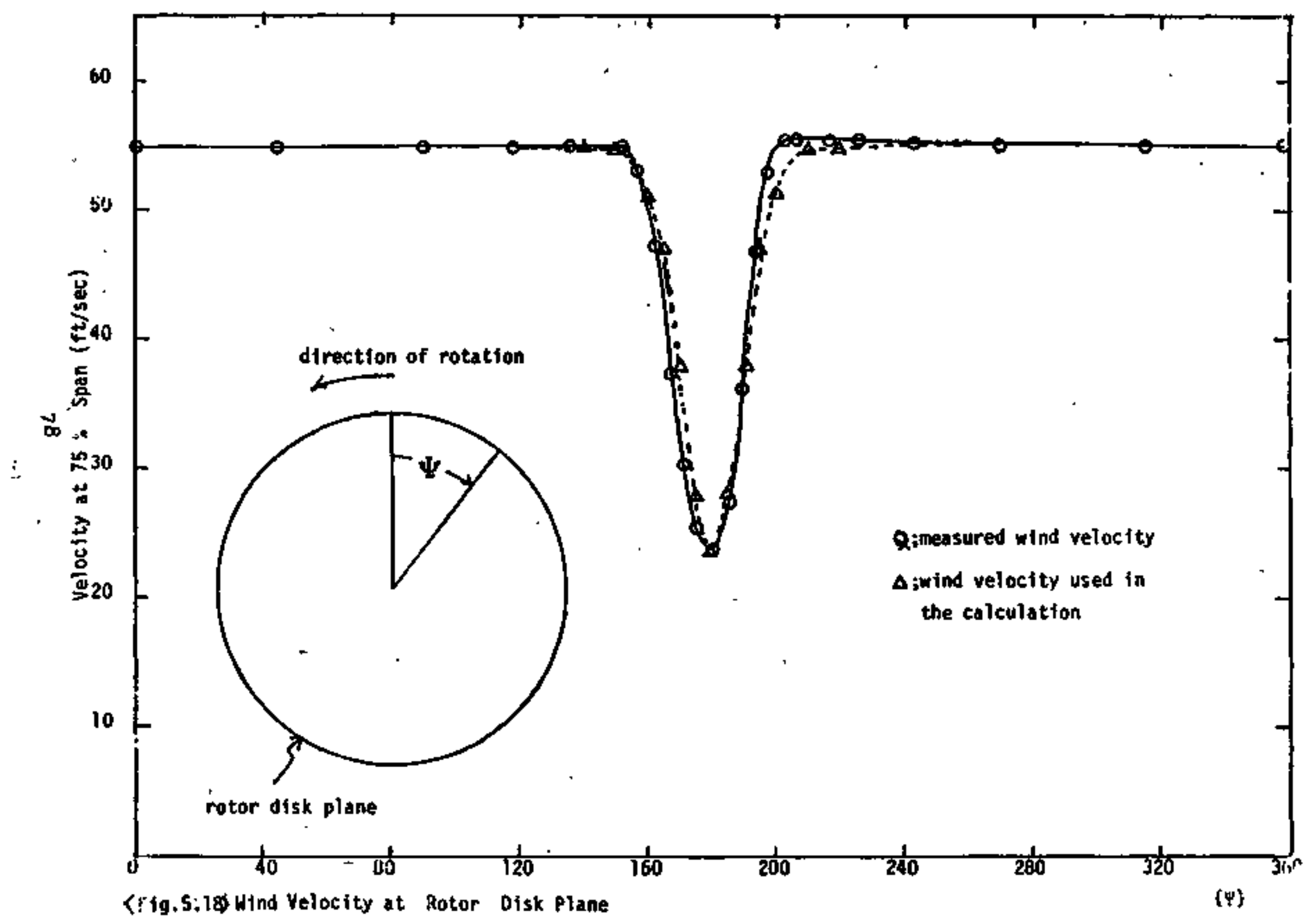




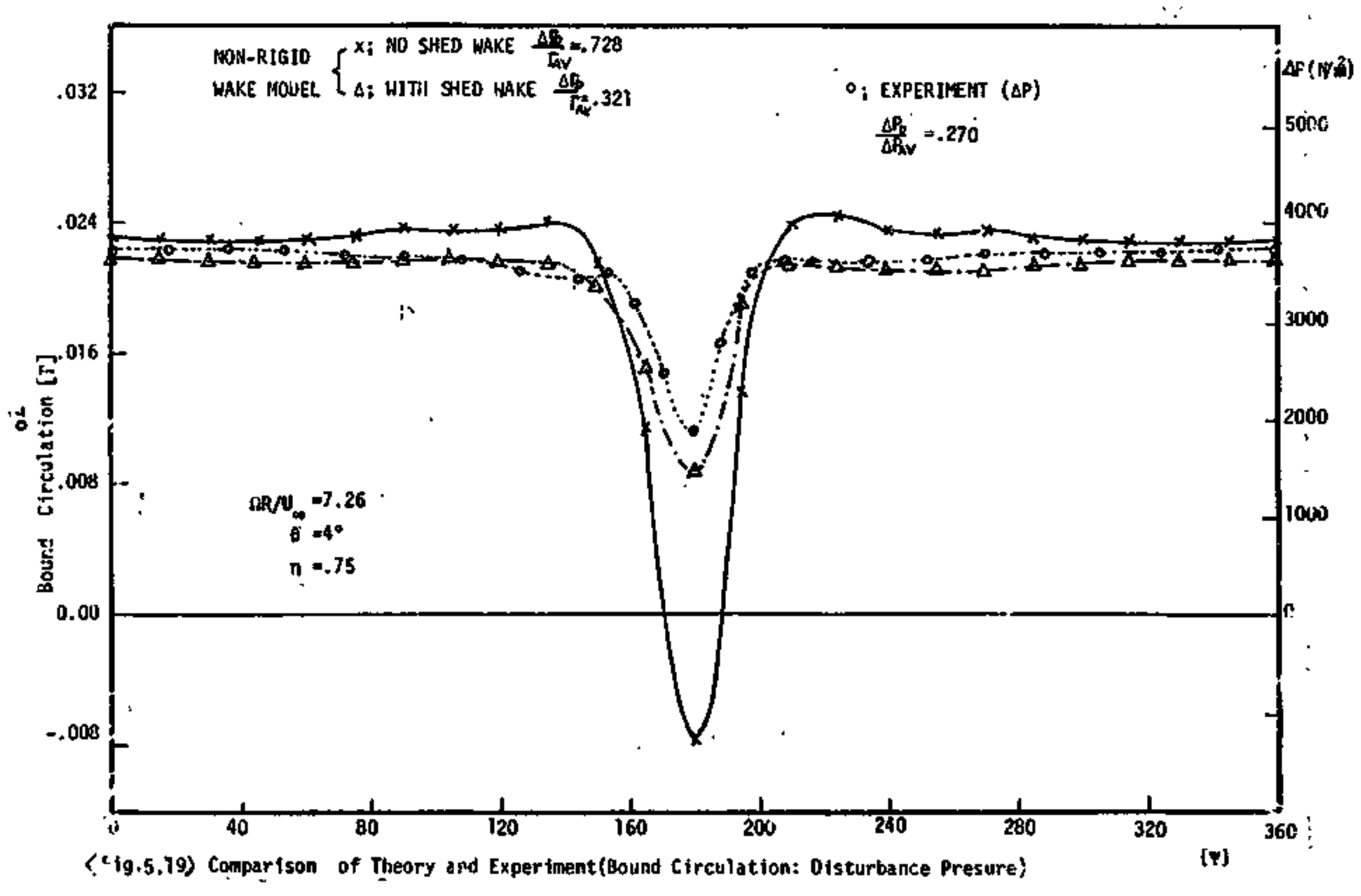




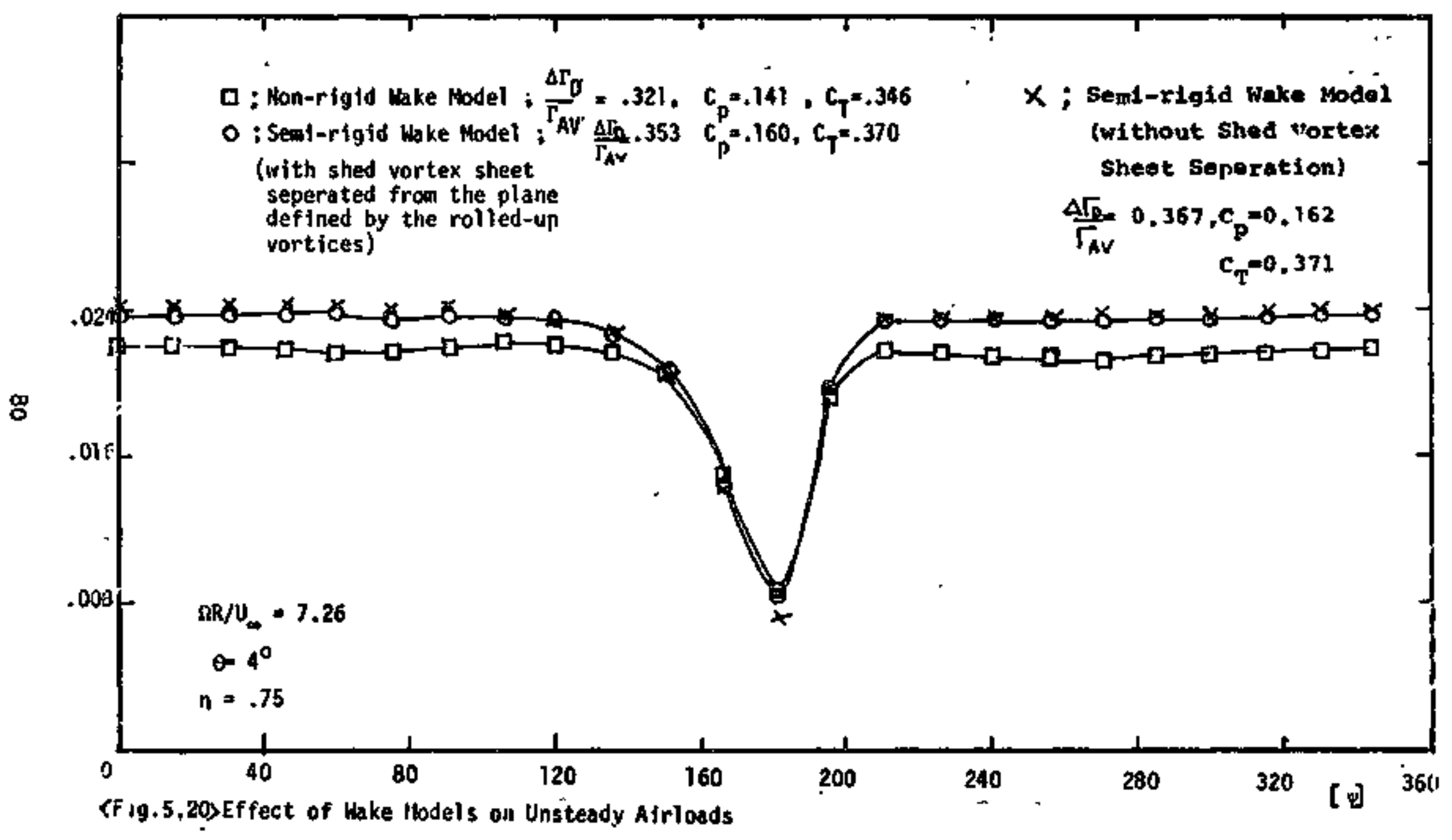




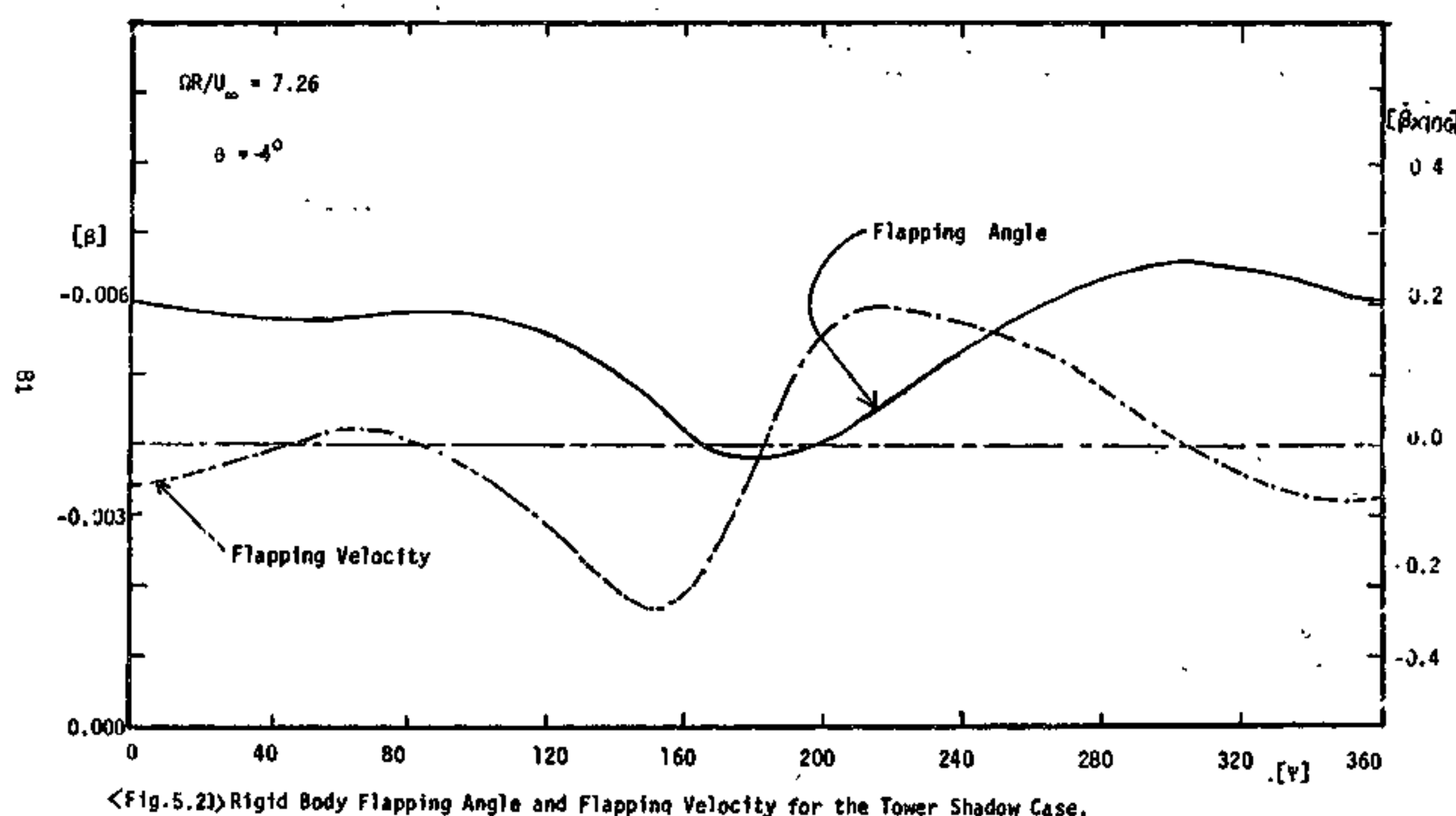




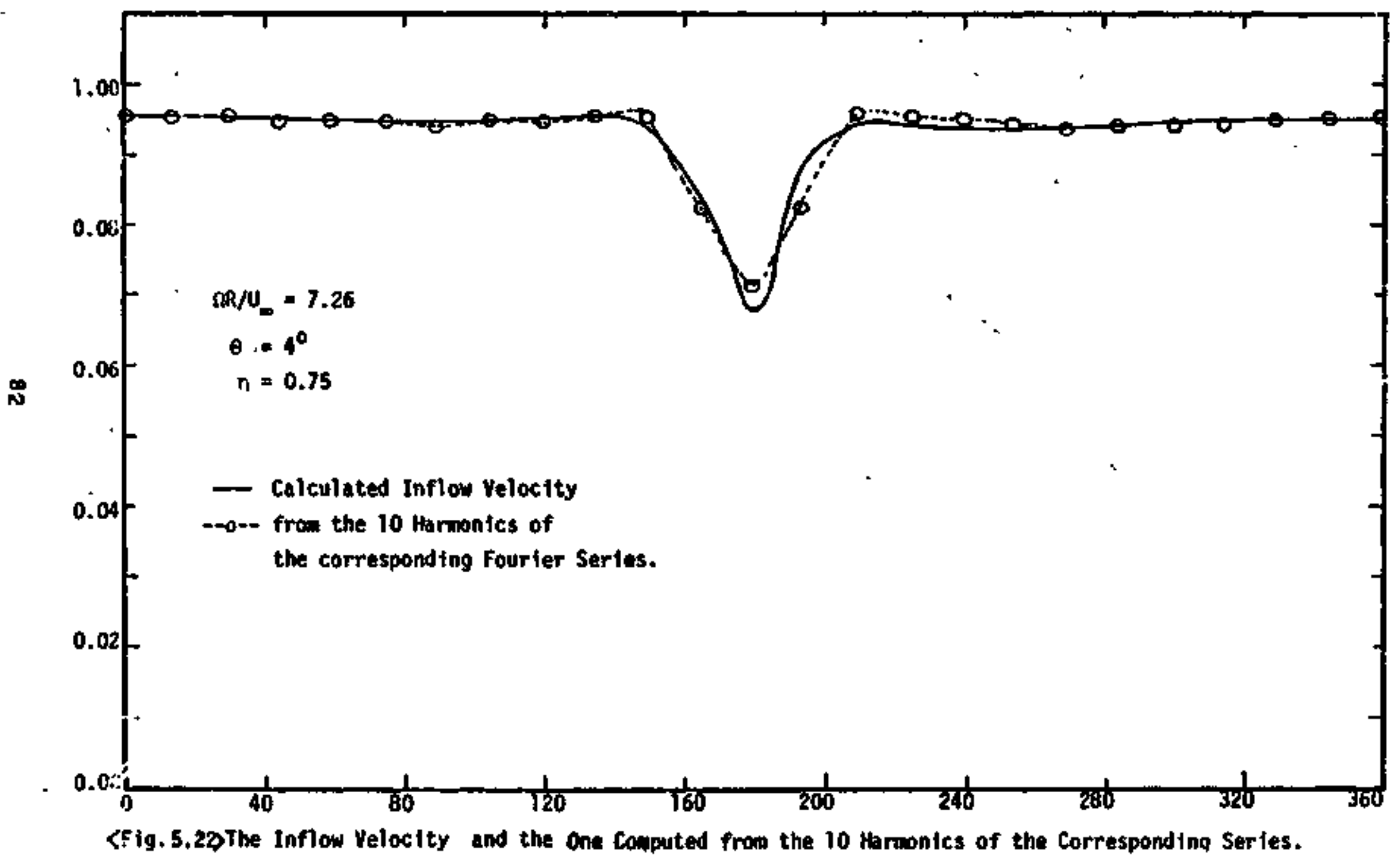




$$
\left[c_{p}\right]
$$

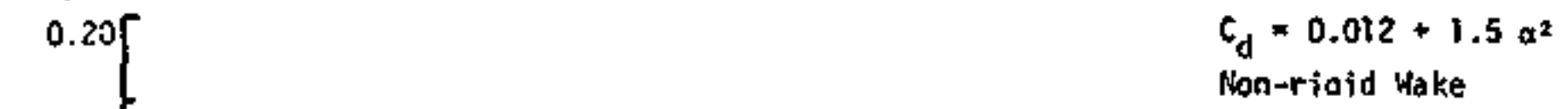

0.15

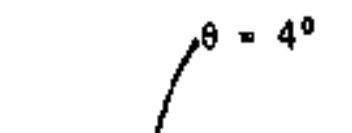

$\sigma=0.1061$

$\triangle: \theta=\mathrm{e}^{\mathrm{a}}$

$O ; \theta=4^{\circ}$ Test Data

$\left.\square ; \theta=0^{\circ}\right]$ from [13]

-

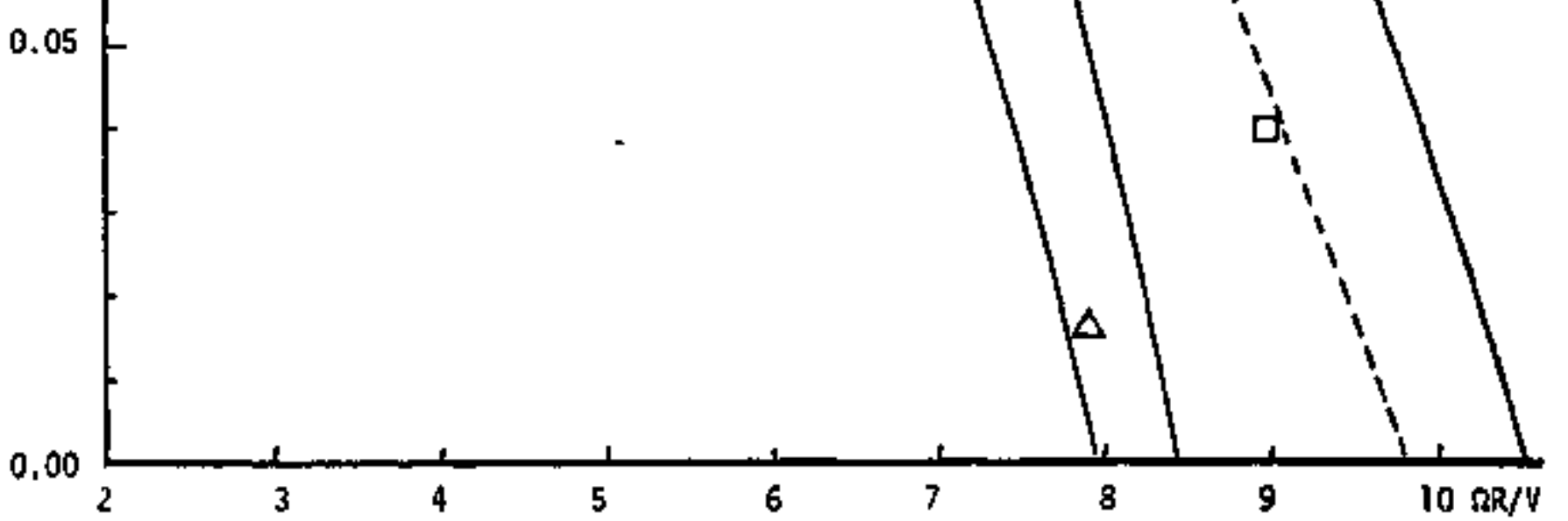

<Fia, 5.23) Comparison of Steady Hon-rioid Hake Results with Test Data 


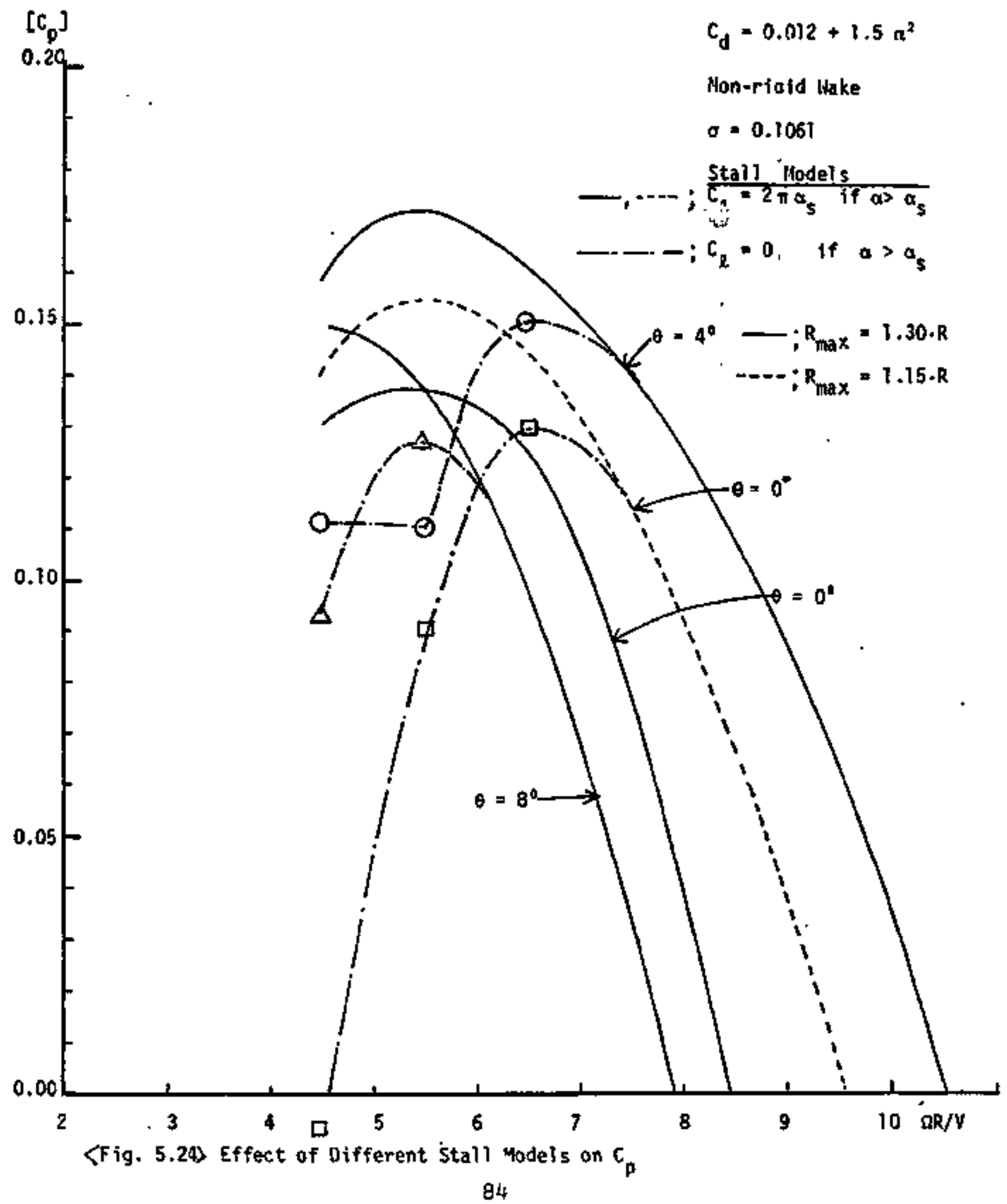




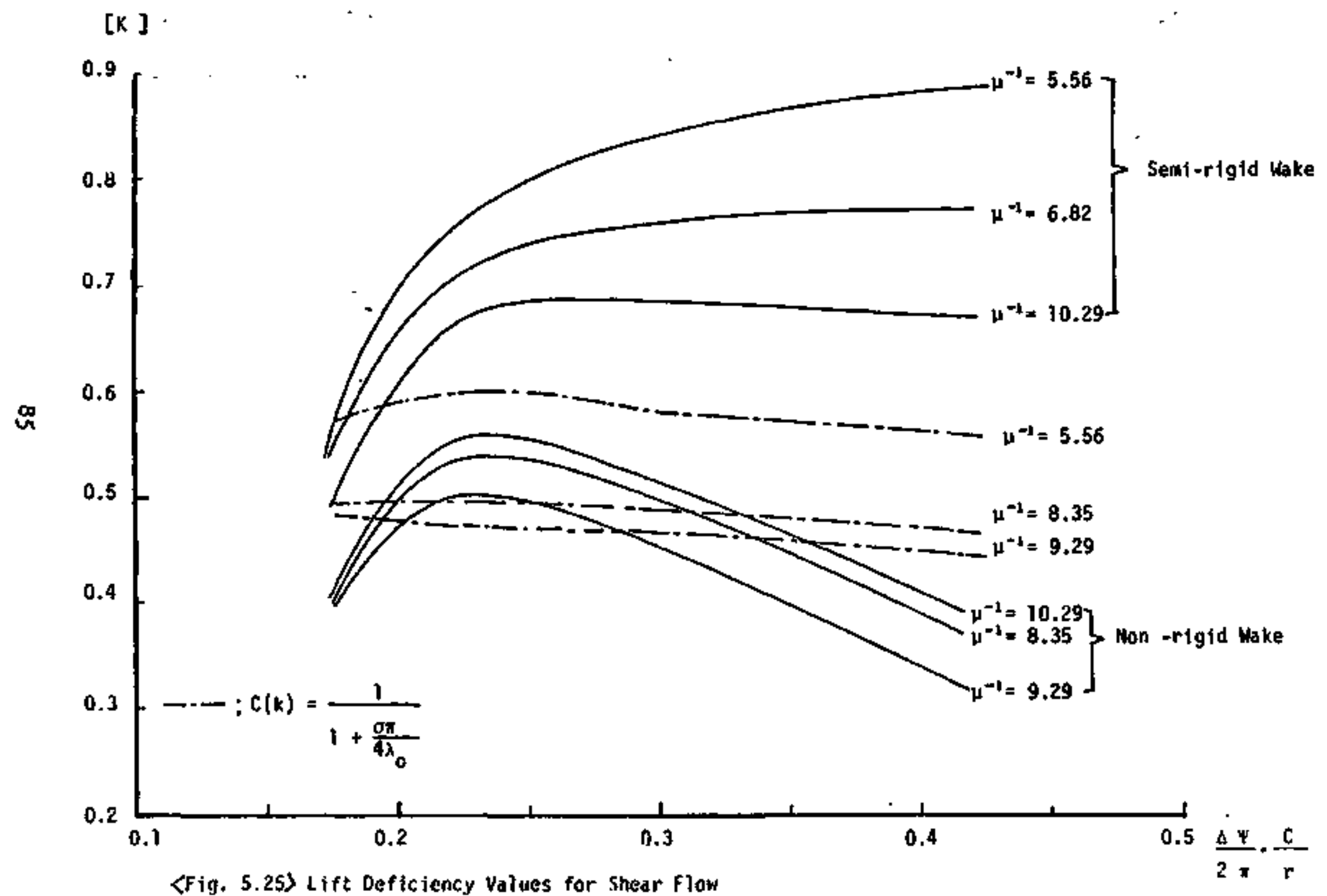




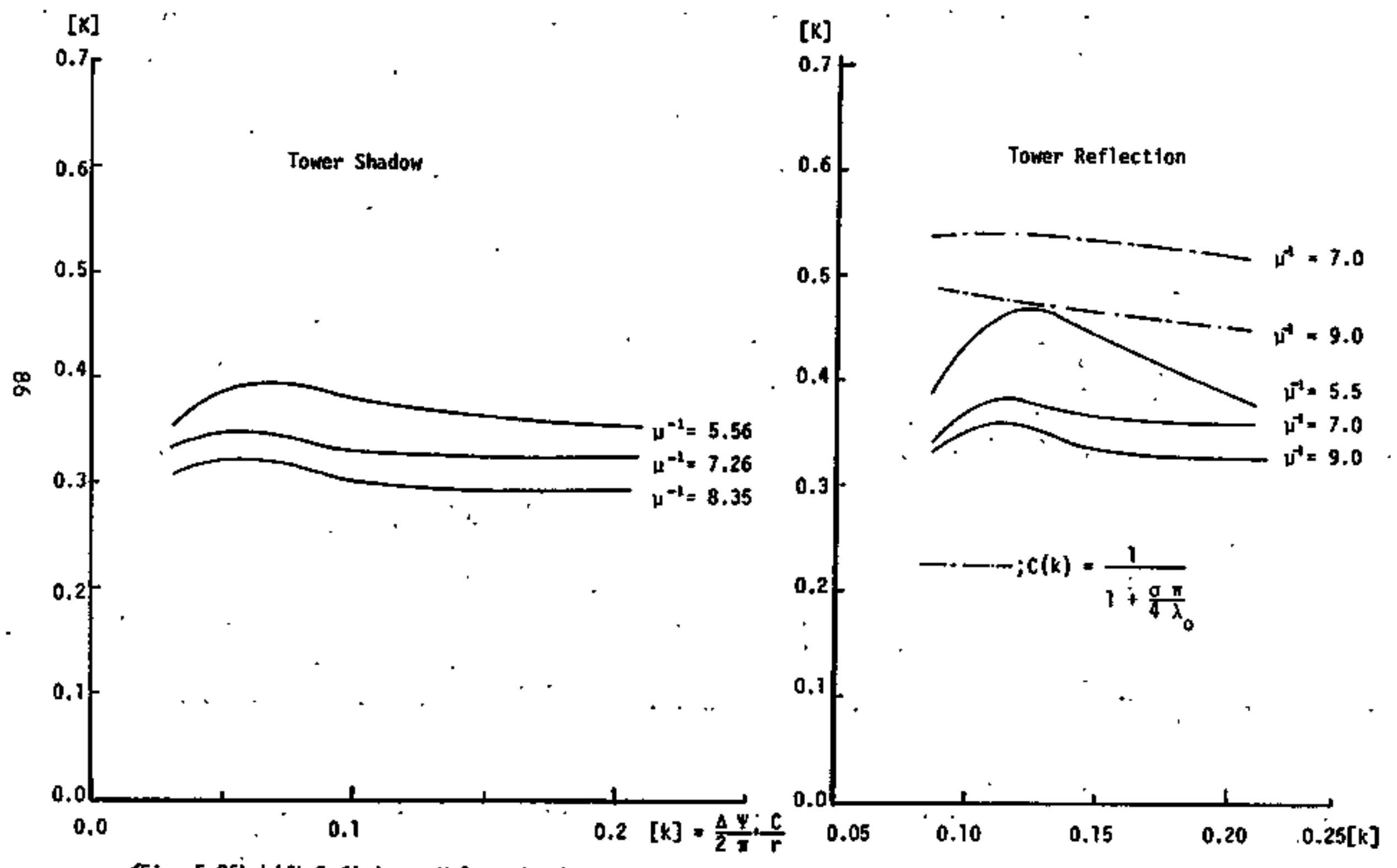

〈Fig. 5.26〉 Lift Deficiency Values for Tower Shadow and Reflection 


\section{Appendix A \\ CALCULATION OF INFLUENCE COEFFIC:ENTS $c_{i j}$}

A influence coefficient $c_{i j}$ gives the velocity induced at 1-th control point by the wake which is generated from $j$-th component of bound sirculation series, and of unit amplitude. The induced velocity $\left(W_{i}\right)$ at $i$-th control point is $\sum_{J} A_{j} \cdot C_{i j}$. From the application of the Blot-Savart law to the wake whose geometry is determined from the previous induced velocity distribution on blade, one can compute influence coefficlents $C_{i j}$ as follows.
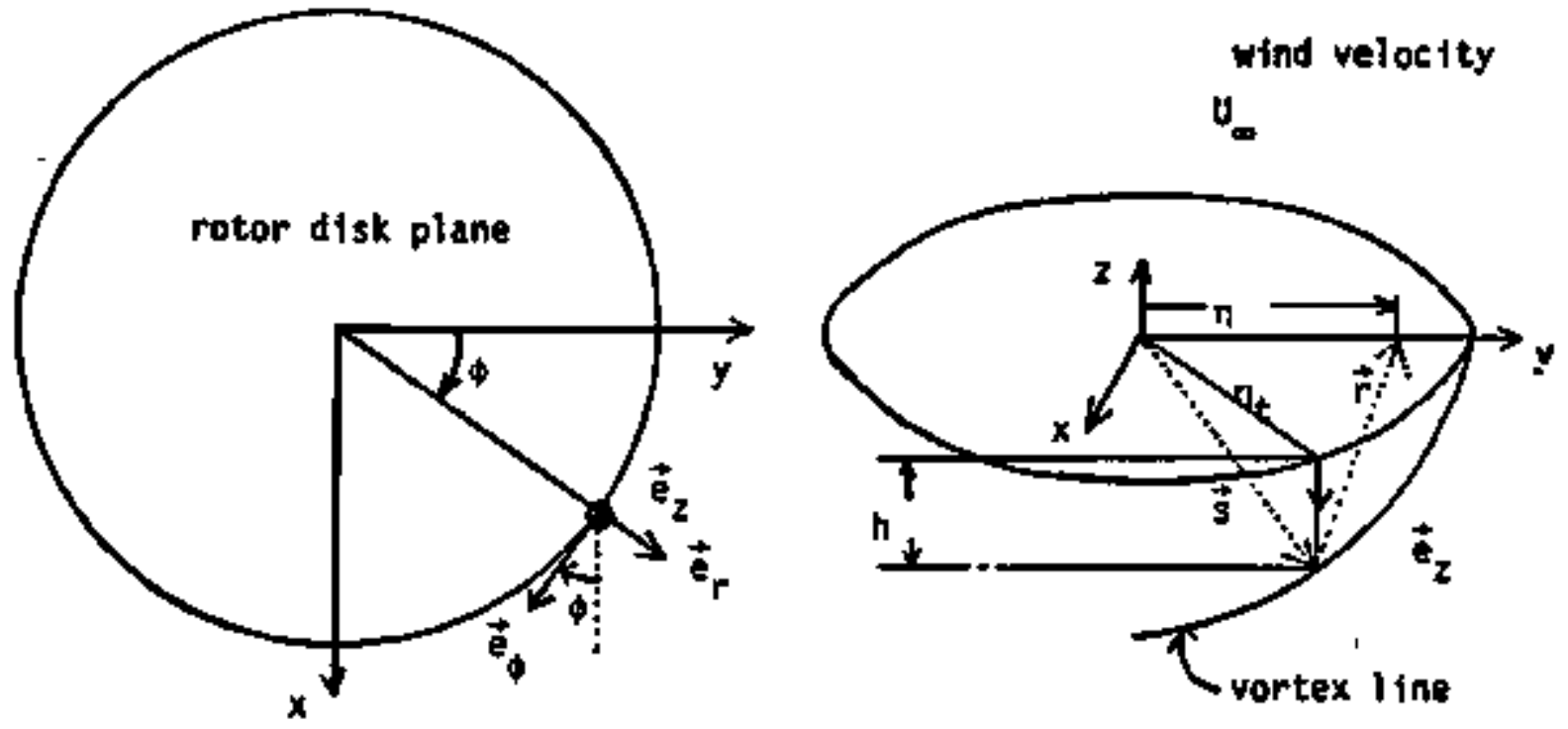

<Fig. A.1〉 Geometry for the Calculation of $C_{i j}$

$h$; axial distance normalized by $R$ trom the rotor plane to a vortex line $\vec{F}=\eta \vec{j}-\vec{s}, \vec{s}=\eta_{t} \vec{e}_{t}+h \vec{e}_{x}\left(\vec{e}_{\mathrm{a}}=-\vec{k}\right)$

$d \vec{W}\left(\tau_{1}\right)=-\frac{d r}{4 \pi} \int_{0}^{n \text { spinels } \vec{r} x d \vec{S}} \frac{\left.\vec{s}\right|^{3}}{\mid \vec{r}}$ 
This equation gives the induced velocity due to a ling vortex of strength dr and of $n$ spirals.

$$
\frac{d \vec{s}}{d \phi}=\frac{d \eta_{t}}{d \phi} \vec{e}_{r}+\eta_{t} \frac{d \vec{e}_{r}}{d \phi}+\frac{d h}{d \phi} \vec{e}_{z}
$$

$\vec{f}$ I a position version frow a point on the vortex line to the position of the blade at which the induced velocity is compused

$$
\overrightarrow{d s}=\left(w_{r} \vec{e}_{r}+\pi_{t} \vec{e}_{\phi}+v \overrightarrow{e_{r}}\right) d \phi
$$

${ }_{r}$, outward radial induced velocity normalized by ${ }^{-} R$ on a vortex $\checkmark$ - axial velocity of a trailing vortex

$$
\begin{aligned}
\vec{r} \times d \vec{s}= & {\left[\left\{\eta_{t}^{2}-\eta\left(w_{r} \sin \phi+\eta_{t} \cos \phi\right)\right\} \vec{k}\right.} \\
& +\left\{\left(\eta_{t} \vee-h w_{r}\right) \cos \phi+h \eta_{t} \sin \phi-\eta \vee\right\} \vec{i} \\
& \left.+\left\{-\left(\eta_{t} \vee-h w_{r}\right) \sin \phi+h \eta_{t} \cos \phi\right\} \vec{j}\right] d \phi \text { (A.,2) } \\
|\vec{F}|^{2}=\eta^{2}+\pi_{t}^{2}+h^{2}-2 \eta \eta_{t} \cos \phi & \text { (A., 3) }
\end{aligned}
$$

From equations (A, 1), (A, 2), and (A, 3), three components of the induced velocity are derived.

$$
\begin{aligned}
& d w_{z}=\frac{d \Gamma}{4 \pi} \int_{0}^{2 \pi \pi} \frac{\eta\left(w_{r} \sin \phi+\eta_{t} \cos \phi\right)-\eta_{t}^{2}}{\left(\eta^{2}+\eta_{t}^{2}+h^{2}-2 \eta \eta_{t} \cos \phi\right)^{3 / 2}} d \phi \\
& d w_{y}=\frac{d \Gamma}{4 \pi} \int_{0}^{2 \pi \eta} \frac{\left(\eta_{t} V-h w_{r}\right) \sin \phi-\eta_{t} h \cos \phi}{\left(\eta^{2}+\eta_{t}^{2}+h^{2}-2 \eta \eta_{t} \cos \phi\right)^{3 / 2}} d \phi \\
& d w_{x}=\frac{d r}{4 \pi} \int_{0}^{2 \pi m} \frac{-\left(\eta_{t} v-h \omega_{r}\right) \cos \phi-h \eta_{t} \sin \phi+\eta v}{\left(\eta^{2}+\eta_{t}^{2}+h^{2}-2 \eta \eta_{t} \cos \phi\right)^{3 / 2}} d \phi
\end{aligned}
$$

88 
Here, $V=\bigsqcup_{+}+W$ where $U_{0,1 s}$ the free strean velocity and $k_{i}$ is the induced valocity on the tip vortex itself. Assuming that w is linearly varying up to $k_{1}$ spiral of vortex $1 i n e$ and after $k_{1}$ spiral is constant as discussed in section 2.2 , W is obtatned as follows.

$w=w_{0}+\frac{\phi}{2 \pi h_{1}} \cdot w_{0} \cdot R D=w_{0}+\frac{w_{0} \cdot R D}{2 \pi R_{1}} \cdot \phi_{0}+\frac{w_{0} \cdot R D}{2 \pi k_{1}} \cdot x^{\prime \prime}=A_{2}+t_{2} \cdot x^{*}$

, where $w_{0}$ is the. Induced velocity of a tralling vortex when it

is trailed. RD $1 \mathrm{~s}$ a parameter of the change of $W$ after $k_{1}$ apiral , and $x^{*}$ is a azimuthal angle rariable around $\phi_{0}$. Then,

when $\phi \leqq 2 \pi-R_{1}$

$V=\left(L_{\infty}+w_{0}\right)+\frac{\phi}{2 \pi-R_{1}} w_{0} \cdot R D$

$\therefore h=\left(U_{\omega}+\omega_{0}\right) \phi+\frac{\phi^{2}}{4 \pi \bar{R}_{t}} w_{0} \cdot R D$

By permittine small variations in $\phi$ around to is iven by $h=\left(U_{0}+w_{0}\right)\left(\phi_{0}+x^{*}\right)-\frac{w_{0} \cdot R D}{4 \pi R_{1}}\left(\phi_{0}+x^{*}\right)^{2}$

$h=\alpha_{1}+\beta_{1} \cdot x^{*}+\gamma_{1} \cdot x^{+2}$

$h^{2}=\alpha_{1}^{2}+2 \alpha_{1} \beta_{1} x^{*}+\left(\beta_{1}^{2}+2 \alpha_{1} \gamma_{1}\right) x^{* 2}+\left(2 x^{* 3}+() x^{* 4}\right.$

When $\phi>2 \pi R, w=(1+R D) w_{0}$

$h=h_{0}+\left(U_{0}+w^{\prime} \phi^{\prime}, \phi^{\prime}=\phi-2 \pi h_{1}\right.$

$h=h_{0}-\left\{U_{\infty}+w_{0}(v+R D)\right\} 2 \pi R_{1}+\left\{U_{\infty}+w_{0}(1+R D)\right\} \phi$

From equation $(A \cdot 7) \cdot h_{0}=h\left(\phi=2 \pi \beta_{1}\right)=\pi k_{1}\left\{I \omega_{\infty}+w_{0}(1+R D \phi\right.$ $h=\rightarrow R D w_{0} \pi R_{1}+\left\{\omega_{\infty}+w_{0}(1+R D)\right\}\left(\phi_{0}+x^{*}\right)$

$=\alpha_{2}+\beta_{2} x^{*}$

$h^{2}=\alpha_{2}^{2}+2 \alpha_{2} \beta_{2} x^{*}+\beta_{2}^{2} x^{* 2}$ 
Likewlse $w_{F}$ is assumed to vary linearly.

$$
w_{r}=w_{\text {ro }}-\frac{\phi}{2 \pi \phi_{2}} \cdot w_{\text {ro }}
$$

- where $N_{\text {ro }}$ is the radial induced velocity of the tip vortex on the rotor disk plane. After $k_{2}$ spirals of the tip vortex, $v_{r}$ is zero.

$$
\begin{aligned}
w_{r} & =w_{r_{0}}-\frac{w_{r_{0}} \phi_{0}}{2 \pi h_{2}}-\frac{w_{r_{0}}}{2 \pi t_{2}} x^{*} \\
& =x_{1}+t_{1} x^{m}
\end{aligned}
$$

The radial position of the tip rortex is defined by $\eta_{t}$.

$$
\eta_{t}=\eta_{t_{0}}-w_{r_{0}} \phi-\frac{\phi^{2}}{4 \pi-t_{2}} w_{r_{0}}
$$

where $\eta_{t_{0}}$ is the radial position when the tip vortex is trailed. substitution of $\phi$ with $\left(\phi_{0}+\chi^{*}\right)$ lnto the above equation gives

$$
\begin{aligned}
& \eta_{t}=\eta_{r_{0}}+w_{r_{0}} \phi_{0}-\frac{w_{r o}}{4 \pi t^{2}} \phi^{2}+\left(w_{r_{0}}-\frac{w_{r_{0}} \phi_{t}}{2 \pi t_{2}}\right) x^{2}-\frac{w_{r_{0}}}{4 \pi t_{2}} x^{-2} \\
& =\alpha_{3}+\beta_{3} x^{*}+r_{3} x^{* 2} \\
& \eta_{t}^{2}=\alpha_{3}^{*}+2 \alpha_{3} \beta_{3} x^{*}+\left(\beta_{3}+2 \alpha_{3} r_{3}\right) x^{* 2} \\
& \cos \phi=\cos \left(\phi_{0}+x^{*}\right)=\cos \phi_{0}-\mu_{1} \phi_{0} \cdot x^{*}-\frac{1}{2} \cos \phi_{0} \cdot x^{*-1} \\
& =p-g \cdot x^{*}-\frac{1}{2} p \cdot x^{* 2} \\
& \sin \phi=\sin \left(\phi_{0}+x^{*}\right) \\
& =q+p x^{*}-\frac{1}{2} q \cdot x^{m-2}
\end{aligned}
$$


From equations (A.13), (A.14) and (A.15), $\left(\eta^{2}+\eta_{t}^{2}-2 \eta \eta_{t} \cos \phi\right)$ tern is obtained to the second order of $x^{*}$.

$$
\begin{aligned}
& \eta^{2}+\eta_{t}^{2}-2 \eta \eta_{t} \cos \phi \\
& =\eta^{2}+\alpha_{3}^{2}-2 \eta \alpha_{3} p+2\left\{\alpha_{3} \beta_{3}+\eta\left(\alpha_{3} g-\beta_{3} p\right)\right\} x^{\mu} \\
& \quad+2\left\{\alpha_{3} r_{3}+\beta_{3}^{2} / 2+\eta\left(\frac{1}{2} \alpha_{3} p-r_{3} p+\beta_{3} g\right)\right\} x^{-2} \\
& =a+2 b x^{2}+c x^{-2}
\end{aligned}
$$

(1). $\phi \leqq 2 \pi k_{1}$

From equations $(x, 9)$ and $(\lambda, 17)$,

$$
\begin{aligned}
* & \eta^{*}+\eta_{t}^{2}+h^{2}-2 \eta \eta_{t} \cos \phi \\
& =\left(\alpha_{1}^{2}+a\right)+2\left(\alpha_{1} \beta_{1}+b\right) x^{*}+\left(\beta_{1}^{*}+2 \alpha_{1} \gamma_{1}+c\right) x^{* 2} \\
& =A+2 B x^{*}+c x^{* 2}
\end{aligned}
$$

(A.18)

(ii). $\phi>2 \pi k_{1}$

Prom equations $(\lambda, 11)$ and $(\lambda, 17)$.

$$
\begin{aligned}
& =\eta^{2}+\eta_{t}^{2}+h^{2}-2 \eta \eta_{t} \cos \phi \\
& =\alpha_{2}^{2}+a+2\left(\alpha_{2} \beta_{2}+b\right) x^{-2}+\left(\beta_{2}^{+}+c\right) x^{-2} \\
& =A+2 B x^{-1}+c x^{-2}
\end{aligned}
$$

In the equation $(x, 4), \eta\left(\eta_{t} \cos \phi+v \sin \phi\right)-\eta_{t}^{2}$ term is computed from equations (A.i2), (A.13), (A.14). (A.15) and (A.16) to the second order of $x^{*}$.

$$
\begin{aligned}
* & \eta\left(\eta_{t} \cos \phi+w_{r} \sin \phi\right)-\eta_{t}^{2} \\
= & \eta\left(\alpha_{3} p+\alpha_{1} g\right) \cdots \alpha_{3}^{2}+\left\{\eta_{(}\left(-\alpha_{3} g+\beta_{3} p+\alpha_{1} p+t_{1} g\right)\right. \\
& \left.-2 \alpha_{3} \beta_{1}\right\} x^{*}=D+E x^{*}
\end{aligned}
$$

91 
In the equation 'A.s) $*\left(\eta_{t} \vee-h w_{r}\right) s_{1}+2 \phi-\eta_{t} h \cos \phi$ term 13 obtained as follows.

(1). $\phi \leqq 2 \pi R_{1}$

From the equations $\left(A^{-}, 6\right),(\mathrm{A}, 8),(\mathrm{A}, 12),(\mathrm{A}, 13),(\mathrm{A} .15)$, and $(\mathrm{A}, 16)$,

$\left(\eta_{t} v-h w_{r}\right) \sin \phi-\eta_{t} h \cos \phi$

$=q\left[\alpha_{1}\left(U+\alpha_{2}\right)-\alpha_{1} \alpha_{1}\right\}-\alpha_{3} \alpha_{1} p$

$+\left\{p\left\{\alpha_{3}\left(u+\alpha_{2}\right)-\alpha_{1} \alpha_{1}\right)-\alpha_{1} A_{1}\right\}$

$+q\left\{\alpha_{3} t_{2}+\beta_{1}\left(U+A_{2}\right)-\alpha_{1} t_{1}-\beta_{1} A_{1}\right\}$

$-\alpha_{3} \beta_{1} p-\beta_{3} \alpha_{1} p+\alpha_{3} \alpha_{1} g J x^{*}$

$=F+G x^{*}$

(11). $\phi>2 \pi k_{1}$

$A_{2}=w_{0}(1+R D), t_{2}=0 \quad \& \quad h=\alpha_{2}+\beta_{2} x^{*}$

Bquations (A.1B), (A, 19), (A, 20), and $(A .21)$ give the ftnal form of iquation to compute induced vejoctties.

$$
\begin{aligned}
& d w_{2}=\frac{d \Gamma}{4 \pi} \sum_{\phi} \int_{-\Delta \phi_{0}}^{\Delta \phi_{\phi}} \frac{D+E X^{*}}{\left[A+2 B X^{*}+C X^{* 2}\right]^{3 / 2}} d X^{*}=\frac{d \Gamma}{4 \pi} \sum_{\phi} I_{1} \\
& d w_{y}=\frac{d \Gamma}{4 \pi} \sum_{\phi} \int_{-\Delta \phi_{0}}^{\Delta \phi_{0}} \frac{F+G X^{*}}{\left[A+2 B X^{*}+C X^{* 2}\right]^{3 / 2}} d x^{*}=\frac{d \Gamma}{4 \pi} \sum I_{2} \\
& \eta=\eta_{r c}+\frac{1}{2}(1-\cos \theta) \\
& \Gamma(\eta)=\sum_{\pi} A_{n} \sin n \theta \\
& d \Gamma(\eta)=\sum\left(-n A_{n}\right) \cos n \theta d \theta
\end{aligned}
$$




$$
\begin{aligned}
& w_{z}=\frac{1}{4 \pi} \sum_{n}\left(-n A_{n}\right) \sum_{i} \sum_{i} \cos n \theta I_{i} \cdot 2 \Delta \theta_{0}=\sum_{n} A_{1} C_{n}=w \\
& w_{y}=\frac{1}{4 \pi} \sum\left(\sim n A_{n}\right) \sum_{j} \sum_{i} \cos n \theta I_{*} \cdot 2 \Delta \theta_{0}=\sum_{n} A_{n} D_{n}=w_{r o d}\left(A_{*} 23\right) \\
& \phi=(2 i-1) \Delta \phi_{0}, \theta=2(j-1) \cdot \Delta \theta_{0} \\
& \Delta \theta=2 \Delta \theta \text {. Brcept at the tip and root yort1cos } \\
& \Delta \theta=\Delta \theta \text {. At the tip and root vertices } \\
& I_{1}=\int_{-\Delta \phi_{0}}^{\Delta \phi_{0}} \frac{\left(D+E X^{*}\right)}{\left[A+2 B X^{*}+C X^{* 2}\right]^{3 / 2}} \cdot d X^{*} \text {, } \\
& I_{2}=\int_{-\Delta \phi_{0}}^{\Delta \phi_{0}} \frac{\left(D+E X^{*}\right)}{\left[A+2 B x^{*}+C X^{D}\right]^{3 / 2}} \cdot d X^{*}
\end{aligned}
$$

93 
Appendix B

AIL COEFFICIENTS USED IN CALCULATING $c_{1 j}$

If $A C+B^{2}$

$$
I_{1}=\frac{1}{A C-B^{2}}\left[\frac{(D A-E A)+(D C-E B) \Delta \phi_{0}}{\sqrt{A}+2 B \Delta \phi_{1}+C \Delta \phi_{0}^{2}}-\frac{(D B-E A)}{\sqrt{A-2 B \Delta \phi_{0}+C \cdot \Delta \phi_{0}^{2}}}\right]
$$

If $A C=B^{2}$

$$
I_{1}=\frac{E B-C D}{2 \sqrt{C}}\left[\frac{1}{\left(B+C \Delta \phi_{0}\right)^{2}}-\frac{1}{\left(B-C \cdot \Delta \phi^{2}\right.}\right]+\frac{2 E \cdot \Delta \phi \sqrt{C}}{B^{2}-C^{2} \Delta \phi_{0}^{2}}
$$

In $I_{2}$, $D$ is replaced with $\mathrm{and} E$ with $G$.

(1) $\phi \leqq 2 \pi k_{1}$

$$
\begin{aligned}
& A=\alpha_{1}^{2}+a, B=\alpha_{1} \beta_{1}+b, \quad c=\beta_{1}^{2}+2 \alpha_{1} r_{1}+c \\
& \text { (in) }>2 \pi k_{1} \\
& A=\alpha_{2}^{2}+a_{1} \quad B=\alpha_{2} \beta_{2}+b_{1} \quad c=\beta_{3}^{*}+c \\
& D=\eta\left(\alpha_{j} p+A_{1} q\right)=\alpha_{3}^{2} \\
& E=\eta\left(-\alpha q+\beta_{d} p+\alpha_{1} p+t_{1} q\right)-2 \alpha_{3} \beta_{3} \\
& \left.P=q\left\{v_{\infty}+\alpha_{2}\right)-\alpha_{1} \alpha_{1}\right\}-\alpha_{1} \alpha_{1} P
\end{aligned}
$$

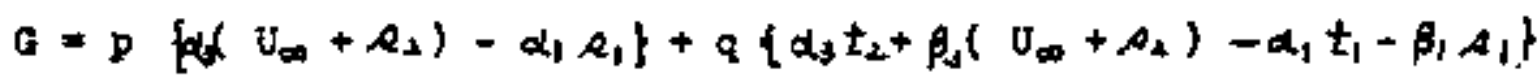

$$
\begin{aligned}
& -\alpha_{0} \beta_{1} p-\beta_{0} \alpha_{1} p+\alpha_{1} \alpha_{1} q
\end{aligned}
$$

Here, when $\phi>2 \pi k_{1}$, then $\alpha_{1}=\alpha_{2}, \beta_{1}=\beta_{2}$.

$$
\begin{aligned}
& \alpha_{1}=\left(U_{\infty}+w_{0}\right) \phi+\frac{w_{0} R D}{4 \pi k_{1}} \phi^{2} \\
& \left.\alpha_{2}=-R D w_{0} \pi k_{1}+1 u_{\infty}+w_{0}(1+R D)\right\} \phi \\
& \alpha_{3}=\eta_{t_{0}}+w_{r_{0}} \phi \cdots \frac{w_{r_{0}}}{4 \pi k_{2}} \phi^{2}
\end{aligned}
$$

94 


$$
\begin{aligned}
& \beta_{1}=U_{\infty}+w_{0}+\frac{w_{0} R D}{2 \pi k_{1}} \phi^{2} \\
& \beta_{2}=U_{\infty}+w_{0}(1+R D) \\
& \beta_{1}=w_{r_{0}}-\frac{w_{\text {ra }}}{2 \pi k_{2}} \phi \\
& r_{1}=\frac{w_{0} R Q}{4 \pi k_{1}} \\
& r_{3}=-\frac{w_{r R_{2}}}{4 \pi k_{2}} \text {. } \\
& p=\cos \phi \\
& g=\sin \phi \\
& Q_{1}=w_{r_{0}}-\frac{w_{r 0}}{2 \pi k_{2}} \phi, \quad t_{1}=-\frac{w_{r_{0}}}{2 \pi k_{2}} \\
& A_{2}=w_{0}+\frac{w_{0} R D}{2 \pi k_{1}} \phi \text {, if } \phi \underline{\underline{2}} 2 \pi \underline{k}_{1}, A_{2}=(1+R D) w_{0} \\
& t_{2}=\frac{w_{0} R D}{2 \pi-h_{1}} \quad \text { if } \phi z 2 \pi k_{1}, t_{2}=0 \\
& a=\eta^{2}+\alpha_{3}^{2}-2 \gamma_{3} p \\
& b=\alpha_{3} \beta_{3}+\eta\left(\alpha_{3} z-\beta_{3} p\right) \\
& c=2\left\{\alpha_{3} r_{3}+\beta_{3} 2 / 2+\eta\left(\frac{1}{2} \alpha_{2} p-r_{3} p+\beta_{3} q\right)\right\}
\end{aligned}
$$

95 


\section{Apperidix $C$}

VELOCITY INDUCED BY A TRAILING OR SHED YORTEX ELEMENT

\section{C.1 Trailing Yortex Element}

The velocity it at position on the blade by trailing vortex element $A$ of otrength $\Gamma(\phi)$ is obtained by applying the Biot-Savart formula. In vectorial form, the rurrula can be witten as

$$
\vec{W}=\frac{1}{4 \pi} \int_{s_{1}}^{s_{2}} \Gamma(\phi) \frac{\overrightarrow{\vec{r}} \times \overrightarrow{d \vec{s}}}{r^{3}}
$$
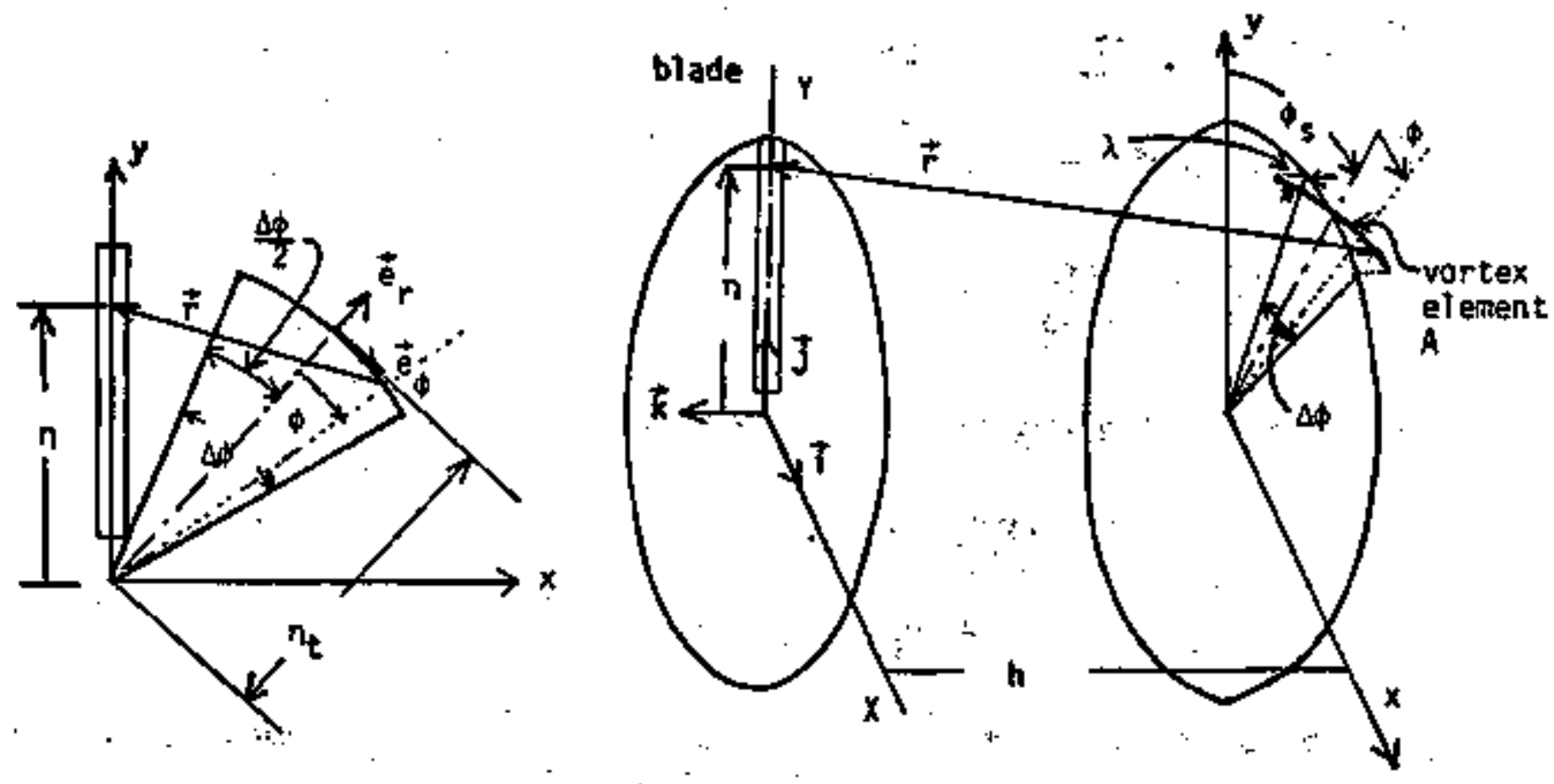

Projection to $x-y$ Plane

Fig. A.2D Geometry for the Calculation of the Veloctty Induced by a Trailing Vortex 
$\vec{E}_{r}, \vec{E}_{f}=$ unit vectors fixed at the midpoint of the vortex element.

$\lambda=$ angle of inclination of the vortex element $W . r$, to $X-Y$ plane.

$h=$ axial distance from the $X-Y$ plane to the midpoint of 'vortex element.

$\phi_{s}=$ azimuthal angle between the blade axis $(j-a x i s)$ and the axis formed by the line from the organ of $x-y$ plane to midpoint.

Vortex element $A$ in fig.A.2 is assumed to be inclined war. to $\vec{e}_{\phi}$ by angle ' $\lambda$ '.

$$
\begin{aligned}
\vec{r}=\eta \vec{f}-\left(\eta_{t} \vec{e}_{r}+\eta_{t} \phi \vec{e}_{\phi}-\eta_{t} \phi \tan (\lambda) \vec{k}-h \vec{k}\right) \\
\overrightarrow{d s}=\eta_{t} d \phi \vec{e}_{\phi}-\eta_{t} d \phi \tan (u) \vec{k}-\eta_{t} \phi d \phi \vec{e}_{r} \\
\tan (\lambda)=\frac{d h}{\eta_{t} d \phi} \\
\vec{r} \times d \vec{s}=\left[-\left(\eta-\eta_{t} \cos \phi_{t}\right) \eta_{t} \tan \lambda+h \eta_{t} \sin \phi_{s}\right] d \phi \vec{i} \\
+\left(\eta_{t}^{\prime}-\eta_{t} \cos \phi_{s}^{\prime}\right) d \phi \vec{k}+\left[\phi\left(\eta \eta_{t} \sin \phi_{s}+\eta_{t} \phi\right) \vec{k}\right. \\
\left.+\phi \eta_{t}\left(h+\eta_{t} \phi \tan \lambda\right) \vec{e}_{\phi}\right] d \phi
\end{aligned}
$$

Linear variation of the strength of element $A$ is assumed as follows.

$$
\begin{aligned}
& \Gamma=\Gamma_{t}+\frac{\Delta \Gamma_{t}}{\Delta \phi}\left(x+\frac{\Delta \phi}{2}\right)=\left(\Gamma_{t}+\frac{\Delta \Gamma_{t}}{2}\right)+\frac{\Delta[t}{\Delta \phi} x=\alpha+\beta x \\
& W=\frac{1}{4 \pi} \int_{x_{l}=-\frac{\Delta p}{2}}^{x_{2}-\frac{\Delta \theta}{2}} \frac{(\alpha+\beta x)((D \vec{i}+E \vec{R})+(G \vec{i}+H \vec{R}) x) d x}{\left(a x^{2}+2 b x+c\right)^{3 / 2}}
\end{aligned}
$$

97 
Why le neglecting the terms of order $\left(x^{2}\right)$ in the numerator, this equation becomes (i). When $b^{2} \neq$ ac,

$$
\begin{aligned}
W=-\frac{\alpha}{4 \pi}\left\{(D \vec{i}+E \vec{k})\left[\frac{a x+b}{\left(a c-b^{2}\right) \sqrt{a x^{2}+2 b x+c}}\right]_{x_{1}}^{x_{2}}\right. \\
\left.+\left(G^{\prime} \vec{\imath}+H \vec{k}\right)\left[\frac{b x+c}{\left(b^{2}-a c\right) \sqrt{a \dot{x}^{2}+2 b x+c}}\right]_{x_{1}}^{x_{2}}\right\}
\end{aligned}
$$

(ii). When $b^{2}=a c$,

$$
\begin{aligned}
W=- & \frac{\alpha}{4 \pi}\left\{(D \vec{i}+E \vec{k})\left[\frac{-\sqrt{a}}{2(a x+b)^{2}}\right]_{x_{1}}^{x_{2}}\right. \\
& \left.+\left(G^{\prime} \vec{i}+H^{\prime} \vec{k}\right)\left[\frac{-1}{\sqrt{a}(a x+b)}+\frac{b}{2 \sqrt{a}(a x+b)^{2}}\right]_{x_{1}}^{x_{2}}\right\}
\end{aligned}
$$

In these expressions,

$$
\begin{aligned}
& D=-\left(\eta-\eta_{t} \cos \phi_{s}\right) \eta_{t} \cdot \tan \lambda+h \eta_{t} \sin \phi_{s} \\
& E=\eta_{t}^{2}-\eta \eta_{t} \cos \phi_{s} \\
& G=\eta_{t} \cos \phi_{s} \\
& H=\eta \eta_{t} \sin \phi_{s} \\
& G^{\prime}=G+\frac{\theta}{2}, H^{\prime}=H+\frac{\theta}{\alpha} E \\
& a=\eta_{t}^{2} \tan ^{2} \lambda+\eta_{t} \cos \phi_{s} \\
& b=\eta \eta_{t} \sin \phi_{s}+\eta_{t} h \tan \lambda \\
& c=\eta_{t}^{2}+\eta^{2}+h^{2}-2 \eta \eta_{t} \cos \phi_{s}
\end{aligned}
$$

All these equations can be derived from equation g (A.2) and $(A, 3)$ by shall angle assumptions around $\phi_{g}$ that $19 ; \phi=\phi_{B}+x_{1}$ where $|x| \leq \frac{\Delta \phi}{2}$

98 
c.2 Shed vortex sheet and Element

the arne equation as in (7) was used to calculate the velocity induced by a shed line vortex. For the shed vortex sheet, a slightly modified form of the equation for the shed line vortex element was used.

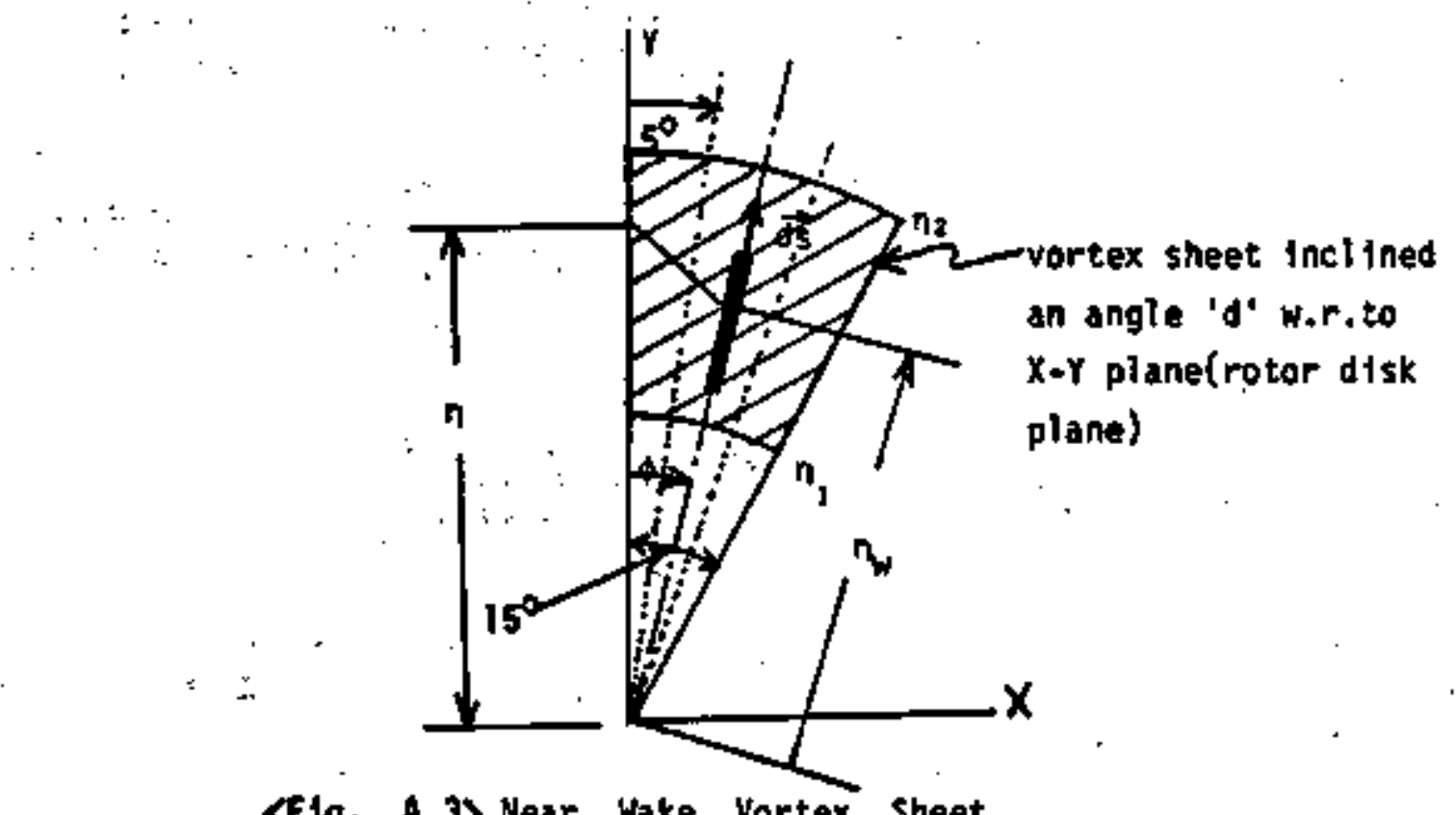

FIg. A.3〉 Near Wake Vortex Sheet

$$
\begin{aligned}
& \overrightarrow{d S}=(\sin \phi \vec{i}+\cos \phi \vec{\jmath}+\tan d \vec{k}) d \eta \omega .2 \omega \\
& W=-\frac{F_{k}}{4 \pi} \int_{\phi_{2}}^{\phi_{2}}(D \vec{i}+E \vec{k}) F^{\prime} \cdot d \phi=-\frac{\Gamma_{1}^{n}}{4 \pi} \sum_{n=1}^{3}\left(D_{n} \vec{t}+E n \vec{K}\right) F_{n}^{\prime} \\
& F^{\prime}=\left[\frac{B \eta_{w}+C}{(B-A C)\left(A \eta_{\omega}^{2}+2 B \eta_{\omega}+C\right)^{1 / 2}}\right]_{\eta_{\omega}=\eta_{1}}^{\eta_{\omega}=\eta_{2}} \\
& A=1+\tan ^{2} d ; B=h_{0} \tan d-\eta \cos \phi, C=\eta^{2}+r_{0}^{2} . \\
& D=\eta \tan d+h_{0} \cos \phi, E=-i \sin \phi, \Gamma_{s}^{n}=\frac{\Gamma(1+1, N)-\Gamma(t, N)}{\eta_{N}} .
\end{aligned}
$$

99 
The atrength of the sheet vortex is $\Gamma_{3}=\frac{\Gamma(L+1, N)-\Gamma(L, N)}{\eta \Delta \phi}$ where $\Gamma(L, N)$ is bound cireulition at the azimuthel position, $L$ and the radial position, N. In this celeulation there are no sinoularitios becauge the integrand is calculeted, at the midpoint of each section. 


\section{Appendix D}

WIND PROFILE UP-NIND OF .THE 'LONER

It is assumed that the free stream undergoes a velocity reduction of the form of a right circular sone on the rotor dfsk . plane due to the up-wind propagation of tha towar disturbancea. The proflile of the disturbed free stream velocity is shown in fig. A.4,

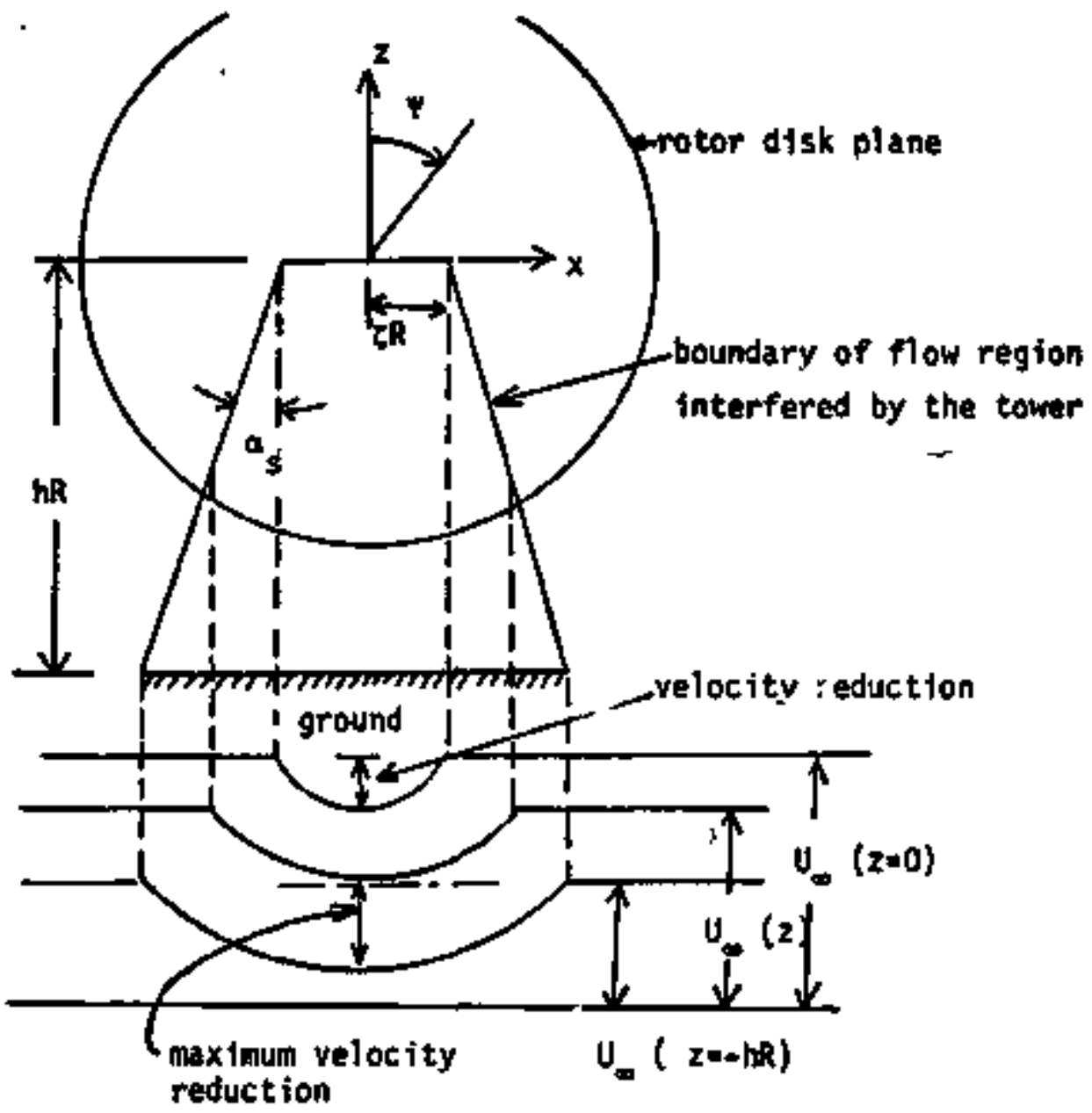

Fig. A.A Geonetry for the Representation of Tower Reftection wind Profile 
Let $v(z)$ be the meximum velocity reduction furction along the height of the tower, and assume $v(z)$ be linear. Then $v(z)=$ $\mathrm{VR} \cdot\left\{1-\frac{s_{t}}{\mathrm{I}} \cdot\left(\frac{2}{R}\right)\right\}$, where $s_{t}=\tan \alpha_{s} R=$ rotor radius, and $V R=$ maximum velocity feduction fate at $z=0$. The velocity reduction function $v(x, 2)$ at an arbitrary point of the flow region up-wind of the tower becomes

$$
v(x, z)=\frac{\sqrt{\left(y-s_{t} \eta \cos \Psi\right)^{2}-\eta^{2} s+\eta^{2} \psi}}{\left(y-s_{t} \eta \cos \Psi\right)} \cdot V R \cdot\left(1-\frac{S_{t}}{y} \eta \cos \Psi\right)
$$

Therefore, the wind profile upwind from the tower can be defined by $u(x, z)$ as follows.

(i) $\cos \Psi \geqq 0 \Rightarrow u(x, z)=U \infty(z) / \Omega R$

(ii) $\cos \Psi<0$ and $\frac{|\xi-\$, \eta \cos \Psi|}{|\eta \sin \Psi|} \leq 1 \Rightarrow u(x, z)=U_{\infty}(z) / \Omega R$ $\cos \Psi<0$ and $\frac{\left|\xi-s_{+} \eta \cos \Psi\right|}{|\eta \sin \Psi|}>1 \Rightarrow u(x, z)=\{1-v(x, z)\} U_{\infty}(z) / \Omega R$

Hore, $\mathrm{U}(\mathrm{z})$ can be a shear flow or a unfform steady flow. In the shear flow case, the velooity reduction function $v(x, z)$ oan be assumed to be proportional to the magnitude of free stream. Then, $u(x, z)$ in above last equation is simply modified as follows.

$$
u(x, z)=\left\{1-v(x, z) \frac{U_{\infty}(z-z)}{U_{\infty}(z=0)}\right\} U_{\infty}(z=z) / \Omega R
$$


For the tows with $x$ mas treo, $v(x, z)$ in determined, from the experimental results.

$$
v(x, z)=v \cdot z e^{-k|x|}
$$

Here, $v_{0}$ is the veloclty reduction rate $a t z=-0.75$ and $x=0$ and $\mathrm{x}$ is the characteristic constant for the given tower. Then the wind profile is

$$
u(x, z)=\{1-v(x, z)\} U_{\infty} / \Omega R
$$

or

$$
u(x, z)=\left\{1-v(x, z) \frac{U_{\infty}(z=z)}{U_{\infty}(z=0)}\right\} U_{\infty}(z=z) / \Omega R
$$

for shear flow.

$v(x, 2)$ is defines as follows.

(1). $2>0$

$v(x, z)=v \cdot x_{x} e^{-k 1 x+z 1}$

(11). $2 x<2<0$

$$
v(x, z)=v \cdot z_{x} e^{-k|x|}
$$

(1ii). $z<z_{x}$

$$
v(x, z)=v_{0} z e^{-k|x|}
$$

$z_{x}$ is the $z$-coordinate of the top and of Xmas tree. 